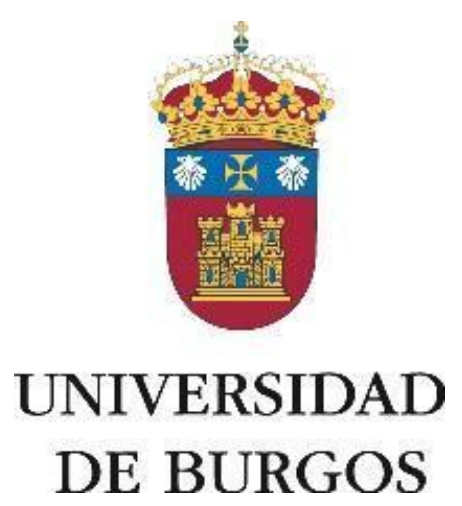

Departamento de Ciencias de la educación

TESIS DOCTORAL

\title{
TIPOLOGIAS MODALES MULTIVARIADAS DE PERSONALIDAD EFICAZ EN POBLACION CHILENA MAYOR DE 60 AÑOS
}

Autora:

Luzmarina Silva Concha

Directores:

Dr. Jerónimo Javier González Bernal.

Dra. María Eugenia Martin Palacio

Burgos, 2014 

Dedicatoria

Dedico esta tesis, primeramente a mis padres que siempre me inculcaron el estudio y la perseverancia para lograr mis metas.

A mis hijos que han estado acompañándome en este proceso en todo momento.

A las personas mayores que he podido conocer en mi desempeño profesional, que me inspiraron para querer saber más. 

Agradecimientos

Gracias a Dios,

Gracias a mis padres por enseñarme el camino a seguir.

Gracias a mis directores de Tesis Dr. Jerónimo González Bernal y

Dra. María Eugenia Martin Palacio por el apoyo, dedicación y guía en el logro de esta meta,

Gracias al profesor Dr. René Flores Castillo por las

oportunidades brindadas,

Gracias Andrea, Patricia y Cristina integrantes del grupo interuniversitario de investigación GOYAD por su constante y valiosa ayuda en el ordenamiento de este documento,

Gracias a mis colaboradoras y amigas Dalila, Roxana y el grupo de estudiantes que apoyaron este trabajo.

Gracias a las personas mayores que conforman la población de este estudio, por haberme entregado su confianza y mostrado parte de su intimidad. 



\section{ÍNDICE}

Introducción 1

I. Marco Teórico

1. Las personas mayores en Chile: situación avances y desafíos 7

2. El constructo de la Personalidad Eficaz 36

2.1. Introducción 36

2.2. Supuestos implícitos del Constructo Personalidad eficaz 38

2.3. Definición de Personalidad Eficaz 39

2.4. Etiología de los planteamientos acerca del constructo 41

2.5. La Personalidad Eficaz como respuesta a estas preguntas 46

2.6. La medición de la Personalidad Eficaz 58

2.6.1. Las variables de la Personalidad Eficaz como rasgos 58

2.6.2. Instrumentos elaborados $\quad 59$

3. Las tipologías modales multivariadas 61

3.1 Crisis del concepto clásico de tipo 62

3.2. Intentos de un posible reencuentro: estrategia diferenciadora de 63

los rasgos

3.3. Reconsideración del concepto de Tipo: Concepción modal 65 multidimensional

3.4. Técnicas de agrupación por conglomerados 66

$\begin{array}{ll}\text { 3.5. Análisis de tipo } & 70\end{array}$ 
3.7. Estudios realizados sobre tipologías en Personalidad eficaz 76

3.7.1. Perfiles de personalidad eficaz obtenidos en España (López 76 Pérez, 2011)

3.7.2. Perfiles tipológicos de Personalidad eficaz en población 82 Chilena (Ramírez, 2013)

3.7.3. Comparativa entre las tipologías españolas y chilenas 89

4. Estado actual de la investigación. Objetivos e hipótesis 97

II. Marco empírico

5. Metodología

5.1. Participantes

5.2. Instrumento

5.3. Aplicación

5.4. Procedimiento

5.5. Análisis de datos

5.5.1. Análisis de fiabilidad

5.5.2. Fiabilidad de los factores

5.5.3. Correlaciones entre los factores

5.5.4. Análisis de diferencias 
5.5.5. Baremos o referencias de normalización de la escala

5.5.6. Análisis de tipologías- conglomerados

III. Discusión

IV. Conclusiones

V. Limitaciones y perspectivas

VI. Referencias bibliográficas

VI. Anexos 



\section{ÍNDICE DE TABLAS}

Tabla 1. Estadísticos descriptivos de la muestra

Tabla 2. Descriptivos de la variable género

Tabla 3. Descriptivos de la variable edad

Tabla 4. Descriptivos de la variable situación ocupacional actual

Tabla 5. Descriptivos de la variable estudios

Tabla 6. Estadísticos de fiabilidad de las dimensiones

Tabla 7. Baremos generales

Tabla 8. Baremos de Relaciones en función del nivel de estudios

Tabla 9. Baremos de Fortalezas en función del rango de edad

Tabla 10. Baremos de Retos en función del rango de edad

Tabla 11. Estadísticos de fiabilidad

Tabla 12. Estadísticos total-elemento

Tabla 13. Estadísticos de fiabilidad del factor Fortalezas

Tabla 14. Estadísticos total-elemento del factor Fortalezas

Tabla 15. Estadísticos de fiabilidad del factor Demandas

Tabla 16. Estadísticos total-elemento del factor Demandas

Tabla 17. Estadísticos de fiabilidad del factor Retos

Tabla 18. Estadísticos total-elemento del factor Retos

Tabla 19. Estadísticos de fiabilidad del factor Relaciones 
Tabla 21. Correlaciones

Tabla 22. Comprobación de supuestos

Tabla 23. Estadísticos descriptivos en función del género

Tabla 24. Contrastes multivariados en función del género

Tabla 25. Estadísticos descriptivos en función de la edad

Tabla 26. Contrastes multivariados en función de la edad

Tabla 27. Estadísticos descriptivos en función de la variable 139 formación

Tabla 28. Contrastes multivariados en función de la variable 140 formación

Tabla 29. Estadísticos descriptivos en función de la variable 141 ocupación actual

Tabla 30. Contrastes multivariados en función de la variable 142 ocupación actual

Tabla 31. Estadísticos de la muestra en cada factor

Tabla 32. Estadísticos descriptivos en las muestras generacionales

Tabla 33. Contrastes multivariados en función de la muestra generacional

Tabla 34. Pruebas de los efectos inter-sujetos

Tabla 35. Baremos generales de la escala

Tabla 36. Centros de los conglomerados finales 
Tabla 37. Centros de los conglomerados expresados en centiles

Tabla 38. ANOVA 150

Tabla 39. Número de casos en cada conglomerado 150 



\section{ÍNDICE DE FIGURAS}

Figura 1. Cuadro comparativo entre tipologías 90

Figura 2. Distribución por género 105

Figura 3. Distribución por edad 106

Figura 4. Distribución de la variable situación laboral actual 107

Figura 5. Distribución por nivel de estudios 108 

Este trabajo persigue un objetivo concreto ya que está centrado en el establecimiento de Tipologías Modales de Personalidad Eficaz en personas mayores de 60 años. Con el mismo se completa una serie de investigaciones desarrolladas en torno al constructo de Personalidad Eficaz en poblaciones anteriores a esta edad de la vida realizados por distintos investigadores vinculados al grupo interuniversitario de investigación de Orientación y Atención a la Diversidad (GOYAD) dirigido y coordinado por los profesores Martín Del Buey (Universidad de Oviedo) y Martín Palacio (Universidad Complutense de Madrid) y que se han desarrollado como tesis doctorales defendidas en distintitas Universidades Españolas y Chilenas.

El constructo de Personalidad Eficaz, que más adelante se detalla, examina la presencia de una serie de rasgos de personalidad que responden a una serie de preguntas básicas y propias de la existencia humana referentes al autoconcepto, la autoestima, la motivación, las atribuciones, las expectativas, el afrontamiento de problemas, la toma de decisiones y las relaciones con los demás, que cualquier persona da a lo largo de su ciclo vital.

Estas dimensiones se agrupan en torno a cuatro categorías vinculadas al yo Personal denominadas: Fortalezas del yo (Autoconcepto y autoestima), Demandas del Yo (Motivaciones, expectativas y atribuciones), 
Retos del Yo (Afrontamiento de problemas y toma de decisiones) y Relaciones del yo (Empatía, asertividad y comunicación).

Si en anteriores investigaciones se ha analizado las respuestas que dan los individuos en su fase infantil, adolescente, juvenil y etapa adulta a estas preguntas y con ello a la presencia de los rasgos de personalidad citados parece necesario completar las investigaciones con el análisis de las respuestas que dan las personas denominadas adultas mayores comprendidas entre los 60 y 90 años de edad.

Tener datos empíricos relacionados con el estado de cada una de las dimensiones citadas y poder compararla con etapas anteriores puede constituir una interesante aportación que con anterioridad y dentro del marco conceptual del constructo de personalidad eficaz no se había abordado.

Para abordar este tema se presentó a los profesores, doctores. Jerónimo Javier González Bernal (Universidad de Burgos) y Dra. María Eugenia Martin Palacio (Universidad Complutense de Madrid, un proyecto de tesis doctoral centrada en este tema y con el ruego de que aceptasen de forma paritaria la dirección del mismo.

Conseguida su aceptación y registrada la temática en la Universidad de Burgos se procedió a su desarrollo, que siguiendo en todo momento sus orientadas directrices lo hemos estructurado en las siguientes partes. 
La primera parte, bajo la denominación de Antecedentes, está dedicada a exponer en primer lugar la situación, avances y desafío de las personas mayores en chile, (el estudio está centrada en este país) al objeto de contextualizar la población participante de nuestro estudio. En segundo lugar la definición, estructura y los avances desarrollados en torno al constructo de la personalidad eficaz al objeto de conocer la base conceptual en la que se mueve este trabajo. En tercer lugar el estado de la cuestión y los avances actuales referentes a los estudios sobre tipologías en la acepción de modal y multivariada. Finaliza esta primera parte con la exposición de los objetivos y la formulación de las hipótesis de trabajo

La segunda parte, bajo la denominación de marco empírico, se desarrolla en distintos apartados la metodología empleada en el estudio siguiendo los puntos que tradicionalmente se siguen en este tipo de investigaciones. Ciertamente no se trata de una investigación de carácter experimental en donde se diseña grupos experimentales y grupos de control. Se trata de una investigación de carácter empírico que se centra en una selección de una parte de la población que se acepta como muestra representativa, sobre la que se aplica un instrumento pertinente y se analizan los datos obtenidos con la intención de cumplir los objetivos previstos y confirmar las hipótesis de trabajo anunciadas.

La tercera parte está dedicada a la exposición y discusión de los resultados obtenidos siguiendo como guía los objetivos señalados 
La cuarta parte está dedicada a las conclusiones finales del trabajo a las que se añade en base a las mismas sugerencias, limitaciones, temas pendientes y aplicaciones de campo.

Finaliza la investigación con los apartados de referencias y anexos. 


\section{MARCO TEÓRICO}




\section{Las personas mayores en Chile: situación, avances y desafíos}

Este trabajo está centrado en personas adultas mayores chilenas comprendidas entre los 60 a los 90 años de edad. Parece oportuno contextualizar en el contexto social Chileno a estas personas y para ello hemos acudido, entre los muchos documentos existentes, a dos fuentes oficiales que nos ofrece la suficiente solidez en base a datos oficiales obtenidos y que presentan de una manera completa y exhaustiva esta realidad.

Nos referimos en primer lugar al trabajo realizado por el Servicio Nacional del Adulto Mayor, (SENAMA) en 2009 bajo el título "Las personas mayores en chile: situación, avances y desafíos del envejecimiento y la vejez" cuya autores son Paula Forttes Valdivia, Directora del Servicio Nacional del Adulto Mayor y Cristián Massad Torres, investigador Unidad de Estudios SENAMA y equipo de colaboradores (Forttes y Massad, 2009).

El Servicio Nacional del Adulto Mayor (SENAMA) ha buscado, a través de la elaboración de este documento, ofrecer una información lo más completa posible que proporcione conocimientos sobre la realidad de las personas mayores, como punto de partida para la discusión y diseño de programas, así como la focalización de recursos en el marco de la construcción de un Sistema de Protección Social para una sociedad distinta. 
El segundo de los documentos se refiere al trabajo realizado por la profesora María Eugenia Morales en torno a la temática "CHILE ENVEJECE: Prospectiva de los impactos políticos y sociales de este fenómeno hacia el bicentenario" (Morales, 2000).

María Eugenia Morales es Magister en Ciencia Política de la Universidad de Chile, especialista en Sistema Político de los Estados Unidos de América, graduada en Southern Illinois University, EEUUA y la actual Presidenta de las Asociaciones Chilenas de Estudios Americanos y Canadienses, miembro de Latin American Studies Association, American Studies Association, y del International Council for Canadian Studies. Es Académica del Instituto de Ciencia Política de la Universidad de Chile, Coordinadora de Relaciones Internacionales. Este trabajo se ha enriquecido con las aportaciones en materiales de la Profesora Marta Glukman del Programa Regional de Bioética dependiente de la Organización Panamericana de la Salud y del Programa de Estudios Gerontológicos de la Universidad de Chile

En el documento aportado por Fortes y Massad (2009) se desarrolla en los siguientes cinco capítulos.

El primer capítulo hace una aproximación conceptual a la temática del envejecimiento y vejez, estableciendo definiciones útiles para la comprensión del fenómeno. 
El segundo capítulo entrega elementos de diagnóstico de la situación de las personas mayores en Chile, proporcionando información que explica el proceso de envejecimiento poblacional a través de dimensiones y descripciones.

Para la construcción de los dos primeros capítulos, se ha tomado como eje organizador la Estrategia Regional de Implementación para América Latina y el Caribe del Plan de Acción Internacional de Madrid sobre el Envejecimiento, la cual define tres áreas prioritarias sobre las cuales los países de la región deben enfocar sus acciones, a saber: las personas de edad y el desarrollo, el fomento de la salud y bienestar en la vejez y la creación de un entorno propicio y favorable.

El tercer capítulo da cuenta de los avances programáticos en materia de política pública para la construcción de un Sistema de Protección Social, cuestión fundamental para un diagnóstico completo de la situación actual de las personas mayores.

El cuarto capítulo y el quinto capítulo incorpora las conclusiones más relevantes que han surgido del documento, enfocándose en aquellas que gozan de mayor consenso entre los actores vinculados a la temática del envejecimiento y la vejez y realiza una propuesta orientadora de los ámbitos en los cuales debiese enfocarse la política pública en el futuro próximo, en función del diagnóstico desarrollado. 
Todo el trabajo expuesto en este primer documento se fundamenta en que uno de los cambios asociados a la modernidad, inédito en la historia de la humanidad y que se observa en la actualidad en nuestras sociedades, es el envejecimiento de la población.

Este fenómeno encuentra explicación en cambios culturales, sociales, políticos y económicos, que han influido en la reducción de las tasas de natalidad y fecundidad.

La conjugación de estos dos fenómenos, ha derivado en una transición demográfica hacia el envejecimiento de la población, que en Chile se encuentra en una etapa avanzada.

En los últimos 30 años, la población del país ha experimentado un proceso de envejecimiento demográfico acelerado y sin precedentes históricos.

Hasta 1970, las personas mayores de 60 años representaban el $8 \%$ de la población. En el Censo de 2002 aumentaron a 11,4\% y cuatro años después, de acuerdo a datos de la Encuesta de Caracterización Socioeconómica (CASEN) 2006, las personas mayores de 60 años alcanzaban al 13\% de la población total del país. En los próximos 20 años se estima una tasa de crecimiento de $3,7 \%$ anual para este grupo etario, por lo que se proyecta una población de 3.825.000 personas de edad para el año 2025, lo que representará el 20\% de los chilenos. 
La expectativa de vida al nacer supera hoy en día los 78 años, sobrepasando los 80 años en el caso de las mujeres. Si a ello se agrega que Chile ha mostrado una drástica disminución de sus tasas de natalidad, se tiene como resultado un envejecimiento a ritmo sostenido.

Esta situación irá profundizándose de acuerdo a estimaciones que señalan que se pasará de 13,12 nacimientos por cada mil personas en el quinquenio 2010-2025, a 10,98 durante los años 2045-2050.

El citado documento propone que el envejecimiento debe ser valorado como un logro que genera oportunidades que deben ser aprovechadas, al tiempo que significa un desafío en función de lograr una mejora en la calidad de vida de las personas mayores, para que estos años los vivan de manera digna y en pleno bienestar.

Con esta meta el documento apunta que la discusión sobre las personas mayores como sujetos de derecho, se ha desarrollado desde una perspectiva teórico-política que sostiene que las políticas públicas deben estar guiadas por la titularidad de los derechos y que el desafío se encuentra en reconocer derechos para aquellos grupos más vulnerables.

Para los autores la protección social está abocada a cubrir la brecha entre los derechos atribuidos y la capacidad de traducir el marco políticonormativo en el que se sustentan los derechos, a un ejercicio efectivo, generando mecanismos que permitan hacerlos garantizables y exigibles. 
Es clave para ello que un sistema de protección fundado en derechos, implique ocuparse de las diversas formas de vulnerabilidad y exclusión social. Tradicionalmente se abordaba la protección desde el asistencialismo, implementando políticas para los grupos en situación de indigencia y pobreza. Los gobiernos de la Concertación han enfocado su quehacer hacia políticas universalistas, que incorporen diversas formas de vulnerabilidad además de la pobreza. En esta área adquiere una relevancia especial la situación de las personas mayores, considerando el crecimiento que este segmento etario ha tenido en los últimos años y las múltiples dimensiones de desprotección que vive este sector de la población.

La vulnerabilidad y la desprotección tienen múltiples expresiones, tantas como dimensiones en las que las personas se desenvuelven. Las personas mayores viven esta realidad en inestables condiciones de salud, seguridad económica y bienestar social, enfrentando, además, la subvaloración y discriminación que se expresan en discursos, símbolos y estructuras socioculturales respecto a la vejez y el envejecimiento.

Concluye el documento indicando que a pesar de los avances sustantivos desarrollados para responder a las demandas por protección y seguridad, existe en Chile un déficit estructural frente al envejecimiento poblacional, que debe ser cubierto mediante acciones del Estado que permitan contar con estructuras, capacidades y recursos para el logro de las tareas. 
En materia de política pública, la promoción de los derechos de las personas mayores requiere acompañarse con un énfasis especial en los aspectos relativos a su salud, funcionalidad, vinculación social, participación y autonomía, indicadores clave de la calidad de vida de las personas mayores. Es necesario, asimismo, generar servicios sociales en ámbitos tan importantes, como la dependencia de las personas mayores, con una cobertura amplia y de calidad.

El segundo de los documentos (Morales, 2000) presenta la siguiente tabla de contenidos: Reflexiones sobre Democracia y Mercado; Envejecimiento y vejez; El cambio Demográfico en Chile ; y Reflexiones finales.

De este trabajo destacamos a modo de encuadre algunas consideraciones que nos parecen oportunas cara a la contextualización de nuestra investigación.

Chile se encuentra en un proceso de cambio profundo en cuanto a su distribución demográfica, inserto en la permutación ocurrida en Occidente durante el siglo $\mathrm{XX}$ desde la sociedad post-industrial a la moderna y de ésta, a la post-moderna.

La transición del componente poblacional ya se evidenciaba en los informes de las Naciones Unidas publicados en el año 1982: La población mayor de 60 años del mundo está aumentando decían, mientras la menor de 
15 años está disminuyendo, fenómeno éste último, que ya mostraba una mayor acentuación en los países más desarrollados.

Este hecho puede enfocarse a juicio de sus autoras desde dos perspectivas: la individual y la social.

Desde la perspectiva individual el avance de la edad es responsable de cambios morfológicos y funcionales que se traduce en problemas en el aparato locomotor, la piel, los sistemas digestivo, respiratorio, inmunológico, nervioso central y periférico, entre otros. Estos cambios llamados fisiológicos, esperados a esta altura de la vida, son frecuentemente complicados por la existencia de patologías crónicas, tales como la hipertensión, diabetes, osteoporosis, cataratas, patologías dentales y trastornos emocionales para enumerar a los más conocidos.

Estas alteraciones sumadas al deterioro "normal", demandan mayores exigencias en cuanto al manejo del adulto mayor como problema médico, lo que tuvo como consecuencia que en Chile hasta los años 90, se mantuviera una idea de atención centrada en los aspectos terapéuticos ("medicalización" del adulto mayor), en desmedro de una perspectiva más integral.

La segunda perspectiva es la social, en el sentido que son las condiciones propias de cada sociedad las que determinan en último término, cuántos años y con qué calidad va a vivir una persona mayor. De acuerdo a este enfoque, existe una relación entre la edad cronológica de los 
individuos y las funciones que se asignan a los miembros de una comunidad dada, resultante de un sistema de racionalización del tiempo biológico, adaptado a los distintos roles que los individuos deberían ir cumpliendo en sus etapas de la vida como parte de ese conjunto social. Este concepto es la llamada "edad social".

Ambas dimensiones, la individual y la social, están en constante superposición y no pueden tratarse en forma aislada. La evolución de las distintas etapas de la vida humana está relacionada con el papel más o menos activo que desempeña el individuo en la sociedad, de tal manera que se es más dinámico en las más tempranas y menos en las más tardías. En estas últimas, es frecuente que las personas suspendan sus obligaciones laborales y comiencen a depender cada vez más de sus familias, de su comunidad y de la sociedad. Si bien esta transferencia gradual es de toda conocida y en muchos casos hasta anhelada, tiene un fuerte impacto en las condiciones de vida del afectado.

Asumida esta doble perspectiva sobre la ancianidad este segundo documento aporta información complementaria al primero de los documentos que consideramos de especial interés y al que vamos a referirnos a continuación extrayendo de este estudios aquellas que hemos considerado más pertinentes en relación a la temática de nuestro trabajo.

Respecto al cambio demográfico son del mayor interés las consideraciones del Ministerio de Planificación Nacional del Gobierno de 
Chile (MIDEPLAN), que señalan como problema relevante al envejecimiento, pero también otorgan relevancia a otra consecuencia adicional derivada de este cambio demográfico: el aumento de los embarazos en adolescentes.

Tomando como base la estructura de la población por edades, es interesante los siguientes índices que MIDEPLAN ha elaborado y que reflejan el impacto de esta transformación para la sociedad:

- Índice de dependencia: Permite aproximarse a cuantificar la carga económica que soportaría la población potencialmente activa. Mientras mayor sea la fecundidad, esta carga es más alta. Los "dependientes" son los menores de 15 y mayores de 65. Se establece la relación frente a las personas en edad activa, que son las mayores de 15 y menores de 65, por cada cien habitantes. Chile aparece en la tabla con un valor muy alto en los años '70s, debido a la gran proporción de niños de entonces. El indicador va descendiendo a lo largo de los años. Acorde con la tendencia de incremento que van adquiriendo los senescentes, el índice de dependencia aumentará, aunque la otra categoría de dependientes que incluye a niños y jóvenes vaya en disminución.

- Índice de vejez: Este es una clara demostración del cambio estructural que ha sufrido la población chilena hacia la senectud. Mientras que en el año 2000 la relación es de 25 adultos mayores 
(65 y más años) por cada cien menores de 15 años, lo que equivale a un cuarto; la correspondencia en el 2010 será de 35 a 100, es decir aumentará al 35\%. Al llegar el 2020, de mantenerse las tendencias observadas, la proporción de senescentes frente a menores de 15 años será de casi la mitad.

- Índice juvenil: Este indicador se comporta a la inversa del índice de vejez, y aquí apreciamos el efecto del descenso de la fecundidad que impactó especialmente en el tramo de 0 a 15 años. En 1970 el 64\% estaba entre los 0 a 14 y mayores de 15 años. El Censo del '82 demuestra una baja al 48\%, continúa la tendencia hasta proyectar el 2020 con solamente el 30\% de su población juvenil.

- Índice de edad media: Se refiere al promedio de edad de la población. Mientras en 1970 la edad promedio de los chilenos era de 26 años, el 2000 es de 31 años, y al 2020 aumentará a 35.

Ahora bien, es necesario señalar que el proceso de envejecimiento no es homogéneo en todo el país, sino tiene expresiones distintas según regiones. Basados en el Censo del '92, el promedio de habitantes mayores de 60 años corresponde al 9.8\% de la población total, lo que significa que en ese año la población de adultos mayores chilena era de 1.305.557 individuos. Las regiones más envejecidas son en primer lugar la Quinta, que concentra al $10.37 \%$ de la población total del país, y donde el $12.44 \%$ 
de ellos son mayores de 60 años, es decir, 162.445 adultos mayores. En segundo lugar está la Novena Región, donde $10.7 \%$ de sus habitantes están en esta condición, en tercer lugar la Décima con el 10.1\%, y a continuación la Cuarta Región, cuyo $10.0 \%$ es mayor de 60 . La menos envejecida es la Undécima, con el 6.8\%. Vale destacar que la Región Metropolitana está bajo el promedio nacional, con $9.7 \%$, pero concentra a casi el $40 \%$ de la población chilena, lo que significa que en Santiago viven 508.209 adultos mayores, lo que equivale a decir que el $38.39 \%$ de los ancianos de todo Chile viven en el Área Metropolitana.

En cuanto a área de residencia, los adultos mayores se distribuyen en forma bastante semejante a la población de otros grupos. El 81.8\% vive en sectores urbanos, y el $18.2 \%$ reside en áreas rurales. En lo relativo a su distribución por sexo, mientras en la población total el $50.9 \%$ de los individuos son mujeres, en la población mayor ellas aumentan al 56.3\%, asociado a la expectativa superior de vida femenina.

En relación a responsabilidades frente a sus respectivos grupos familiares, el $22 \%$ de todos los jefes de hogar del país tiene más de sesenta años, Por el mismo razonamiento anterior, las mujeres casi doblan a los hombres en esta condición. En Chile, 283.265 adultas mayores son jefes de hogar.

Conforme a los resultados arrojados por la encuesta nacional CASEN del Ministerio de Planificación 1992, el 43\% de la población 
adulta mayor ocupada no está afiliada a ningún sistema previsional, lo que representa un universo de más o menos 120.000 personas, situación más grave en zonas rurales que urbanas. En áreas rurales, la mitad de la población que desarrolla alguna actividad económica, no estaba afiliada a ningún sistema de previsión social.

En cuanto a recepción de beneficios en dinero por retiro y/o pensión asistencial, un estudio realizado por MIDEPLAN en conjunto con la Universidad Católica citado en el documento de Política Nacional, señala que el $73.3 \%$ de los adultos mayores recibía alguno (el 4\% recibía ambos), mientras que el $20 \%$ de los entrevistados expresaba no recibir nada. De ellos, solamente un $40 \%$ era ayudado por familiares.

Los afiliados a ISAPRES son solamente el $8.8 \%$ de los adultos mayores. La parte estatal para los más desposeídos está a cargo del Fondo Nacional de Salud, FONASA, que de acuerdo a los resultados de CASEN 1996, otorga cobertura al 76.9\% de los mayores de 60 años.

Respecto a la posición del Estado Chileno frente a la dinámica demográfica en el citado estudio se señala que una de las preocupaciones prioritarias desde los albores de la Independencia ha sido el poblamiento del territorio, en especial en términos de establecer asentamientos humanos en áreas aisladas. Durante el Gobierno Militar no hubo intervenciones en la forma de política de Estado en el campo del envejecimiento, sino más bien efectos de acciones generales derivadas del gran objetivo de 
modernización hacia un modelo económico neo-liberal, siendo la de mayor relevancia la relativa a la Seguridad Social. Entre los años 1980 y 1981, el Estado traspasó responsabilidades a los privados constituidos como Administradoras de Fondos de Pensiones (AFP), destinadas a tutelar el ahorro de los trabajadores para el momento del retiro, pero siguió manteniendo los de menores recursos en el Instituto de Normalización Previsional, INP. Al mismo tiempo se implementó un sistema paralelo de salud privado, ISAPRES, también para los de mayores medios. La Seguridad Social de los chilenos es desde entonces un sistema mixto, que descansa en un pilar público y en otro privado. En el mismo período se registra una medida política de injerencia negativa, cuando producto de la recesión económica de los años 1982-1983, el reajuste del 10.6\% que correspondía aplicar a los jubilados no fue cancelado, en virtud de otras prioridades. Esta deuda fue saldada sólo parcialmente en 1995, porque los montos pagados no correspondían exactamente a los adeudados. Otras intervenciones tuvieron carácter asistencial, tales como la creación de la Pensión Asistencial, PASIS, exclusiva para ancianos calificados en tramos de pobreza de acuerdo al instrumento de medición de la época. CONAPRAN, la organización de voluntariado femenino que agrupó ancianos en clubes con fines recreativos y asistenciales, y una política de reajuste de pensiones automática cuando el IPC llegaba a acumular 15\%. 
En los primeros años del retorno democrático el Gobierno se abocó a la elaboración de una política específica para el adulto mayor a través de MIDEPLAN, a partir de un razonamiento metodológico de "inversión en capital humano" como alternativa integral para superar la pobreza, a través de un proceso de "identificación de colectivos", estrategia que buscaba reconocer ciertos grupos sociales como sujetos preferentes de atención, dentro de los cuales considera a niños, jóvenes, discapacitados, pueblos nativos, mujeres jefes de hogar y tercera edad, lo que condujo a la elaboración de la Política Nacional sobre Envejecimiento y Vejez: Lineamientos Básicos. Las principales aportaciones son las siguientes:

- Es el primer documento oficial que reconoce explícitamente el cambio demográfico que ha experimentado Chile hacia el envejecimiento de su población. Para abordar la generación de esta Política, se reconocen tanto la dimensión individual como la social, involucradas en el tratamiento del adulto mayor, como uno de los sujetos prioritarios de cobertura de la política social integral del Gobierno.

- Los adultos mayores se definen como actores de su propio proceso de envejecimiento individual y también social. De esta forma se buscan desplazar por una parte, los antiguos enfoques caritativos donde el sujeto era más bien una víctima que un objeto de atención; y por la otra, la orientación preponderante hacia los 
aspectos médicos curativos. Este carácter es lo que le da la dimensión de "envejecimiento activo", según el cual las personas mayores son miembros tan útiles a la sociedad como los otros, por tanto interesa facilitarles interactuar en el máximo de los niveles, para poder recoger su aporte en los niveles familiar, comunitario y político. En este contexto la intervención estatal frente al envejecimiento es entendida como una acción multisectorial, que genera acciones a partir de precisiones sobre coberturas esperadas frente a necesidades físicas, materiales, de integración social y política y recreativa.

En relación a las Percepciones de los Adultos Mayores sobre sí mismos son muy interesantes los resultados del estudio "Encuesta de Necesidades de los Ancianos en Chile", auspiciado por la Organización Panamericana de la Salud y realizado por el sociólogo O. Domínguez, relativo a entrevistas realizadas en un universo de 1.572 adultos mayores de las comunas urbanas de la Región Metropolitana, que entrega la percepción de los senescentes frente a su propia salud y funcionalidad para las actividades cotidianas, como indicadores de bienestar físico, mental y social.

Según los propios ancianos, sus problemas más importantes estaban relacionados con las exigencias económicas y de salud, representando lo económico la principal preocupación para los menores de 75, mientras la 
salud se manifestó como tema prioritario sólo en los grupos más altos, especialmente en mujeres. Aquí surge un elemento clave para el rediseño de las políticas dirigidas a la vejez, y es que culturalmente existe un acondicionamiento para considerarlos como "enfermos". Este estudio revela que los mismos afectados declararon sentirse "sanos" en más del $65 \%$ de los casos.

El 71.9\% de ellos declaró tener algún problema de salud al momento de ser interrogado, más las mujeres que los hombres. Entre los problemas que ellos señalaron con mayor frecuencia estaban los asociados al aparato circulatorio, al sistema osteo-muscular, traumatismos, accidentes y enfermedades de los órganos de los sentidos, respecto a ésta última alrededor del $30 \%$ refirió problemas secundarios para enfrentar sus actividades diarias por disminución de la visión y un $12 \%$ de audición. Al $28 \%$ de los entrevistados la falta de piezas dentales le impedía la masticación.

Este estudio aportó un elemento innovador al manejo del adulto mayor, por cuanto demostró que contrariamente a la percepción cultural que se tenía de ellos en la sociedad chilena, los senescentes entrevistados tenían buena capacidad para cuidar de sí mismos.

Para conocer su medida, se elaboró un Índice de las Actividades de la Vida Diaria (AVD) que permite agrupar a la población objetivo en tres categorías: los auto-valentes, que desarrollan su vida normalmente sin 
ayuda; los que requieren ayuda para determinadas actividades, y los frágiles e inválidos, que están impedidos de atender a su cuidado sin asistencia. Esta clasificación permite identificar los servicios de apoyo necesarios para conservar la autonomía o atenuar la dependencia según el caso. Los resultados muestran que el $66.7 \%$ de la población mayor cubierta en este estudio puede definirse como funcionalmente sana, capaz de llevar una vida independiente, $30 \%$ son funcionalmente frágiles, es decir requieren auxilio para ciertas actividades, y el $3.3 \%$ es funcionalmente dependiente y padece invalidez severa.

El estudio de la profesora Morales (2000) finaliza con dos apartados de sumo interés; Uno se refiere a la consideración del adulto mayor chileno como actor social y político. Y otras a unas reflexiones en torno a lo estudiado.

Respecto a lo primero señala que una vez conocida la transición demográfica ocurrida en Chile, esta ha tenido sus consecuencias políticas cuyo impacto en la esfera del Gobierno y las instituciones que de él dependen debe ser valorado en términos de explorar las intervenciones que demandará la atención de este grupo de edad. Interesa especialmente proyectar avances en términos del pleno ejercicio de su condición de personas valiosas y ciudadanos, más allá de discursos sobre sus derechos y deberes. Los adultos mayores deben ser considerados como actores de acuerdo al enfoque político oficial vigente, y averiguar si la sociedad y sus 
instituciones políticas y sociales están en condiciones de hacer posible este aporte. Este evento de permutación generacional en la composición de la población, debe ser entendido no como una simple valoración estadística, sino como una profunda transformación de la sociedad chilena y de aquellas que se encuentran en situación similar, tanto en Latinoamérica como en el mundo, porque involucra aspectos de tal variedad y complejidad, que obligan a replantear desde vínculos afectivos hasta necesidades materiales, desafiando las capacidades estructurales y funcionales de todos los actores involucrados. La variación es eminentemente cultural, y sus consecuencias también deben ser leídas en el largo plazo como agentes introductores de nuevas exigencias que requieren para su satisfacción de elaboraciones políticas frescas y creativas.

Respecto a lo segundo nos merece especial interés una serie de reflexiones que hacen las autoras en torno al envejecimiento que están relacionadas con la temática de nuestro trabajo y que nos parece oportuno seleccionar algunas de ellas y presentarlas en este trabajo.

La primera de las reflexiones está centrada en la dificultad que socialmente se tiene de la aceptación del envejecimiento.

Las imágenes que tiene la sociedad actual respecto a la senectud, tanto las que elabora quien está experimentando el proceso como sus cercanos y la sociedad en general, corresponden a patrones culturales de negación, de no querer reconocer que el envejecimiento es una situación 
insoslayable para el ser humano, aún el del siglo XXI, integrante de una sociedad que ha logrado tantos avances científicos y tecnológicos cuyos beneficios deberían ser capaces de corregir situaciones tan indeseables como ésta. Nuestra aldea global refuerza constantemente esta idea, apoyada por los medios de comunicación. Para sustentar estos dichos, señalemos algunas observaciones que desde luego no son exclusivas de nuestro país, que nos demuestran la existencia concreta de estas conductas de no aceptación de esta etapa inevitable, como si por el simple hecho de desearlo así se pudiera lograr:

- La vejez es percibida como una situación angustiosa, estereotipada en imágenes de ancianos enfermos, inválidos, que sufren graves alteraciones emocionales, y que por sobre todo, representan una carga emotiva y económica para sus familias, sea que compartan el hogar con sus parientes, vivan solos (as) o estén internos (as) en instituciones especiales. Los medios de comunicación en general se refieren al "problema de envejecer", como algo completamente ajeno a las realidades individuales de todos los involucrados en el proceso comunicacional. Es como si comunicadores, lectores, auditores o tele espectadores estuvieran completamente a salvo de vivir este tránsito. Esto se expresa abundantemente en documentales y programas testimoniales que ilustran destructivamente este paso y también en la ausencia de 
imágenes de adultos mayores en la televisión. No hay conductores de este grupo de edad en la programación de alto "rating"; por el contrario, hay profusión de figuras muy jóvenes.

- Intentar detener el envejecimiento se ha convertido en una obsesión y por cierto, también en una nueva y prolífica fuente de ingresos al crear un hábito de consumo diferente. Cirugías, cosméticos, aparatos de ejercitación física, vestuario, alimentos especiales, suplementos vitamínicos, anti-oxidantes, etc., una enorme gama de productos y servicios que prometen la recuperación de la juventud o al menos, la detención del proceso de envejecimiento.

La primera conclusión de esta prospectiva entonces, es que la sociedad chilena debe orientarse hacia el cambio de imagen tanto frente al proceso de envejecimiento como a la vejez, en el sentido de revalorizarla positivamente, erradicando mitos, estereotipos y tabúes. De no ser así, los objetivos políticos proclamados acerca del envejecimiento activo, digno, integrado, o adulto mayor actor de su propio paso, responsable, consciente y participante, no podrán realizarse sin este progreso previo. Para ello se requiere implementar acciones educativas en la población a nivel general, y por cierto en lo particular con la población objetivo.

La segunda se refiere a la participación del adulto mayor en la vida social y política. Los adultos mayores constituyen un mercado electoral 
relevante, de creciente importancia en cuanto a su fuerza electoral. Ellos poseen una realidad propia y distinta a las de otros grupos de edad. De acuerdo a su disponibilidad de tiempo libre y condición de auto-valentes, que tiene el $66.7 \%$ de ellos, si existiera la posibilidad de buenos canales de organización, los mayores podrían movilizarse en torno a demandas económicas y de servicios sociales en la búsqueda de mejorar su actual estado, hecho que creemos apoyaría el proceso de cambio tanto de la imagen que tienen de sí mismos, como aquella que la sociedad tiene de ellos. Pero antes, los actores políticos deberán establecer vinculaciones con este grupo, lo que pasa primero por la inclusión del tema de la tercera edad en la agenda política. Si bien el Estado lo ha estado haciendo, los actores políticos no lo han incorporado en sus agendas de campaña, salvo algunos en elecciones municipales. Los partidos políticos y los candidatos en primer término, deberán ser capaces de convocar su interés, de interpretar sus inquietudes, y especialmente, darles confianza acerca de lo relevante que es para el país obtener su aporte democrático. Por su parte el Estado deberá perseverar y perfeccionar en los esfuerzos que actualmente está realizando, puesto que como ya hemos señalado repetidamente, de la satisfacción de sus necesidades básicas, va a depender que los ancianos puedan o no superar su actual estado de segregación social y política. En este sentido, el gobierno chileno democrático tiene a nuestro juicio dos responsabilidades básicas: Primero, mantener el crecimiento económico 
sostenido para poder mantener sus esfuerzos de profundización de políticas sociales, con miras a alcanzar un país más solidario. Segundo, crear e implementar medidas especiales para obtener su expresión de voluntad política a través del sufragio. Tercero, estimular su organización social para fomentar la creación de iniciativas de educación cívica. Y cuarto, propender a la integración de otros segmentos distintos al estado, en planes de colaboración orientados a vigorizar la participación política y social de los senescentes. Estimamos que actualmente la contribución privada o por parte de ONGs, son todavía muy insignificantes.

La tercera hace referencia a la calidad de vida del adulto mayor. El concepto de "calidad de vida" considera que la subjetividad es un elemento esencial, por tanto la expectativa es ante todo individual. Externamente, podrá afirmarse que una calidad de vida es mejor o peor, pero en último término es la propia persona la que la valida. En la senectud esto es una crucial fuente de conflictos y por cierto de reflexión moral. Cuando se piensa en forma analógica, basándose en los propios criterios, es difícil hacer justicia a los demás. Se descubre que individuos gravemente limitados, viviendo vidas casi inhumanas, aún en las peores circunstancias, desean conservarlas. En otros casos, no se entiende por qué alguien desea terminar su propia vida si a juicio del observador, posee bienes materiales y espirituales suficientes. Esto ocurre porque existen profundas anomalías que conducen a percepciones erróneas acerca de la relación interpersonal, 
porque son elaboraciones que desconocen al otro como agente autónomo. Parte de esta anomalía, deriva de las buenas intenciones o de lo que se cree que es solidaridad, que conduce frecuentemente a los seres humanos, cual más cual menos, a practicar el paternalismo, que no es otra cosa que hacer el bien al otro sin dejarle la posibilidad de negarse.

La "calidad de vida" es multidimensional, por tanto no puede evaluarse atendiendo solamente a los bienes materiales o al estado de salud. Debe comprender el estado físico, la espiritualidad, la capacidad de desplazarse, la independencia, la satisfacción, esto es, innumerables dimensiones. No es de extrañar entonces, que en algunos aspectos haya mayor precisión que en otros, siempre teniendo en cuenta que lo que es estimado como bueno, pueda variar según el tipo de escala o la forma de medir. Así llegamos al tercer elemento del constructo: su complejidad, producto de la heterogeneidad.

El cuarto componente es que calidad de vida es un concepto dinámico. La apreciación al respecto que se tiene a los veinte años es distinta a los cuarenta o cincuenta, no solamente porque algunas preferencias han cambiado, sino porque determinadas limitaciones fisiológicas imponen diversos tipos de satisfacciones, y porque además, el propio criterio con que se evalúan las cosas cambia. Una cuantificación o una evaluación cualitativa que no tome en cuenta este hecho, perderá algo indispensable para comprender la diversidad por edades. 
Si se comparan dos grupos de senescentes dentro de un mismo rango de edad, podemos advertir pérdidas distintas, de modo que lejos de constituir los ancianos un grupo uniforme, se caracterizan por ser en extremo diversos entre sí. No todos los sistemas orgánicos y los atributos psicológicos envejecen al mismo ritmo. Y ello induce a más diferencias individuales. Así, hay sujetos más añosos en su sistema cardio-vascular que en su sistema gastro-intestinal. Hay algunos cuyas funciones cognoscitivas quedan intactas por mayor tiempo. La característica esencial es que cuesta evidenciar el cambio. Primero por los atributos y la complejidad de la calidad de vida y luego por la mayor diferenciación que las experiencias vitales introducen en las personas. En épocas anteriores, tales cambios no alcanzaban a mostrarse en plenitud, simplemente porque las personas morían antes.

Como consecuencia de ello las autoras proponen adoptar este concepto "calidad de vida" en sus posibles aplicaciones para el estudio y elaboración de políticas públicas en beneficio de la población de adultos mayores, teniendo en cuenta que por ser un concepto subjetivo, multidimensional, complejo y dinámico, es el marco que ofrece la mejor interpretación integral para abordar futuras acciones.

La cuarta reflexión está relacionada con la salud de la persona adulta mayor. La atención de salud del senescente debe ser llevada a cabo por un equipo transdisciplinario, debidamente entrenado. Aquí tiene especial 
importancia la formación académica de post-grado en gerontología, la que se está abordando a través de algunas universidades, pero todavía dista de alcanzar niveles de suficiencia. Referente a lo mismo, es muy importante disponer de recursos humanos y materiales especializados en gerontología en aquellas regiones más envejecidas: $\mathrm{IV}$, IX y X, y también donde se concentra la población de senescentes más pobres: VIII, y otra vez la IX y IV. Ahora bien, todo este proceso terapéutico debe esforzarse en considerar al paciente anciano sujeto y no objeto de las atenciones recibidas. Por una parte, él o ella deben ser capaces de valorar los progresos, retrocesos o situaciones estacionarias que van experimentando con el tratamiento, y por la otra, las normativas y los programas deben tener cierta flexibilidad para poder respetar estas diferencias individuales, lo que es una permanente tensión frente a la cuantía siempre escasa de recursos. La recuperación de la salud del adulto mayor debe ser entonces, una propuesta integral que a partir del reconocimiento y aceptación de la subjetividad del anciano, se oriente hacia la satisfacción de la dimensión individual, para desde allí proyectar el impacto colectivo que estamos preconizando.

Como cuarta conclusión de esta prospectiva, es razonable admitir que los servicios entregados por la salud estatal, deberían incorporar nuevas acciones derivadas específicamente de las necesidades de protección del adulto mayor, con mayor énfasis en aspectos de fomento y prevención, sin perjuicio de mantener y perfeccionar las curativas. 
La quinta reflexión hace relación con la educación. Por los resultados del Censo sabemos que el $49.33 \%$ de la población mayor de 50 años chilena posee entre 1 a 6 años de estudios básicos aprobados y más del $12 \%$ nunca asistió a la escuela. En cuanto a los analfabetos, el porcentaje promedio en la población total es de $5.4 \%$, pero en los adultos mayores este porcentaje se triplica, llegando al 17.1\%. Al descomponer el analfabetismo, éste se concentra tres veces más en las áreas rurales, 39,8\%, que en las urbanas, $12 \%$, siendo superior en las mujeres que en los hombres. Ha habido avances al respecto, especialmente en cuanto a corregir condiciones de analfabetos por desuso a través de algunos programas especiales implementados en varios municipios. Pero no obstante, tanto la escasa instrucción primaria como la menguada capacidad de lecto-escritura, son condiciones altamente negativas para poder realizar acciones tanto de valoración personal como de inserción laboral. Es importante considerar que así como los adultos mayores son diversos en cuanto a sus asuntos biológicos y psicológicos, es tal vez en el aspecto educacional donde mayormente se advierten estas diferencias, en relación a los niveles de educación formal alcanzados. Aún cuando es mayoritaria la porción que nunca recibió educación o tiene escasos años cursados, no podemos dejar de considerar que el 23\% tiene entre 9 y 12 años realizados, mientras solamente el $4 \%$ tiene estudios superiores. 
De este hecho las autoras señalan que aún cuando la actual generación de adultos mayores sea más proclive a mantenerse vigente y autónoma y se interese en adquirir nuevos conocimientos, para aprender especialmente sobre formas de cuidarse a sí mismos y así tener una vejez mejor en términos de calidad de vida, la pobreza intelectual puede ser tan limitante como la material. La misma sociedad, cada vez más profesionalizante y tecnificada, exige mayores requisitos para ser aceptado, lo que aumenta la segregación de los que están en peores condiciones, caso en el que se encuentra gran parte de la población chilena.

La sexta reflexión hace relación a la integración familiar del adulto mayor. Al respecto, es importante conocer la situación de pareja de nuestra población objetivo. El 55.5\% de los adultos mayores vive en parejas y el 45 restante no tiene. Entre los que están sin pareja, el $27.9 \%$ se encuentra en situación e viudez. El 13.2\% son hombres viudos, porcentaje que se triplica en el caso de las mujeres, ya que afecta al 39.3\% de las mayores de 60 años. Esta última cifra se explica por dos razones: Primero porque la expectativa de vida de las mujeres es superior. Para el quinquenio 20002005 ésta es 76.6 años para la mujer y 69.4 para el hombre, mientras en el quinquenio 2020-2025 se estima aumentará a 78 años para las mujeres y 71 para los hombres. Y segundo, por el patrón cultural que orienta a las mujeres a establecer pareja con hombres de mayor edad que ellas. El 16.6\% restante son separados o solteros. En resumen, podemos señalar que más 
del $70 \%$ de los hombres mayores enfrenta su ancianidad en pareja, mientras mayoritariamente las mujeres deben hacerlo solas (más del 50\%). La familia es el entorno al que el adulto mayor pertenece y del que no debiera salir. Sin embargo, la soledad por pérdida del o la compañera les hacen cuestionarse el sentido de sus vidas, especialmente en el caso de las mujeres, que sabemos que tienen mayores índices de dependencia porque son más desvalidas en términos económicos, numéricamente son más que los varones, y también viven más tiempo.

La convivencia familiar para los adultos mayores es el ambiente natural donde ellos pueden en mejor forma recibir el afecto y comprensión necesarios para adaptarse a los cambios del envejecimiento. Por una parte, el grupo familiar les ayuda a sobrellevar sus limitaciones y el dolor de sus pérdidas disminuyendo factores de angustia, porque se sienten respaldados por los apoyos que reciben expresados en consejos e información; y por la otra, les permite satisfacer una de las necesidades más importantes de todo ser humano: amar y sentirse amado. Es importante señalar que estos apoyos son mejores y más sólidos dentro de los sectores calificados en tramos socio-económicos medios, mientras que en los más pobres no solamente faltan recursos económicos, sino además sus recursos afectivos están deteriorados, lo que para los ancianos tiene repercusiones especialmente serias. 


\section{El constructo de la Personalidad Eficaz}

\subsection{Introducción}

Este trabajo pretende ser un aporte a los estudios en torno al Constructo de Personalidad Eficaz iniciado por el Grupo de Investigación de Orientación y Atención a la Diversidad (GOYAD) fundado por el Dr. Martín del Buey e integrado en calidad de cofundadores por la Dra. Martín Palacio en la Universidad Complutense de Madrid, Doctora Dapelo Pellerano y Dr. Marcone Trigo de la Universidad Estatal de Playa Ancha, Valparaíso, Chile. En consecuencia es necesario hacer una breve presentación del citado constructo.

La "personalidad eficaz" es una constructo teórico iniciado y formulado por el profesor Martín del Buey (Universidad de Oviedo) a lo largo de los años 1995-2000. La idea empezó a manifestarla en forma escrita a partir de un curso de doctorado que sería dictado en torno al tema. El curso fue formulado y emitido simultáneamente en la Facultad de Psicología de la Universidad de Oviedo y en la Facultad de Educación de la Universidad de Playa Ancha, Valparaíso, Chile durante dos cursos académicos: 1996 y 1997.

A partir de dicho curso se iniciaron numerosas investigaciones sobre dicha temática en dos líneas muy definidas: la evaluadora y la de intervención. 
En la línea evaluadora se han elaborado escalas de medición de las dimensiones del constructo en distintos niveles de edad a excepción de la población objeto de nuestro trabajo: edad comprendida a partir de los 60 años. Los criterios usados para la construcción de escalas de medida han sido la reducción mínima de ítems con el máximo de fiabilidad posible y la aportación de información sobre el desarrollo en la persona de estas dimensiones y de las pautas a seguir en el desarrollo de los programas conducentes a su mejora.

En la línea de la intervención se han desarrollado y aplicado programas en diferentes niveles educativos y diversos contextos desde la educación básica, media, superior y adultos.

Como consecuencia de esta actividad desplegada ésta se ha manifestado en variadas comunicaciones presentadas en congresos de ámbito nacional e internacional, artículos en revistas científicas, realización de tesis doctorales, tesinas de licenciatura y memorias de investigación, para la consecución del Diploma de Estudios Avanzados (D.E.A), y cursos de Extensión Universitaria. Igualmente en programas desarrollados en Centros educativos públicos, concertados y privados españoles y chilenos.

En este contexto este trabajo se centra en la evaluación de la personalidad eficaz en contextos de población comprendida en la 
denominada tercera edad: edad superior a los 60 años sobre la que el citado grupo tiene un especial interés y no ha sido abordado con anterioridad ni en contextos chilenos ni en contextos españoles.

Como marco referencial conceptual presentamos las ideas esenciales en torno al constructo de Personalidad Eficaz siguiendo para ellos los textos escritos de los Dres. Martín del Buey, Martín Palacio (2012) y los investigadores que ha seguido su línea de trabajo y defendido sus tesis tales como los doctores Fernández Zapico (2009), Fueyo (2010), López Pérez (2011), Pizarro (2012) , Di Giusto (2013), Muñoz Rojo (2013), Ramírez (2013), Bernal (2014) y Arraño (2014).

\subsection{Supuestos implícitos del Constructo Personalidad Eficaz}

El profesor Martín del Buey, en su reciente trabajo recopilatorio en torno al tema (2012) hace la formulación del constructo Personalidad eficaz desde los siguientes postulados psicológicos en los que encuadra su pensamiento: el constructivismo, los planteamientos cognitivos, la teoría de los rasgos, la opción psicométrica y la investigación empírica.

La opción constructiva en la investigación psicológica no deja de ser válida pero también muy criticable. Pero su autor acepta el reto. Pretende, y así lo asume, demostrar en la medida de lo posible que las relaciones de ideas (en este caso dimensiones psicológicas) empíricamente están 
relacionada entre si y forman una estructura y no solamente dejan de ser una formulación puramente teórica.

A la formulación del constructo han contribuido distintos planteamientos psicológicos vigentes entre los que cabe señalar por su singular interés los relacionados con el concepto de madurez, las inteligencias múltiples, la teoría de los rasgos, la opción psicométrica, y los niveles de relativa aceptación en psicología de la investigación empírica no experimental.

Con estos mimbres se ha elaborado el constructo.

\subsection{Definición de Personalidad Eficaz}

Desde los citados planteamientos define el constructo Personalidad eficaz en los siguientes términos:

“Una persona eficaz es un ser vivo con conocimiento y estima de sí mismo (autoconcepto y autoestima) en proceso de maduración constante (en cualquier estado de su evolución) con capacidad (inteligencia) para lograr (eficacia) lo que desea (motivación) y espera (expectativa) empleando para ello los mejores medios (entrenamiento) posibles (eficiencia), controlando las causas (atribución de causalidad) de su consecución (éxito o fracaso), afrontando para ello las dificultades personales, circunstanciales y sociales (afrontamiento de problemas) que 
se presenten, tomando las decisiones adecuadas sin detrimento de sus buenas relaciones con los demás (empatía y comunicación) ni renuncia en ellas de sus aspiraciones personales justas (asertividad).” (Martín del Buey, 2012, pp. 35).

Como el mismo indica en esa definición quedan implicados varios conceptos. Por eso es una definición multidimensional. La definición es multidimensional porque hace referencia a los siguientes conceptos:

Autoconcepto en base real

Autoestima correspondiente al Autoconcepto

Motivación

Expectativas adecuadas

Atribución de causalidad

Afrontamiento de problemas

Toma de decisiones

Empatía

Asertividad

Comunicación

Estas diez características constitutivas de la personalidad eficaz las agrupa en cuatro dimensiones entorno al yo que fueron sugeridas en su 
momento por el profesor Rodolfo Marcone de la Universidad de Playa Ancha, Valparaíso Chile.

Las fortalezas del yo integrada por: el Autoconcepto y la autoestima.

Las demandas del yo integrada por: la motivación, las expectativas y las atribuciones de causalidad.

Los retos del yo integrada por: resolución de problemas y la toma decisiones.

Las relaciones del yo integrada por: la empatía, la asertividad y la comunicación.

\subsection{Etiología de los planteamientos acerca del constructo}

En diferentes escritos relacionados con su constructo Martín del Buey y Martín Palacio (2012) plantean que una de las teorías más fuertes consistentes y arraigadas en psicología es la teoría de la incertidumbre.

Esta teoría postula la imperiosa necesidad que tenemos todos de superar esta situación siempre que podamos y lo antes posible. Y que esta tendencia a salir de ello constituye un motivo muy importante, por no decir básico, que genera un activo comportamiento. 
Martín del Buey y Martín Palacio (2012) ante la posible querencia de hacer un listado resumido de las preguntas que nos hacemos y nos hacen sobre nosotros mismos sugieren que es posible que se resuma en el conocido deseo y mandato del "Conócete a ti mismo" que lleva a la pregunta ¿Quién soy?

En psicología vuelve a estar de moda esta pregunta existencial que ya formularon los filósofos. Se la etiqueta con la dimensión de Autoconcepto. Algunos la venden como hallazgo impresionante del final del siglo XX y fuente de inspiración de la investigación actual. Es cierto con todo que se ha intentando su estudio desde supuestas plataformas empíricas y experimentales tratando de comprender mejor las distintas caras que el autoconcepto encierra. Y eso, es a su juicio una labor loable. Pero no es un invento nuevo.

En este contexto y en su calidad de "modesto aprendiz apasionado por la arquitectura de las dimensiones psicológicas" (así se define) se acerca al estudio de las diferentes caras que presenta el autoconcepto y formula la correspondiente arquitectura o constructo de los componentes que lo integran.

A la pregunta ¿Quién soy? se le debe asociar ineludiblemente otras preguntas implícitas que la aclaran, detallan y concretan.

Sugiere las siguientes: 
¿Cómo me valoro?

¿Qué quiero?

¿Qué espero?

¿De qué depende?

¿Qué me lo impide?

¿Cómo los supero?

¿Cómo me relaciono con los

demás?

Formuladas estas preguntas desarrolla su discurso en los siguientes términos:

Entiende que la pregunta de quién soy debe ir acompañada del cómo me valoro o como me estimo. Si el autoconcepto es necesario es conveniente a todos los efectos que tenga un cierto valor subjetivo de aprecio hacia esos elementos o características que lo definen. Por eso que la pregunta de cómo me valoro debe tener connotaciones positivas que se denominan autoestima.

Igualmente entiende que el conocimiento de sí mismo (autoconcepto) valorable de forma positiva (autoestima), todo ello ajustado, ponderado, contrastado y veraz, es decir de calidad, lleva consigo implícito las 
preguntas de que quiero, que espero y de que depende su consecución. Son preguntas existenciales que todos tenemos y que con frecuencia nos hacemos de forma implícita y explicita.

El qué quiero no deja de ser para él una respuesta al sentido que tiene mi yo en la realidad. Podemos llamarlo Motivación. Motivación que tiene un amplio espectro que va desde la pregunta sobre qué hace una persona como yo en un mundo como éste a que me apetece comer al mediodía pasando por saber si quiero ser médico, gasfíter o astronauta.

Y a esa motivación o respuesta a qué quiero debe ir acompañado, a modo de extensión del autoconcepto y la autoestima, la pregunta de qué espero. Conceptualmente sería la expectativa o esperanza tengo de poder conseguir lo que quiero.

Y junto a la pregunta qué quiero (motivación) y qué espero (expectativa) viene la ineludible pregunta íntimamente relacionada con quién soy y como valoro, que es: de qué depende. Se le llama atribución de causalidad. Donde de forma orientativa interesa que cuanto más la consecución dependa de uno mejor que mejor.

Todo lo dicho hasta el momento sería estupendo si fuésemos, a juicio de Martín del Buey y Martín Palacio (2012) un yo autónomo, independiente y biológicamente autótrofo. Pero la realidad no es esa. No se sabe si para bien o para mal. Pero no es esa. 
Por eso a ese conocimiento que se va teniendo del yo y de sus deseos, expectativas y poder se debe añadir, a juicio de Martín del Buey, una concienciación de las dificultades que le rodean que se concreta en la pregunta sobre qué impedimentos tiene para ello. A esto lo llama afrontamiento de problemas, o resolución de conflictos. No es intrascendente esta pregunta. Se diría que es clave y muy existencial. Detectar dónde está el problema y definirlo no es fácil. A veces es necesario acudir a expertos para que nos ayuden a definirlo. En relación a preguntas sobre el yo los médicos, psicólogos, psiquiatras nos ayudan (eso creo y confío) bastante.

Y si conocer los impedimentos que tiene el yo es importante, no lo es menos, saber cómo superarlos. Y esto es más difícil una vez que se da cuenta de que los problemas normalmente no se presentan aislados y únicos y si en racimo o con muchas caras que dificultan su abordaje de una sola vez. Por eso la pregunta de cómo lo supero viene a ser la segunda parte o la otra cara del afrontamiento del problema. La llama toma de decisiones.

Finalmente piensa que a esas preguntas que matizan la relacionada con el autoconcepto había que añadir una que da cuenta del carácter social del yo y su ineludible dependencia de los demás para la consecución de sus metas y autorrealización. Es la pregunta cómo me relaciono con los demás. 
Posiblemente esta pregunta es compleja. O al menos Martín del Buey y Martín Palacio (2012) la perciben con tres apartados.

La relación con los demás implica una acción primera sumamente importante como es la comunicación. Y esta lleva implícita dos acciones básicas a su entender: Como la comprende y cómo me comprenden. A la primera acción la llama empatía. Y a la segunda acción la llama asertividad.

Conocer, para Martín del Buey y Martín Palacio (2012), cómo me relaciono con los demás es importante. Eso hace que conozca mi capacidad de comunicación o el alcance de la misma tanto en su dimensión verbal como no verbal, metiéndome al máximo y en la medida de mis posibilidades en el interlocutor, en su mundo cognitivo y afectivo desarrollando al máximo esa capacidad (empatía) e intentando también expresar mi mundo cognitivo y afectivo contenedores de todo mi yo (autoconcepto, autoestima, motivación, expectativa, atribución, afrontamiento de problemas y toma de decisiones).

\subsection{La Personalidad Eficaz como respuestas a estas preguntas}

Martín del Buey y Martín Palacio (2012) sugieren que a la pregunta existencial que todos nos hacemos en torno a uno mismo de quien soy debe 
ir complementada como mínimo por otras serie de preguntas que completan su contenido, lo clarifican, lo detallan.

En base a ello entiende que toda persona que tenga respuesta a cada una de ellas cabe suponer que está dotada de un buen equipamiento para caminar en la vida y por la vida. Esto está asociado en el éxito, independientemente de que vamos a entender como éxito; también lo podemos asociar al concepto de felicidad, entendida como la superación del "ser", Sobre el "tener".

No obstante, hace las siguientes sugerencias que matizan esta formulación.

Sugiere que las respuestas que tenga no sufran variaciones a lo largo de su caminar. La experiencia y el conocimiento la va aclarando, matizando y en su caso variando. Eso es inevitable. Es más diría que necesario. Pero bueno es que se tenga siempre una respuesta e incorporar respuestas nuevas producto del aprendizaje con base al posible error.

Sugiere que las respuestas se encuentren fácilmente. Supone un aprendizaje y es un proceso laborioso. Posiblemente deba ser un ejercicio constante a lo largo de toda la existencia que se inicia desde niño y finaliza con el transito a otra realidad o muerte. Pero creo que es necesario tener respuesta para no sentirse desorientado o dar bandazos existenciales. 
Sugiere que no sabe si están todas las preguntas y no falta alguna. Pero tiene la creencia de que todas las que formula deben formar parte de ese catálogo.

En este contexto se pregunta nuevamente si las personas que estén en posesión de respuesta a estos interrogantes son personas que pertenecen a una categoría especial o reúnen una serie de cualidades que las hacer pertenecer al grupo de excepcionales.

La experiencia dice que no todos suelen responder con prontitud, rapidez, premura, seguridad a estas preguntas. En general se encuentran dificultades para ello y normalmente se tarda en contestar y en muchos casos se hace con generalidades.

Pero cuando encontramos a una persona que manifiesta....

"seguridad en sí misma,

con metas perfectamente definidas,

con claras aspiraciones de conseguirlas,

sabedor de las dificultades

con las que se encuentra

y capacidad resolutiva para superarlas

con capacidad comunicativa 
con capacidad comprensiva o empática

sin anular a nadie pero

tampoco sin dejarse anular"

.....reconocemos que es una especie singular, no muy habitual, digna de admiración, digna de elogio y generadora de una envidia (digamos sana) por emularla. Un ejemplo para los demás.

Es decir si nos encontramos con una persona que reúne esas características es posible que le atribuya una serie de cualidades. Esas cualidades pueden estar relacionadas con la inteligencia, la madurez, la competencia, la eficacia...etc.

De esas cualidades unas están relacionadas con los aspectos propios del yo y otras relacionadas con el resultado de sus comportamientos.

De alguna forma pensamos que esa persona de alguna forma es una especie de súper hombre o súper mujer de la vida.

Llegado a este punto de su reflexión el profesor Martín del Buey formula las siguientes hipótesis de trabajo:

$1^{\circ}$. Es posible que en la literatura científica centrada en la psicología existan antecedentes o estudios que han relacionado estas preguntas, 
convertidas en dimensiones, $\mathrm{y}$ en base a ello se hayan formulado constructos a modo de aproximaciones.

Pero igualmente es posible que un intento de aproximación que relacione las diez dimensiones de autoconcepto, autoestima, motivación, atribución, expectativas, afrontamiento de problemas, toma de decisiones, empatía, asertividad y comunicación, sea como mínimo novedoso, consistente y posible.

E igualmente es posible que se pueda formular teóricamente que esas características son constitutivas de una personalidad eficaz, efectiva y eficiente.

$2^{\circ}$. Es posible que usando un método empírico adecuado pueda demostrar que todas esas preguntas que he formulado, convertidas en dimensiones estén relacionadas entre sí de forma significativa, y que la persona que tenga esas dimensiones positivas sean en la realidad eficaces, eficientes y efectivas en los contextos en que se las valora.

Respecto a la primera hipótesis Martín del Buey reconoce que en sus planteamientos hay antecedentes significativos. De forma especialmente significativa destaca los siguientes:

Aportes de las distintas escuelas psicológicas respecto al concepto de madurez: 
- Perspectiva de la teoría de las inteligencias múltiples

- Aportaciones de la teoría sobre la inteligencia emocional

- Los estudios realizados por Bandura sobre la auto-eficacia (1975, 1977, 1985 y 1997).

Respecto a las aportaciones al constructo de personalidad eficaz derivadas de los constructos sobre madurez a Martín del Buey le merece especial significado aquellos que relacionan la madurez con la competencia.

Dos modelos cobran especial interés para su constructo:

- El modelo de madurez psicológica de Heath (1965)

- El modelo de competencia propuesto por White (1959) continuado por Garmezy y Masten (1991) y Waters y Sroufe (1983).

Respecto a las aportaciones al constructo de las teorías de las inteligencias múltiples Martín del Buey indica que el constructo de personalidad eficaz parte del postulado siguiente: 
Las conductas generadoras de eficacia son en el fondo respuestas o (si se quiere ser más exacto y preciso) conductas inteligentes, entrenables y objeto de desarrollo.

Por ello parece que es necesario nutrirse de todos aquellos autores que han tratado la inteligencia y las distintas modalidades de la misma.

De forma especial se interesa por dos desarrollos claves en este sentido:

- La teoría de las inteligencias múltiples de Howard Gardner (1983) - posteriormente modificada (Gardner, 1999).

- La Teoría Triarquica de Robert J. Sternberg (1985).

Respecto a las aportaciones al constructo de los planteamientos de la inteligencia emocional, en cuanto concepción de un aspecto específico de inteligencia se interesa por las aportaciones siguientes:

- El modelo de habilidades de Mayer y Salovey (1997). El básico sobre los que pivotan los demás.

- La inteligencia emocional como rasgo (Petrides y Furnham, 2000; Petrides, Furnham y Martin, 2004; Petrides, Pérez González y Furnham, 2007). 
- Modelos mixtos tales como el modelo de competencias emocionales de Goleman (1998) y el de Bradberry y Greaves (2005).

- Modelo de Bar-On (2006) de Inteligencia Emocional-Social.

A juicio del profesor Martín del Buey el constructo de inteligencia emocional entendido como capacidad y definido por Salovey y Mayer (1997) tiene una dimensión y alcance mucho más reducido en la medida que se circunscribe a cuatro dimensiones en escala:

a) Percibir y expresar emociones de forma precisa

b) Usar la emoción para facilitar la actividad cognitiva

c) Comprender las emociones

d) Regular las emociones, todas relacionadas con la inteligencia emocional.

En este sentido el constructo sobre personalidad eficaz es mucho más amplio en la medida que abarca dimensiones mucho más amplias.

En cambio en el constructo de inteligencia emocional concebido como rasgo sí que encuentra unos descriptores que tienen muchos elementos coincidentes con su constructo. Pero la pregunta básica que se hace es ¿hasta qué punto esos rasgos que se describen como perteneciente a 
la inteligencia emocional son realmente rasgos de inteligencia emocional?

De forma más explícita ¿Qué tiene que ver esos rasgos con la inteligencia emocional?

Respecto a las aportaciones de Bandura al constructo de Personalidad eficaz el profesor Martín del Buey indica que la teoría de Bandura ofrece elementos de singular importancia que están presentes en la formulación del Constructo Personalidad Eficaz.

Un componente básico del mismo es el factor denominado "Fortalezas del yo", compuesto fundamentalmente por dos rasgos: el autoconcepto y la autoestima, formando dos aspectos de un mismo concepto. La relación de ambos rasgos con la autoeficacia es clara.

Otro elemento básico integrado del constructo de Personalidad Eficaz son las "Demandas del yo", constituido fundamentalmente por tres rasgos: motivación, atribución y expectativas, rasgos que igualmente están presentes en los postulados de Bandura sobre autoeficacia.

Es necesario puntualizar que el constructo de Personalidad Eficaz se centra en definir los elementos que lo integran, y no únicamente en la importancia que tiene la confianza y creencias personales en la autoeficacia, que es lo que ha investigado y desarrollado Bandura.

Esto constituye la diferencia esencial entre ambos constructos. Por ello la Personalidad Eficaz no puede ser encuadrada entre los postulados 
conductuales de Bandura (al menos en sus inicios) ni corresponde exactamente con su teoría Social Cognitiva.

Respecto a la segunda hipótesis la realidad empírica permite disponer de diferentes pruebas que miden las variables que integran el constructo de personalidad eficaz.

Se ha verificado empíricamente que estas variables están relacionadas entre sí.

El hecho de que estas variables están relacionadas entre sí y su interrelación, permite formular grupos que derivan en perfiles o tipos significativamente diferenciados.

Dichas pruebas, se han aplicado en diferentes campos educativos e institucionales, obteniendo unos índices de validez de constructo, externa y fiabilidad ampliamente satisfactorios.

Con independencia a estas dos hipótesis de partida el profesor Martín del Buey se formula los siguientes planteamientos relacionados con la denominación del constructo Personalidad eficaz

Estos planteamientos se centran en los siguientes aspectos:

¿Eficacia o eficiencia o efectividad? 


\section{¿Eficacia o autoeficacia? \\ ¿Persona o personalidad? \\ ¿Eficacia vs competencia?}

En sus escritos da respuesta a estos planteamientos y formula la siguiente síntesis:

1. Que ha existido preocupación y ocupación por definir y perfilar las características propias de una personalidad competente, madura, emocionalmente estable, inteligente, y si se quiere eficaz, (aparece escasamente) pero que todas esas aproximaciones son en ocasiones dispares a la hora de concretar las dimensiones o rasgos que la integran.

2. Este hecho le ha obligado a realizar un detallado análisis de los conceptos de madurez, inteligencia, competencia, y eficacia, para quedarse finalmente con el de eficaz comprendiendo en el mismo el de eficiencia y el de efectividad y considerando los otros como complementarios y en su caso aclaratorios al de eficaz.

3. Que posiblemente exista unos rasgos comunes que están frecuentemente presentes en esas personas que si bien no son coincidentes en sus nombres si lo sean en sus descriptores. Así lo ha podido observar en los descriptores que se hacen a la hora de definir una persona madura desde 
los distintos postulados en que se formula, como a la hora de definir la inteligencia intra e interpersonal y emocional, como las connotaciones que se atribuyen a una persona sabia, mentalmente sana y en su caso autorrealizada.

4. Que el listado de características que integran ese tipo de personalidad en la mayoría de las veces es ampliamente extenso observándose una posible repetición de los mismos y requiriendo una esencialización de ellos. Dificultad que se acrecienta cuando no existen descriptores de ellos que permitan acotarlos y diferenciarlos.

5. Que las formulaciones de esas dimensiones imputables a esas personas en la mayoría de los casos no tienen soporte empírico y mucho menos experimental, y vienen a ser fruto de una observación empírica laudatoria y en modo alguno de mayor alcance.

5. Que la competencia y sus derivados están muy presentes en la sociedad actual. Hasta tal punto que en las programaciones educativas de todos los países es una palabra puesta de moda. Se habla de programación en competencias. Siempre pensamos que la educación no era otra cosa. Pero ahora parece que los iluminados de turno lo acaban de descubrir. Bienvenido sea esto si ayuda a que se consolide una idea tan antigua en la historia de la educación. Pero concluimos que el concepto eficacia es más 
amplio que competencia y que esta no deja de ser concreciones concretas de eficacia.

\subsection{La medición de la Personalidad Eficaz}

Como se ha descrito en el punto anterior, se considera la Personalidad Eficaz como un conjunto de rasgos. Por ello, a la hora de evaluarla, hay que estudiar las diferentes formas en que los rasgos pueden ser evaluados.

\subsubsection{Las variables de la Personalidad Eficaz como rasgos}

Las variables de Personalidad Eficaz, debido a sus características, se pueden tratar de la misma manera que los rasgos. Por ello, a la hora de evaluarlo, se han construido escalas utilizadas en pruebas para su medición.

En el presente trabajo hemos elegido la forma de escala Likert, cada ítem se respondía de 1 a 5 siendo 1 nada de acuerdo con el ítem; 2 poco de acuerdo con el ítem; 3 algo de acuerdo con el ítem; 4 bastante de acuerdo con el ítem y; 5 totalmente de acuerdo con el ítem.

Con las respuestas emitidas por los sujetos se sumaban las puntuaciones por dimensiones obteniendo así un perfil de cómo se encontraba el participante en cada una de las dimensiones. 


\subsubsection{Instrumento elaborados}

Los cuestionarios que se han construido hasta el momento centrado en población adulta (no citamos los construidos para población infantil y adolescente) han sido los siguientes:

\section{"El cuestionario para el desarrollo de la personalidad eficiente} $\underline{(\boldsymbol{C D P E})}$ " es el primer cuestionario que se construye para la Evaluación de la Personalidad Eficaz y se enmarca en el ámbito empresarial. Presenta un coeficiente de fiabilidad de .78 (Martín del Buey y Martín Palacio, 2012).

Es un instrumento empleado para el Programa de Desarrollo de la Eficacia Profesional elaborado bajo la dirección del profesor F. Martín del Buey (2003), de la Universidad de Oviedo y Profesora Martín Palacio de la Universidad Complutense de Madrid.

\section{“Cuestionario de Personalidad Eficaz en Contextos Educativos"}

El instrumento elaborado ad hoc para la investigación consta de 44 ítems. Presenta un coeficiente de fiabilidad de .80 (Martín del Buey y Martín Palacio, 2012).

\section{"Cuestionario de Personalidad Eficaz en Secundaria". Surge} como respuesta a la revisión del "Cuestionario de Personalidad Eficaz en Contextos Educativos" (Martín del Buey, 2003) está compuesto por 28 
ítems que no experimenta una gran descenso en su fiabilidad respecto al cuestionario inicial .869 .

"Cuestionario de Personalidad eficaz para adolescentes" (Dapelo, Marcone, Martín Palacio, Martín del Buey y Fernández, 2006) consta de 24 ítems, divididos en cuatro factores:

Esta investigación se centra en la adaptación del Cuestionario de Personalidad Eficaz en contextos educativos a la realidad chilena.

La versión original del Cuestionario está conformada por 58 ítems. Se introducen modificaciones en 30 de sus ítems. Presenta un coeficiente de fiabilidad de .81 .

"Cuestionario de Personalidad eficaz para ciclos formativos de formación profesional” (Martín del Buey, Fernández, Martín, Dapelo, Marcone y Granados, 2008) consta de 22 ítems, distribuidos en seis factores. Presenta un coeficiente de fiabilidad de .76.

"Cuestionario de Personalidad eficaz (pece) en el contexto de la educación técnico-profesional” (Dapelo y Martín del Buey, 2007) de a 22 ítems, arroja un coeficiente alfa de Cronbach de 0,8064. Se obtienen cinco factores de primer orden que explican el 58,029\% de la varianza total. 
"El Cuestionario de Personalidad Eficaz al ámbito universitario"

de Dapelo y Martín del Buey (2006) compuesta de 30 ítems. Presenta un coeficiente de fiabilidad de .87 .

La estructura factorial del PECED revela una alta correspondencia conceptual con el modelo que lo sustenta, en consecuencia es posible identificar claramente las cuatro esferas del yo y sus variables.

"Cuestionario de Personalidad eficaz en población adulta española de 30 a 60 años de edad de López Pérez (2011). Existe del mismo una adaptación Chilena de Ramírez (2013). Reúne todas las características pertinentes en cuanto a fiabilidad, validez de contenido, y baremación diferenciada.

Haremos referencia a él más adelante pues es el instrumento que hemos empleado para la realización del trabajo.

\section{Las tipologías modales multivariadas}

Habla de tipologías no dejar de ser igualmente arriesgado pues durante bastante tiempo ha sido un término desechado en la investigación psicológica. En este apartado tratamos de justificar, siguiendo a Martín del Buey y Martín Palacio (2012) las bases que justifican asumir este riesgo. 
Las tipologías o ciencias de los tipos humanos se han construido muy lentamente, pero posee cartas de nobleza que remontan muy lejos en el tiempo y se extiende a todos los países y culturas (Martín del Buey, 1985).

El hecho de que hayan surgido tantas tipologías en la mente de los investigadores o pensadores científicos o precientíficos a lo largo de muchos siglos, como un modo de ordenar de alguna manera el complejo reino de las diferencias individuales nos prohíbe rechazarlas a la ligera.

Según su inspiración más que su orden cronológico de aparición se pueden apreciar tres grandes movimientos tipológicos: el causal, el metafísico y el factorial. Dentro de éste último se encontraría la corriente psicoestadística y la corriente correlacional (Martín del Buey, 1985).

\subsection{Crisis del concepto clásico de tipo}

Durante el siglo XX los psicólogos, y especialmente los psicólogos americanos, han venido sometiendo a dura crítica los conceptos de tipo y la razón fundamental que se manifiesta no es solamente la posible ambiguiedad del término sino por la implicación que lleva de ser clasificaciones mutuamente exclusivas, lo cual se opone lógicamente a la cuantificación de los atributos de los seres humanos. En consecuencia las mismas concepciones tipológicas clásicas, a excepción de las dos corrientes últimas señaladas han caído en desuso en la psicología moderna porque, 
bajo la influencia anglosajona, esencialmente conductista, se ha centrado enteramente en la investigación de dimensiones mensurables y objetivables de la personalidad.

\subsection{Intentos de un posible reencuentro: estrategia diferenciadora de} los rasgos

Se intenta poner orden en las diferencias individuales mediante el estudio de los rasgos. En vez de adscribir cada individuo a su clase, como hacen las tipologías clásicas, se dirige la atención a los rasgos que se manifiestan en su conducta. El describir a muchos individuos con los mismos rasgos sirve para expresar cuantitativamente las diferencias entre ellos (Tyler 1972).

Un rasgo es una marca distintiva de algo, de un individuo o clase. En psicología de la personalidad el término se utilizó como clasificatorio, como de estructura disposicional o como fuerza o principio interior (Pinillos, 1978).

El rasgo debe ser una nota representativa de otras muchas notas conductuales propias de un sujeto o grupo de sujetos.

Stein (1963) dice que en la actividad de las personas hay una parte variable y una parte propositiva constante, y ésta última la que se pretende identificar con el rasgo. 
Los rasgos concebidos como motivos participan en el aspecto de la disposición, o estructura facilitadora de respuestas ante cierto tipo de situaciones. El rasgo puede tener un fundamento biológico innato, puede ser temperamental, facilitando la respuesta. Pinillos lo define como: una estructura regulativa de carácter tendencial que facilita, pero no produce, una clase de respuesta (Pinillos, 1978).

Operacionalmente el rasgo se define a partir de una intercorrelación de respuestas semejantes ante estímulos diversos. La iniciación de la respuesta corresponde a la estimulación; pero la personalidad la hay que entender como dependiente de fundamentos biológicos $y$ de sus condiciones (Pinillos, 1978).

El problema que surge al entender los rasgos como variables de personalidad radica que en unas casos son muy pocas y en otras son demasiados.

Los conceptos de rasgo hacen posible la comparación de una persona con otra. Pero los rasgos no son inconexos e independientes entre sí y algunos son más importantes que otros dentro de la personalidad. Los detalles más concretos emergen de las características de los actos y experiencias particulares; luego el conjunto de rasgos de un comportamiento de un sujeto o clase se llama tipo. 
Para Cattell un tipo es un modelo constituido por medidas de rasgos que figuran dentro de ciertos valores modelos (Cattell, 1979).

\subsection{Reconsideración del concepto de Tipo: Concepción modal multidimensional}

Varios investigadores se preguntaban si no puede ser que los tipos sean compatibles con una medición o un método cuantitativo para abordar las diferencias individuales.

Cattell, Couter y Tsujioka (1966) han considerado 3 modelos de tipos que se usan en medición: el modelo de tipo polar que se refiere a los extremos de un rasgo bipolar distribuido donde se supone que el rasgo es amplio. El tipo modal se define mediante un aglutinamiento de individuos a lo largo de un rasgo simple donde cada aglutinamiento o modelo representa un tipo. El tipo de especies o multidimensionsal, aquí se agrupan a los individuos en tipos basándose en la similitud de sus perfiles (Bolz, 1972).

La identificación de los tipos de especies o tipos modales multidimensionales; consiste en identificar grupos de individuos determinando la similitud de diferentes perfiles de rasgos.

Dos perfiles pueden diferir en términos de elevación, dispersión o forma, resultante de la equiparación de ambos perfiles. Un coeficiente de similitud que tenga en cuenta 3 parámetros se pueden encontrar diferencias 
y similitudes de individualizados perfiles de rasgos lo que hacen un agrupamiento multivariado más rico y más analítico.

La ubicación de los tipos, basándose en los rasgos, según la tipología multidimensional se puede aplicar a problemas nuevos e importantes (Buss y Poley, 1979).

\subsection{Técnicas de agrupación por conglomerados}

Bolz (1972) los agrupa en 7 categorías entre las que destaca las técnicas de agrupación por conglomerados.

Esta técnica consiste en un conjunto de técnicas de análisis de datos; cuyo objetivo consiste en encontrar describir y explicar alguna estructura simple dentro de una compleja masa de datos. También es objetivo reproducir y automatizar los procesos que pueden observarse visualmente en dos dimensiones y ampliarlos a cualquier número de dimensiones; agrupar las unidades en clases, dentro de las cuales las unidades o datos tengan perfiles análogos, configurando así una reducción de datos y simplificar el análisis que pueda explicar las estructuras latentes en los datos.

Cada clase puede describirse mediante un perfil medio o típico. El método de agrupamiento por conglomerados no se inició hasta finales de 
los años 50 cuando aparecen los ordenadores. Los métodos de agrupamiento por conglomerados se reducen a las siguientes etapas:

- $\quad$ Selección de las unidades y variables.

- $\quad$ Determinación de las medidas de similitud entre las unidades.

- $\quad$ Agrupación de las unidades en conglomerados

- Interpretación y descripción de los resultados del agrupamiento.

Otros análisis e interacciones.

Vamos a ver cada una de ellas:

a) Selección de unidades y variables

La especificación de los datos exige la correlación de unidades y variables y la elección de una escala para cada variable.

La inclusión de muchas unidades en un tipo hará que este tipo aparezca como conglomerado. La representación excesiva de un tipo no afecta al agrupamiento del resto. No existe un universo claro de unidades y las fácilmente disponibles no constituyen una muestra probabilística de cualquier población.

La selección de variables y atributos es más importante que el de las unidades y determina que aspectos del comportamiento de las unidades se 
representan en el agrupamiento. La representación excesiva de variables en un área puede afectar al resultado total. Las variables pueden refinarse, subdividiéndose y combinándose. Las variables tendrán dependencia estadística con respecto a grupos de unidades. La elección de variables es subjetiva y es también un elemento crucial del proceso de agrupamiento por conglomerados. En un proceso de agrupamiento los datos pueden disponerse en una tabla rectangular, correspondiendo las filas a unidades y las columnas a las variables o atributos observados.

b) Medidas de similitud.

Una medida natural de disparidad entre los puntos es la distancia euclidiana al cuadrado y si las variables son dimensionadas, es necesaria una distancia ponderada para que el análisis tenga sentido.

No hay una sola elección correcta de las ponderaciones, pero si operativa y preferible una elección subjetiva cuidadosa basada en el conocimiento externo de las variables.

Respecto a las variables cuantitativas, las medidas de similitud utilizadas son equivalentes al cuadrado de una de las distancias ponderadas o sin ponderar.

c) Cálculo las agrupaciones por conglomerados 
Los métodos de agrupamiento exigen una gran cantidad de cálculo. Así, encontrar los pares más próximos de agrupamiento, combinarlos en un nuevo agrupamiento más grande y calcular la distancia entre el nuevo grupo y cada uno de los restantes.

d) Interpretación y descripción de los resultados

El resultado puede representarse mediante un árbol o dendograma.

e) Interacción.

La posibilidad de tratar conglomerados como proceso interactivo, utilizando resultados de uno de ellos para mejorar el siguiente representa un papel esencial en cualquier procedimiento de agrupamiento.

Hay una relación entre análisis factorial y la técnica de agrupamiento por conglomerados. Ambos métodos tratan de descubrir y describir estructuras en una tabla de datos sin estructurar. Buscan diferentes tipos de estructuras, pero son muchas las coincidencias. El análisis factorial trata de encontrar variables independientes tales que la regresión con respecto a las variables se ajusta a los datos observados. Por el contrario el análisis de conglomerados es un análisis de clasificación de la varianza de las unidades que se ajusta a los datos observados.

Cualquier estructura de grupos puede explicarse mediante una estructura de factores, aunque son necesarios tanto factores como grupos. 
De todos los métodos de agrupamiento destaca el Análisis de tipos propuesto por Bolz, basado en el coeficiente de similitud de patrones de Cattell.

\subsection{Análisis de tipo}

El coeficiente de similitud de patrones de Cattell (1966) es un índice útil de similitud que tiene en cuenta, como indicamos en la concepción tipológica modal multivariada los 3 parámetros a lo largo de los mismos, pueden diferir los perfiles.

La psicología social centra sus estudios en los procesos básicos de la interacción humana con sus semejantes. Para ello propone el estudio de cuatro conductas básicas y secuencias de la interacción: la conducta perceptiva y la conducta comunicativa mediante las cuales nos formamos una idea del otro u otros, cuyo fruto será una conducta de aceptación (con los posibles grados existentes) o de rechazo (con igual categoría de grados). Para ese proceso de formación de una idea del otro que se describe como complejo, discutido y discutible, dónde entran en juego infinidad de teorías tales como las de Primeras impresiones, las taxonómicas, atribuciones de causalidad y otras, muy sometidas a error claro de percepción se ve conveniente incorporar para incrementar y enriquecer esa precisión perceptual las tipologías modales de especies o multivariadas donde la 
presencia de unos rasgos combinados puede dar lugar a una especie o tipo con mayor base de objetividad.

En psicología de la educación es objeto de especial estudio todo lo referente al proceso evaluativo del educador sobre el educando, dónde los sesgos procedentes implícitos en los citados procesos han sido objeto de abundantes estudios y formulación de teorías tales como el efecto Pigmalión y otras. Las tipologías de especies desarrolladas en estos contextos y aplicadas a rasgos tanto de carácter cognitivo, afectivo o motórico pueden aportar un excelente referencial a la hora de formarse una idea inicial, que deberá ser posteriormente ampliada en base a la interacción con el alumno, con una cierta base de objetividad.

En el presente trabajo hemos seguido la propuesta metodológica de Bolz (1972) que resumiendo en siete grandes grupos los métodos utilizados por los investigadores para determinar una tipología adecuada, destaca por su especial significación para el estudio de las tipologías modales multivariadas las técnicas de agrupamiento por conglomerados.

El método de agrupación por conglomerados consiste en encontrar, describir y posiblemente explicar alguna estructura simple dentro de una masa compleja de datos. Su objetivo consiste en reproducir y automatizar los procesos en dos y ampliarlas a cualquier número de dimensiones. Si es posible agrupar los datos en un número moderado de clases (tipos) dentro 
de los cuales tengan perfiles análogos, se consigue una reducción de los datos fácil de describir, que simplifica su análisis y que puede indicar las estructuras teóricamente latentes de los datos. En algunos casos los grupos pueden corresponder a tipos latentes explicados por la Teoría. En otros pude representar una útil reducción empírica de datos.

\subsection{Renacimiento de trabajos en torno a las Tipologías}

Como representación no exhaustiva de esta reactivación por el interés de las tipologías cabe destacar los trabajos de:

Coie, Dodge y Coppotelli (1982) sobre "Dimensions and types of social status: A cross-age perspective".

Newcomb y Bukowski (1983) sobre "Social impact and social preference as determinants of Children's Peer Group Status".

Maassen, Akkermans y van der Linden (1996); Maassen y Lanndsheer (1998); Maassen, Steenbeek y van Geert (2004).

Saunders (1992) sobre “A typology of men who batter: Three types derived from cluster analysis".

Holtzworth-Munroe y Stuart (1994) sobre "Typologies of male batterers: Three subtypes and the differences among them" y Holtzworth- 
Munroe, Meehan, Herron, Rehman, y Stuart (2004) sobre "Do subtypes of martially violent men continue to differ over time?".

Waltz, Babcock, Jacobson y Gottman (2000) sobre "Testing a typology of batterers".

Petersen, Doody, Kurz, Mohs, Morris, Rabins (2001) sobre "A typology of men who batter: Three types derived from cluster analysis".

Chambers y Wilson, (2007) sobre "Assessing male batterers with the Personality Assessment Inventor".

Huss y Ralston, (2008) sobre "Do batterer subtypes actually matter? Treatment completion, treatment response and recidivism across a batterer typology".

Y en nuestro entorno más cercano los trabajos de:

Martín del Buey 1985 sobre "Tipologías Modales Multivariadas y Rendimiento Académico".

Marcote (2001) sobre "Tipologías motivacionales y su incidencia sobre el rendimiento académico".

Romero (2001) sobre "Motivación, atribución, expectativas y rendimiento académico en la Enseñanza Secundaria Obligatoria”. 
Mulet, Sanchez-Casas, Arrufat, Figuera, Labad y Rosich (2005) sobre "Deterioro cognitivo ligero anterior a la enfermaedad de alzheimer: tipologías y evolución”.

Muñoz, Navas, Graña y Martínez, (2006); sobre "Subtipos de drogodependientes en tratamiento: apoyo empírico para una distinción entre tipo a y tipo b".

Ortiz-Tallo, Cardenal, Blanca, Sánchez y Morales, (2007) sobre "Multiaxial evaluation of violent criminals".

Muñoz, Moreno y Jiménez (2008) sobre "Las Tipologías de estatus sociométrico durante la adolescencia: Contraste de distíntas técnicas y fórmulas para su cálculo. Entre Iguales en el Contexto Escolar”.

Y Loinaz, Echeburúa y Torrubia, (2010) sobre "Tipología de Agresores contra la Pareja en Prisión".

Cabe señalar que las funciones y la transcendencia metodológica de la clasificación tipológica tiene un doble aspecto: la codificación y la predicción. Una tipología va más allá de la simple descripción, por el contrario, simplifica la ordenación de los elementos de una población y los rasgos relevantes de dicha población en agrupamientos distintos. Gracias a esta capacidad la clasificación tipológica pone orden en el caos potencial. Pero el codificar de este modo los fenómenos, permite también investigar y 
predecir las relaciones entre fenómenos que no parecían estar en conexión a simple vista. Esto es debido a que una buena tipología no es una simple colección de entidades diferenciadas, sino que está compuesta de un enjambre de rasgos que en realidad se mantienen unidos y esto permite establecer cierto carácter predictor entre ellos.

En este trabajo nos hemos centrado únicamente en las competencias personales y socio-afectivas relacionadas con el Constructo de la Personalidad Eficaz formulado igualmente por Martín del Buey y Martín Palacio (2012) y en base a los resultados que obtengamos del cuestionario objeto de nuestro trabajo.

En relación al establecimiento de tipologías modales multivariadas de personalidad eficaz es importante indicar que se han realizados numerosos trabajos con varias muestras en diferentes edades previas a la que es objeto de esta investigación.

Así tenemos las tipologías obtenidas en las siguientes muestras: infantil: Fueyo (2010) y Pizarro (2012); adolescente: Di Giusto (2013), Muñoz Rojo (2013); y Arraño (2014); juvenil: Gómez (2011) y Bernal (2014); y adulta: López Pérez (2011) y Ramírez (2013).

En todos estos estudios se han obtenido cuatro tipos diferenciados de personalidad eficaz. 
Centrados en la edad adulta (edad comprendida entre los 30 a 59 años de edad) presentamos a continuación los perfiles obtenidos en ambos trabajos.

\subsection{Estudios realizados sobre tipologías en Personalidad eficaz}

\subsubsection{Perfiles de personalidad eficaz obtenidos en España (López} Pérez, 2011)

López Pérez (2011) presenta la siguiente clasificación tipológica de personalidad eficaz en su investigación doctoral sobre tipologías modales multivariadas de personalidad eficaz en contextos adultos españoles de 30 a 59 años.

Tipo I: Eficaz Introvertido. Estos sujetos presentan un buen funcionamiento en dos de las cuatro esferas del yo que conforman el cuestionario de Personalidad Eficaz. Puntúan por encima de la media, en los factores Demandas de yo y Retos del yo. Son sujetos con valores ligeramente superiores a la media en motivación orientada a la tarea. Establecen atribuciones de éxito (debidas al esfuerzo o la capacidad) en la mayoría de las situaciones, y por lo general, suelen mantener expectativas de éxito futuro. Frecuentemente adoptan una perspectiva resolutiva a la 
hora de abordar situaciones problemáticas, reflexionando antes de tomar una decisión o actuar.

Esta tipología pone de manifiesto la relación existente entre las variables motivación, atribución y expectativas y las variables afrontamiento de problemas y toma de decisiones. Una visión optimista de los problemas y la confianza en que se superarán; un estilo atribucional con locus de control interno que les permite partir de la idea de que con más esfuerzo se superan las dificultades, así como las atribuciones de éxitos pasados a sus capacidades; y el disfrute (o motivación) que nace del propio ejercicio de desempeñar una tarea parece tener relación directa con una postura resolutiva (frente a evitativa o pasiva) a la hora de afrontar problemas y reflexiva, o poco impulsiva: buscando información y tomando en consideración distintas alternativas antes de actuar.

Sin embargo, presentan deficiencias en las dos esferas restantes, especialmente en Relaciones del yo. En este factor puntúan por en el percentil 20, casi una desviación típica por debajo de la media. Y en el factor Fortalezas del yo puntúan en el percentil 40. Demuestran, por tanto, una valoración negativa de sí mismos, pero sobretodo, déficit en habilidades sociales: comunicación asertividad y empatía.

En resumen, estamos hablando de adultos caracterizados por un estilo motivacional y atribucional adaptativo, expectativas optimistas y competentes en el afrontamiento de problemas y la toma de decisiones; 
pero con baja autoestima, dificultades en las relaciones con los iguales y para desenvolverse en situaciones sociales.

En cuanto al número de sujetos de la muestra integrante en esta tipología, podemos observar que es el segundo grupo con mayor muestra Tipo II: Ineficaz. Los sujetos que quedan enmarcados dentro de este clúster presentan puntuaciones muy bajas en los cuatro factores del cuestionario de Personalidad Eficaz: Fortalezas del yo, Demandas del yo, Retos del yo y Relaciones del yo.

Se ven a ellos mismo como problemáticos, poco importantes y en desacuerdo con su forma de ser y actuar. No se gustan ni físicas, ni emocionalmente. Presentan una baja autoestima como trabajadores y como amigos, repercutiendo en sus labores y en sus relaciones con los iguales. La imagen negativa que tienen de sí mismos afecta a las otras esferas de su yo desembocando en un funcionamiento poco adaptativo o lo que podríamos llamar, siguiendo con la terminología del constructo, "Personalidad Ineficaz".

Representarían la antítesis del sujeto prototipo de "Personalidad Eficaz" (Tipo IV), que cuenta con un amplio abanico de competencias personales y sociales para desenvolverse en su vida cotidiana.

Presenta escasa motivación laboral repercutiendo en su rendimiento. Sus atribuciones no presentan locus de control interno, y se perciben con falta de aptitudes para obtener buen rendimiento. Esto repercute en una 
visión pesimista sobre acontecimientos futuros. En el contexto laboral se concreta en la creencia de que en la actualidad su rendimiento será bajo o que en el futuro no les va a ir bien, pudiendo desembocar en "profecías autocumplidas" por las escasas herramientas que estos sujetos despliegan para hacer frente a las creencias negativas que tienen de sí mismos, y que queda reflejado en sus bajas puntuaciones en el factor Retos del yo.

Muestran dificultades en el afrontamiento de problemas y la toma de decisiones, presentando dificultades para decidir por sí mismos y optando por una actitud en ocasiones pasiva, y en ocasiones impulsiva, a la hora de abordar conflictos. Poniendo en relación estas actitudes y la pobre imagen que tienen de sí mismos se hace difícil que, por ellos mismos, den el paso de "tomar las riendas" ante las dificultades o pongan en marcha recursos que les permitan mejorar su autoestima.

Se perciben con pocas amistades y dificultad para relacionarse con sus iguales. Manifiestan expectativas de fracaso en relaciones sociales hipotéticas futuras. Sus escasas capacidades empática y asertiva y sus problemas a la hora de desenvolverse en situaciones social explican las bajas puntuaciones en el segundo factor del cuestionario, aunque estas se sitúan dentro de la normalidad.

Son por tanto adultos que presentan cogniciones y comportamientos desadaptativos: baja autoestima, escasa motivación laboral (ni de logro, ni orientada a la tarea), expectativas pesimistas, déficit en habilidades sociales 
y dificultades para afrontar dificultades de su día a día. Hablaríamos, como ya se ha señalado, de Personalidad Ineficaz.

Por otro lado, la muestra integrante en esta tipología, representa el menor número de todas las cuatro tipologías encontradas.

Tipo III: Ineficaz Social Los sujetos que quedan enmarcados dentro de este clúster presentan puntuaciones muy bajas en tres factores del cuestionario CPE-Adultos: Fortalezas, Demandas y Retos del YO. Por el contrario, la única dimensión que presenta un funcionamiento por encima de la media es las Relaciones del yo cuyo percentil se sitúa por encima de 50.

Demuestran, por tanto, una valoración negativa de sí mismos y en resolución de problemas, destacando la falta de una motivación interna, atribución a esfuerzo o capacidad y expectativas de éxito.

Estamos hablando de adultos caracterizados por buenas relaciones con los iguales y para desenvolverse en situaciones sociales de manera adaptativa, pero con carencias en competencias de afrontamiento de problemas y la toma de decisiones, con baja autoestima, y presentan escasa motivación laboral repercutiendo en su rendimiento. Sus atribuciones no presentan locus de control interno, y se perciben con falta de aptitudes para obtener buen rendimiento.

Tipo IV: Eficaz Esta tipología de sujetos demuestra puntuaciones superiores a la media en los cuatro factores del cuestionario. Los adultos 
que pertenecen a este cluster presentan puntuaciones cercanas al centil 70 en todos los factores a excepción de Retos del yo con un centil 60, pero en los factores Fortalezas y Relaciones se encuentran por encima del percentil 75. Representarían el prototipo de Persona Eficaz.

Hablamos de adultos con un buen autoconcepto, pero sobretodo, que se valoran y quieren como son. Son personas que valoran positivamente sus actitudes y capacidades en los principales contextos en los que se desenvuelven en estas edades (trabajo, familia y grupo de iguales). Se consideran atractivos, estables emocionalmente, capaces e importantes.

En esa buena imagen que tienen de sí mismo reside la principal fortaleza de su personalidad, el pilar sobre el que sustentan el funcionamiento eficaz de las otras esferas de su "yo". Serían personas adaptadas, que evalúan correctamente "qué" quieren conseguir y "cómo", que gestionan adecuadamente sus recursos y que mantienen una visión positiva sobre su futuro. Presentan motivación interna hacia los estudios, un funcionamiento atribucional eficaz y orientado a la obtención de rendimiento académico (atribuye sus éxitos tanto a su esfuerzo como a su capacidad) y expectativas optimistas sobre su rendimiento inmediato y a más largo plazo.

Esa actitud positiva frente a acontecimientos futuros, su autopercepción como estables emocionalmente, la adecuada gestión de sus recursos y la capacidad para establecer atribuciones de forma correcta 
sobre lo que les ocurre, explican en gran medida su buen funcionamiento a la hora de afrontar problemas y tomar decisiones (esfera Retos del yo). No adoptarán actitudes pasivas de afrontamiento, ni esperarán a que otros les resuelvan sus problemas. Se juzgarán capaces de resolverlos y antes de tomar una decisión reflexionarán sobre sus consecuencias, manteniendo una postura confiada y optimista sobre su resolución.

Con respecto a la esfera Relaciones del yo, este grupo de sujetos se percibe con habilidades sociales y capacidad asertiva. Se desenvuelven bien en situaciones sociales, sin timidez. Refieren un amplio círculo de amistades y expectativas de éxito en sus relaciones con el grupo de iguales.

Así, las personas encuadradas dentro del Tipo IV son adultos con buen autoconcepto y alta autoestima, con motivación orientada a la tarea, un estilo atribucional adaptativo, expectativas optimistas sobre su futuro, estilo resolutivo en el afrontamiento de sus problemas y buena capacidad asertiva y comunicativa.

La muestra de esta tipología es la que como la más numerosa.

\subsubsection{Perfiles tipológicos de Personalidad eficaz en población}

\section{Chilena (Ramírez, 2013)}

Ramírez (2013) presenta, como una réplica vs confirmación a la investigación precedente de López Pérez (2011), la siguiente clasificación 
tipológica de personalidad eficaz pero en contextos adultos chilenos de 30 a 59 años.

Tipo I: Eficaz. Esta tipología de sujetos demuestra puntuaciones superiores a la media en los cuatro factores del cuestionario. Los adultos que pertenecen a este cluster presentan puntuaciones cercanas por encima del centil 75 en todos los factores. Representarían el prototipo de Persona Eficaz.

Hablamos de adultos con un buen autoconcepto, pero sobretodo, que se valoran y quieren como son. Son adultos que valoran positivamente sus actitudes y capacidades en los principales contextos en los que se desenvuelven en estas edades (trabajo, familia y grupo de iguales). Se consideran atractivos, estables emocionalmente, capaces e importantes.

En esa buena imagen que tienen de sí mismo reside la principal fortaleza de su personalidad, el pilar sobre el que sustentan el funcionamiento eficaz de las otras esferas de su "yo". Serían personas adaptadas, que evalúan correctamente "qué" quieren conseguir y "cómo", que gestionan adecuadamente sus recursos y que mantienen una visión positiva sobre su futuro. Presentan motivación interna hacia el trabajo, un funcionamiento atribucional eficaz y orientado a la obtención de rendimiento profesional (atribuye sus éxitos tanto a su esfuerzo como a su capacidad) y expectativas optimistas sobre su rendimiento inmediato y a más largo plazo. 
Esa actitud positiva frente a acontecimientos futuros, su autopercepción como estables emocionalmente, la adecuada gestión de sus recursos y la capacidad para establecer atribuciones de forma correcta sobre lo que les ocurre, explican en gran medida su buen funcionamiento a la hora de afrontar problemas y tomar decisiones (esfera Retos del yo). No adoptarán actitudes pasivas de afrontamiento, ni esperarán a que otros les resuelvan sus problemas. Se juzgarán capaces de resolverlos y antes de tomar una decisión reflexionarán sobre sus consecuencias, manteniendo una postura confiada y optimista sobre su resolución.

Con respecto a la esfera Relaciones del yo, este grupo de sujetos se percibe con habilidades sociales y capacidad asertiva. Se desenvuelven bien en situaciones sociales, sin timidez. Refieren un amplio círculo de amistades y expectativas de éxito en sus relaciones con el grupo de iguales. Así, las personas encuadradas dentro del Tipo I son adultos con buen autoconcepto y alta autoestima, con motivación orientada a la tarea, un estilo atribucional adaptativo, expectativas optimistas sobre su futuro, estilo resolutivo en el afrontamiento de sus problemas y buena capacidad asertiva y comunicativa.

La muestra de esta tipología es mayor que el resto con 203, aspecto que consideramos positivo ya que es la tipología donde se representa un buen funcionamiento de la personalidad eficaz en todas sus dimensiones. 
Tipo II: Ineficaz social. Los sujetos que quedan enmarcados dentro de este clúster presentan puntuaciones bajas en tres factores del cuestionario CPE-Adultos. Demandas y Retos están en torno al centil 30 y el centil 40 en Fortalezas. Por el contrario, el único factor que presenta un funcionamiento eficaz es Relaciones del yo cuyo percentil se sitúa por encima de 60.

Muestran, por tanto, una valoración algo negativa de sí mismos y cierta dificultad en la resolución de problemas y la toma de decisiones y una baja motivación intrínseca hacia las tareas, la falta de locus de control en lo que le ocurre y la presencia de expectativas pesimistas.

Sin embargo, sí que consideran que tienen un buen desempeño social. Se consideran extrovertidos, asertivos y empáticos.

En resumen, estamos hablando de adultos caracterizados por buenas relaciones con los iguales y para desenvolverse en situaciones sociales de manera adaptativa, pero con carencias en competencias de afrontamiento de problemas y la toma de decisiones, con baja autoestima, y presentan escasa motivación laboral repercutiendo en su rendimiento. Sus atribuciones no presentan locus de control interno, y se perciben con falta de aptitudes para obtener buen rendimiento. Es decir, se consideran bien adaptados e integrados socialmente a pesar de la mala imagen que tienen de sí mismos en los otros tres factores del cuestionario. 
Tipo III: Eficaz Introvertido. Estos sujetos presentan un buen funcionamiento en tres de los cuatro factores que conforman el cuestionario de Personalidad Eficaz.

Relaciones del yo Autorrealización Social el que funciona de manera diferente al resto. Sería la tipología opuesta a la II.

Son sujetos con valores ligeramente superiores a la media en motivación orientada a la tarea, autoestima y autoconcepto y en afrontamiento y resolución de problemas. Establecen atribuciones de éxito (debidas al esfuerzo o la capacidad) en la mayoría de las situaciones, y por lo general, suelen mantener expectativas de éxito futuro. Frecuentemente adoptan una perspectiva resolutiva a la hora de abordar situaciones problemáticas, reflexionando antes de tomar una decisión o actuar.

Presentan una visión optimista de los problemas y la confianza en que se superarán; un estilo atribucional con locus de control interno que les permite partir de la idea de que con más esfuerzo se superan las dificultades, así como las atribuciones de éxitos pasados a sus capacidades; y el disfrute (o motivación) que nace del propio ejercicio de desempeñar una tarea parece tener relación directa con una postura resolutiva (frente a evitativa o pasiva) a la hora de afrontar problemas y reflexiva, o poco impulsiva: buscando información y tomando en consideración distintas alternativas antes de actuar. 
Sin embargo, presentan deficiencias en el factor Relaciones del yo. Puntúan por debajo del percentil 20, demostrando, por tanto, déficit en habilidades sociales: comunicación, asertividad y empatía. Se sienten poco integrados y con dificultades para desenvolverse en situaciones sociales.

En definitiva, estamos hablando de adultos caracterizados por un estilo motivacional y atribucional adaptativo, expectativas optimistas, competentes en el afrontamiento de problemas y la toma de decisiones y con alta autoestima, pero con dificultades en las relaciones con los iguales y afrontar interacciones sociales. Tendrían dificultades para defender sus derechos frente a otros, para hablar en público o para interaccionar con el otro sexo.

Tipo IV: Ineficaz. Los sujetos que quedan enmarcados dentro de este clúster presentan puntuaciones muy bajas en los cuatro factores del cuestionario de Personalidad Eficaz CPE-A. En Demandas y Fortalezas puntúan por debajo del percentil 10. Y en Retos y Relaciones, por debajo del percentil 20.

Se ven a ellos mismo como problemáticos, poco importantes y en desacuerdo con su forma de ser y actuar. No se gustan ni física, ni emocionalmente. Presentan una baja autoestima como trabajadores y como amigos, repercutiendo en sus labores y en sus relaciones con los iguales. La imagen negativa que tienen de sí mismos afecta a las otras esferas de su yo desembocando en un funcionamiento poco adaptativo o lo que podríamos 
llamar, siguiendo con la terminología del constructo, "Personalidad Ineficaz".

Representarían la antítesis del sujeto prototipo de "Personalidad Eficaz" (Tipo I), que cuenta con un amplio abanico de competencias personales y sociales para desenvolverse en su vida cotidiana.

Presenta escasa motivación laboral repercutiendo en su rendimiento. Sus atribuciones no presentan locus de control interno, y se perciben con falta de aptitudes para obtener buen rendimiento. Esto repercute en una visión pesimista sobre acontecimientos futuros. En el contexto laboral se concreta en la creencia de que en la actualidad su rendimiento será bajo o que en el futuro no les va a ir bien, pudiendo desembocar en "profecías autocumplidas" por las escasas herramientas que estos sujetos despliegan para hacer frente a las creencias negativas que tienen de sí mismos, y que queda reflejado en sus bajas puntuaciones en el factor Retos del yo.

Muestran dificultades en el afrontamiento de problemas y la toma de decisiones, presentando dificultades para decidir por sí mismos y optando por una actitud en ocasiones pasiva, y en ocasiones impulsiva, a la hora de abordar conflictos. Poniendo en relación estas actitudes y la pobre imagen que tienen de sí mismos se hace difícil que, por ellos mismos, den el paso de "tomar las riendas" ante las dificultades o pongan en marcha recursos que les permitan mejorar su autoestima. 
Se perciben con pocas amistades y dificultad para relacionarse con sus iguales. Manifiestan expectativas de fracaso en relaciones sociales hipotéticas futuras. Sus escasas capacidades empática y asertiva y sus problemas a la hora de desenvolverse en situaciones social explican las bajas puntuaciones en el segundo factor del cuestionario, aunque estas se sitúan dentro de la normalidad.

Son por tanto adultos que presentan cogniciones y comportamientos desadaptativos: baja autoestima, escasa motivación laboral (ni de logro, ni orientada a la tarea), expectativas pesimistas, déficit en habilidades sociales y dificultades para afrontar dificultades de su día a día. Hablaríamos, como ya se ha señalado, de Personalidad Ineficaz.

La muestra integrante en esta tipología, representa el menor número de sujetos de todas las tipologías.

\subsubsection{Comparativa entre las tipologías españolas y chilenas}

En los trabajos realizados con el CPE-A chileno y español se observan las siguientes similitudes:

Similitud entre el tipo I chileno y el tipo IV español

Similitud entre el tipo II chileno y tipo y Tipo III español

Similitud entre el Tipo IV chileno y el tipo II Español

Similitud entre el tipo III chileno y Tipo I español 
Se presenta a continuación un cuadro comparativo entre ambas tipologías (Figura 1):

\begin{tabular}{|c|c|}
\hline Tipología española & Tipologia Chilena \\
\hline $\begin{array}{l}\text { Tipo IV: Eficaz Esta tipología de } \\
\text { sujetos demuestra puntuaciones } \\
\text { superiores a la media en los cuatro } \\
\text { factores del cuestionario. Los } \\
\text { adultos que pertenecen a este cluster } \\
\text { presentan puntuaciones cercanas al } \\
\text { centil } 70 \text { en todos los factores a } \\
\text { excepción de Retos del yo con un } \\
\text { centil 60, pero en los factores } \\
\text { Fortalezas y Relaciones se } \\
\text { encuentran por encima del percentil } \\
\text { 75. Representarían el prototipo de } \\
\text { Persona Eficaz. } \\
\text { Hablamos de adultos con un buen } \\
\text { autoconcepto, pero sobretodo, que } \\
\text { se valoran y quieren como son. Son } \\
\text { personas que valoran positivamente } \\
\text { sus actitudes y capacidades en los } \\
\text { principales contextos en los que se } \\
\text { desenvuelven en estas edades } \\
\text { (trabajo, familia y grupo de iguales). } \\
\text { Se consideran atractivos, estables } \\
\text { emocionalmente, capaces e e } \\
\text { importantes. } \\
\text { En esa buena imagen que tienen de } \\
\text { sí mismo reside la principal } \\
\text { fortaleza de su personalidad, el pilar } \\
\text { sobre el que sustentan el } \\
\text { funcionamiento eficaz de las otras } \\
\text { esferas de su "yo". Serían personas } \\
\text { adaptadas, que evalúan } \\
\text { correctamente "qué quieren } \\
\text { conseguir y "cómo", que gestionan } \\
\text { adecuadamente sus recursos y que } \\
\text { mantienen una visión positiva sobre } \\
\text { su futuro. Presentan motivación } \\
\text { interna hacia los estudios, un } \\
\text { funcionamiento atribucional eficaz v }\end{array}$ & $\begin{array}{l}\text { Tipo I: Eficaz. Esta tipología de } \\
\text { sujetos demuestra puntuaciones } \\
\text { superiores a la media en los cuatro } \\
\text { factores del cuestionario. Los } \\
\text { adultos que pertenecen a este cluster } \\
\text { presentan puntuaciones cercanas por } \\
\text { encima del centil } 75 \text { en todos los } \\
\text { factores. Representarían el prototipo } \\
\text { de Persona Eficaz. } \\
\text { Hablamos de adultos con un buen } \\
\text { autoconcepto, pero sobretodo, que } \\
\text { se valoran y quieren como son. Son } \\
\text { adultos que valoran positivamente } \\
\text { sus actitudes y capacidades en los } \\
\text { principales contextos en los que se } \\
\text { desenvuelven en estas edades } \\
\text { (trabajo, familia y grupo de iguales). } \\
\text { Se consideran atractivos, estables } \\
\text { emocionalmente, capaces } \\
\text { importantes. e } \\
\text { En esa buena imagen que tienen de } \\
\text { sí mismo reside la principal } \\
\text { fortaleza de su personalidad, el pilar } \\
\text { sobre el que sustentan el } \\
\text { funcionamiento eficaz de las otras } \\
\text { esferas de su "yo". Serían personas } \\
\text { adaptadas, que evalúan } \\
\text { correctamente "qué" quieren } \\
\text { conseguir y "cómo", que gestionan } \\
\text { adecuadamente sus recursos y que } \\
\text { mantienen una visión positiva sobre } \\
\text { su futuro. Presentan motivación } \\
\text { interna hacia el trabajo, un } \\
\text { funcionamiento atribucional eficaz y } \\
\text { orientado a la obtención de } \\
\text { rendimiento profesional (atribuye } \\
\text { sus éxitos tanto a su esfuerzo como } \\
\text { a su capacidad) y expectativas }\end{array}$ \\
\hline
\end{tabular}


orientado a la obtención de
rendimiento académico (atribuye sus
éxitos tanto a su esfuerzo como a su
capacidad) y expectativas optimistas
sobre su rendimiento inmediato y a
más largo plazo.

Esa actitud positiva frente a acontecimientos futuros, su autopercepción como estables emocionalmente, la adecuada gestión de sus recursos y la capacidad para establecer atribuciones de forma correcta sobre lo que les ocurre, explican en gran medida su buen funcionamiento a la hora de afrontar problemas y tomar decisiones (esfera Retos del yo). No adoptarán actitudes pasivas de afrontamiento, ni esperarán a que otros les resuelvan sus problemas. Se juzgarán capaces de resolverlos y antes de tomar una decisión reflexionarán sobre sus consecuencias, manteniendo una postura confiada y optimista sobre su resolución.

Con respecto a la esfera Relaciones del yo, este grupo de sujetos se percibe con habilidades sociales y capacidad asertiva. Se desenvuelven bien en situaciones sociales, sin timidez. Refieren un amplio círculo de amistades y expectativas de éxito en sus relaciones con el grupo de iguales.

Así, las personas encuadradas dentro del Tipo IV son adultos con buen autoconcepto y alta autoestima, con motivación orientada a la tarea, un estilo atribucional adaptativo, expectativas optimistas sobre su futuro, estilo resolutivo en el afrontamiento de sus problemas y optimistas sobre su rendimiento inmediato y a más largo plazo.

Esa actitud positiva frente a acontecimientos futuros, su autopercepción como estables emocionalmente, la adecuada gestión de sus recursos y la capacidad para establecer atribuciones de forma correcta sobre lo que les ocurre, explican en gran medida su buen funcionamiento a la hora de afrontar problemas y tomar decisiones (esfera Retos del yo). No adoptarán actitudes pasivas de afrontamiento, ni esperarán a que otros les resuelvan sus problemas. Se juzgarán capaces de resolverlos y antes de tomar una decisión reflexionarán sobre sus consecuencias, manteniendo una postura confiada y optimista sobre su resolución.

Con respecto a la esfera Relaciones del yo, este grupo de sujetos se percibe con habilidades sociales y capacidad asertiva. Se desenvuelven bien en situaciones sociales, sin timidez. Refieren un amplio círculo de amistades y expectativas de éxito en sus relaciones con el grupo de iguales.

Así, las personas encuadradas dentro del Tipo I son adultos con buen autoconcepto y alta autoestima, con motivación orientada a la tarea, un estilo atribucional adaptativo, expectativas optimistas sobre su futuro, estilo resolutivo en el afrontamiento de sus problemas y buena capacidad asertiva y comunicativa.

La muestra de esta tipología es mayor que el resto con 203, aspecto 


buena capacidad asertiva y
comunicativa.
La muestra de esta tipología es la
que como la más numerosa..

\section{Tipo III: Ineficaz Social Los} sujetos que quedan enmarcados dentro de este clúster presentan puntuaciones muy bajas en tres factores del cuestionario CPEAdultos: Fortalezas, Demandas y Retos del YO. Por el contrario, la única dimensión que presenta un funcionamiento por encima de la media es las Relaciones del yo cuyo percentil se sitúa por encima de 50 .

Demuestran, por tanto, una valoración negativa de sí mismos y en resolución de problemas, destacando la falta de una motivación interna, atribución a esfuerzo o capacidad y expectativas de éxito.

Estamos hablando de adultos caracterizados por buenas relaciones con los iguales y para desenvolverse en situaciones sociales de manera adaptativa, pero con carencias en competencias de afrontamiento de problemas y la toma de decisiones, con baja autoestima, y presentan escasa motivación laboral repercutiendo en su rendimiento. Sus atribuciones no presentan locus de control interno, y se perciben con falta de aptitudes para obtener buen rendimiento. que consideramos positivo ya que es la tipología donde se representa un buen funcionamiento de la personalidad eficaz en todas sus dimensiones

Tipo II: Ineficaz social. Los sujetos que quedan enmarcados dentro de este clúster presentan puntuaciones bajas en tres factores del cuestionario CPE-Adultos. Demanmadas y Retos están en torno al centil $30 \mathrm{y}$ el centil 40 en Fortalezas . Por el contrario, el único factor que presenta un funcionamiento eficaz es Relaciones del yo cuyo percentil se sitúa por encima de 60.

Muestran, por tanto, una valoración algo negativa de sí mismos y cierta dificultad en la resolución de problemas y la toma de decisiones y una baja motivación intrínseca hacia las tareas, la falta de locus de control en lo que le ocurre y la presencia de expectativas pesimistas.

Sin embargo, sí que consideran que tienen un buen desempeño social. Se consideran extrovertidos, asertivos y empáticos.

En resumen, estamos hablando de adultos caracterizados por buenas relaciones con los iguales y para desenvolverse en situaciones sociales de manera adaptativa, pero con carencias en competencias de afrontamiento de problemas y la toma de decisiones, con baja autoestima, y presentan escasa motivación laboral repercutiendo en su rendimiento. Sus atribuciones no presentan locus de control interno, y se perciben con falta de aptitudes para obtener buen rendimiento. Es 


\begin{tabular}{|c|c|}
\hline & $\begin{array}{l}\text { decir, se consideran bien adaptados } \\
\text { e integrados socialmente a pesar de } \\
\text { la mala imagen que tienen de sí } \\
\text { mismos en los otros tres factores del } \\
\text { cuestionario. }\end{array}$ \\
\hline $\begin{array}{l}\text { Tipo II: Ineficaz. Los sujetos que } \\
\text { quedan enmarcados dentro de este } \\
\text { clúster presentan puntuaciones muy } \\
\text { bajas en los cuatro factores del } \\
\text { cuestionario de Personalidad Eficaz: } \\
\text { Fortalezas del yo, Demandas del yo, } \\
\text { Retos del yo y Relaciones del yo. } \\
\text { Se ven a ellos mismo como } \\
\text { problemáticos, poco importantes y } \\
\text { en desacuerdo con su forma de ser y } \\
\text { actuar. No se gustan ni físicas, ni } \\
\text { emocionalmente. Presentan una baja } \\
\text { autoestima como trabajadores y } \\
\text { como amigos, repercutiendo en sus } \\
\text { labores y en sus relaciones con los } \\
\text { iguales. La imagen negativa que } \\
\text { tienen de sí mismos afecta a las } \\
\text { otras esferas de su yo desembocando } \\
\text { en un funcionamiento poco } \\
\text { adaptativo o lo que podrímos } \\
\text { llamar, siguiendo con la } \\
\text { terminología del constructo, } \\
\text { "Personalidad Ineficaz". } \\
\text { Representarían la antítesis del sujeto } \\
\text { prototipo de "Personalidad Eficaz" } \\
\text { (Tipo IV), que cuenta con un amplio } \\
\text { abanico de competencias personales } \\
\text { y sociales para desenvolverse en su } \\
\text { vida cotidiana. } \\
\text { Presenta escasa motivación laboral } \\
\text { repercutiendo en su rendimiento. } \\
\text { Sus atribuciones no presentan locus } \\
\text { de control interno, y se perciben con } \\
\text { falta de aptitudes para obtener buen } \\
\text { rendimiento. Esto repercute en una } \\
\text { visión pesimista sobre } \\
\text { acontecimientos futuros. En el }\end{array}$ & $\begin{array}{l}\text { Tipo IV: Ineficaz. Los sujetos que } \\
\text { quedan enmarcados dentro de este } \\
\text { clúster presentan puntuaciones muy } \\
\text { bajas en los cuatro factores del } \\
\text { cuestionario de Personalidad Eficaz } \\
\text { CPE-A. En Demandas y Fortalezas } \\
\text { puntúan por debajo del percentil } 10 . \\
\text { Y en Retos y Relaciones , por } \\
\text { debajo del percentil } 20 . \\
\text { Se ven a ellos mismo como } \\
\text { problemáticos, poco importantes y } \\
\text { en desacuerdo con su forma de ser y } \\
\text { actuar. No se gustan ni física, ni } \\
\text { emocionalmente. Presentan una baja } \\
\text { autoestima como trabajadores y } \\
\text { como amigos, repercutiendo en sus } \\
\text { labores y en sus relaciones con los } \\
\text { iguales. La imagen negativa que } \\
\text { tienen de sí mismos afecta a las } \\
\text { otras esferas de su yo desembocando } \\
\text { en un funcionamiento poco } \\
\text { adaptativo o lo que podríamos } \\
\text { llamar, siguiendo con la } \\
\text { terminología del constructo, } \\
\text { "Personalidad Ineficaz". } \\
\text { Representarían la antítesis del sujeto } \\
\text { prototipo de "Personalidad Eficaz" } \\
\text { (Tipo I), que cuenta con un amplio } \\
\text { abanico de competencias personales } \\
\text { y sociales para desenvolverse en su } \\
\text { vida cotidiana. } \\
\text { Presenta escasa motivación laboral } \\
\text { repercutiendo en su rendimiento. } \\
\text { Sus atribuciones no presentan locus } \\
\text { de control interno, y se perciben con } \\
\text { falta de aptitudes para obtener buen } \\
\text { rendimiento. Esto repercute en una }\end{array}$ \\
\hline
\end{tabular}




\begin{tabular}{|c|c|}
\hline $\begin{array}{l}\text { contexto laboral se concreta en la } \\
\text { creencia de que en la actualidad su } \\
\text { rendimiento será bajo o que en el } \\
\text { futuro no les va a ir bien, pudiendo } \\
\text { desembocar en profecías } \\
\text { autocumplidas" por las escasas } \\
\text { herramientas que estos sujetos } \\
\text { despliegan para hacer frente a las } \\
\text { creencias negativas que tienen de sí } \\
\text { mismos, y que queda reflejado en } \\
\text { sus bajas puntuaciones en el factor } \\
\text { Retos del yo. } \\
\text { Muestran dificultades en el } \\
\text { afrontamiento de problemas y la } \\
\text { toma de decisiones, presentando } \\
\text { dificultades para decidir por sí } \\
\text { mismos y optando por una actitud en } \\
\text { ocasiones pasiva, y en ocasiones } \\
\text { impulsiva, a la hora de abordar } \\
\text { conflictos. Poniendo en relación } \\
\text { estas actitudes y la pobre imagen } \\
\text { que tienen de sí mismos se hace } \\
\text { difícil que, por ellos mismos, den el } \\
\text { paso de "tomar las riendas" ante las } \\
\text { dificultades o pongan en marcha } \\
\text { recursos que les permitan mejorar su } \\
\text { autoestima. } \\
\text { Se perciben con pocas amistades y } \\
\text { dificultad para relacionarse con sus } \\
\text { iguales. Manifiestan expectativas de } \\
\text { fracaso en relaciones sociales } \\
\text { hipotéticas futuras. Sus escasas } \\
\text { desadaptativos: baja autoestima, } \\
\text { escasa motivación laboral (ni de } \\
\text { sus problemas a la hora de } \\
\text { desenvolverse en situaciones social } \\
\text { explican las bajas puntuaciones en el } \\
\text { segundo factor del cuestionario, } \\
\text { aunque estas se sitúan dentro de la } \\
\text { normalidad. }\end{array}$ & 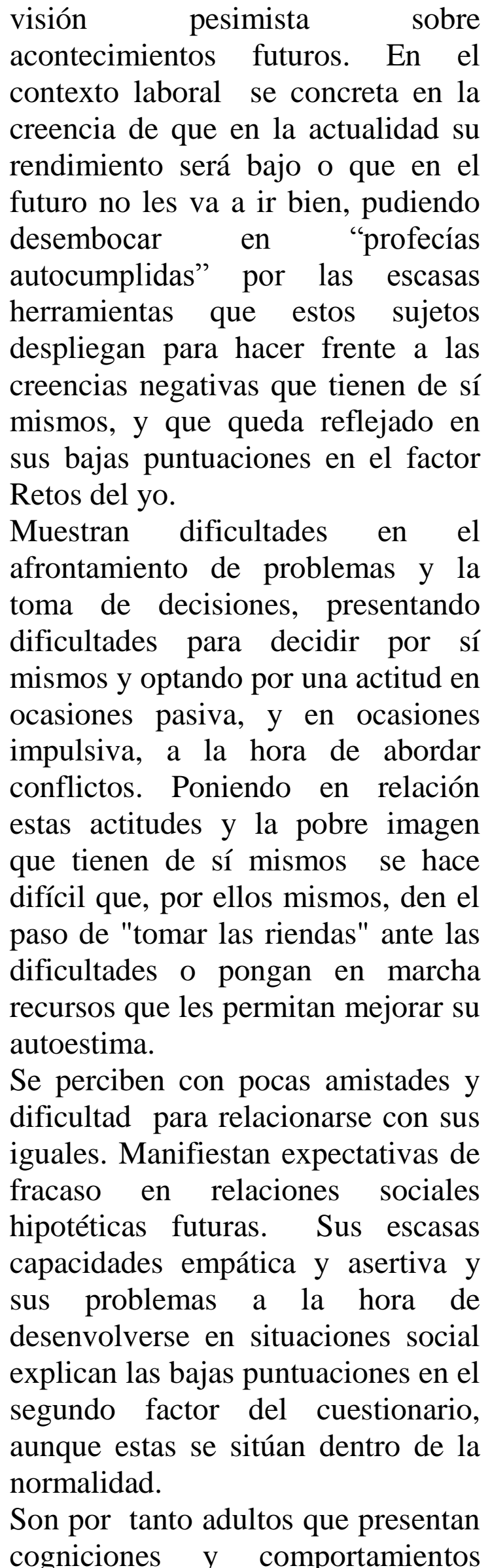 \\
\hline
\end{tabular}


logro, ni orientada a la tarea), expectativas pesimistas, déficit en habilidades sociales y dificultades para afrontar dificultades de su día a día. Hablaríamos, como ya se ha señalado, de Personalidad Ineficaz. Por otro lado, la muestra integrante en esta tipología, representa el menor número de todas las cuatro tipologías encontradas.

Tipo I: Eficaz Introvertido. Estos sujetos presentan un buen funcionamiento en dos de las cuatro esferas del yo que conforman el cuestionario de Personalidad Eficaz. Puntúan por encima de la media, en los factores Demandas de yo y Retos del yo. Son sujetos con valores ligeramente superiores a la media en motivación orientada a la tarea. Establecen atribuciones de éxito (debidas al esfuerzo o la capacidad) en la mayoría de las situaciones, y por lo general, suelen mantener expectativas de éxito futuro. Frecuentemente adoptan una perspectiva resolutiva a la hora de abordar situaciones problemáticas, reflexionando antes de tomar una decisión o actuar.

Esta tipología pone de manifiesto la relación existente entre las variables motivación, atribución y expectativas y las variables afrontamiento de problemas y toma de decisiones. Una visión optimista de los problemas y la confianza en que se superarán; un estilo atribucional con locus de control interno que les permite partir de la desadaptativos: baja autoestima, escasa motivación laboral (ni de logro, ni orientada a la tarea), expectativas pesimistas, déficit en habilidades sociales y dificultades para afrontar dificultades de su día a día. Hablaríamos, como ya se ha señalado, de Personalidad Ineficaz.

La muestra integrante en esta tipología, representa el menor número de sujetos de todas las tipologías

\section{Tipo III: Eficaz Introvertido.} Estos sujetos presentan un buen funcionamiento en tres de los cuatro factores que conforman el cuestionario de Personalidad Eficaz. Relaciones del yo Autorrealización Social el que funciona de manera diferente al resto. Sería la tipología opuesta a la II.

Son sujetos con valores ligeramente superiores a la media en motivación orientada a la tarea, autoestima y autoconcepto y en afrontamiento y resolución de problemas. Establecen atribuciones de éxito (debidas al esfuerzo o la capacidad) en la mayoría de las situaciones, y por lo general, suelen mantener expectativas de éxito futuro. Frecuentemente adoptan una perspectiva resolutiva a la hora de abordar situaciones problemáticas, reflexionando antes de tomar una decisión o actuar.

Presentan una visión optimista de los problemas y la confianza en que se superarán; un estilo atribucional con locus de control interno que les permite partir de la idea de que con más esfuerzo se superan las 


\begin{tabular}{|c|c|}
\hline $\begin{array}{l}\text { esfuerzo se } \\
\text { s, así como } \\
\text { os pasados a } \\
\text { disfrute (o } \\
\text { del propio } \\
\text { ar una tarea } \\
\text { ecta con una } \\
\text { e a evitativa } \\
\text { de afrontar } \\
\text { iva, o poco } \\
\text { formación y } \\
\text { ión distintas } \\
\text { uar. } \\
\text { deficiencias } \\
\text { restantes, } \\
\text { iones del yo. } \\
\text { n por en el } \\
\text { a desviación } \\
\text { media. Y en } \\
\text { yo puntúan } \\
\text { nuestran, por } \\
\text { egativa de sí } \\
\text { o, déficit en } \\
\text { omunicación } \\
\text { hablando de } \\
\text { por un estilo } \\
\text { atribucional } \\
\text { optimistas y } \\
\text { ntamiento de } \\
\text { e decisiones; } \\
\text { autoestima, } \\
\text { iones con los } \\
\text { volverse en } \\
\text { sujetos de la } \\
\text { sta tipología, }\end{array}$ & $\begin{array}{l}\text { dificultades, así como las } \\
\text { atribuciones de éxitos pasados a sus } \\
\text { capacidades; y el disfrute (o } \\
\text { motivación) que nace del propio } \\
\text { ejercicio de desempeñar una tarea } \\
\text { parece tener relación directa con una } \\
\text { postura resolutiva (frente a evitativa } \\
\text { o pasiva) a la hora de afrontar } \\
\text { problemas y reflexiva, o poco } \\
\text { impulsiva: buscando información y } \\
\text { tomando en consideración distintas } \\
\text { alternativas antes de actuar. } \\
\text { Sin embargo, presentan deficiencias } \\
\text { en el factor Relaciones del yo. } \\
\text { Puntúan por debajo del percentil } 20 \text {, } \\
\text { demostrando, por tanto, déficit en } \\
\text { habilidades sociales: comunicación, } \\
\text { asertividad y empatía. Se sienten } \\
\text { poco integrados y con dificultades } \\
\text { para desenvolverse en situaciones } \\
\text { sociales. } \\
\text { En definitiva, estamos hablando de } \\
\text { adultos caracterizados por un estilo } \\
\text { motivacional y atribucional } \\
\text { adaptativo, expectativas optimistas, } \\
\text { competentes en el afrontamiento de } \\
\text { problemas y la toma de decisiones y } \\
\text { con alta autoestima, pero con } \\
\text { dificultades en las relaciones con los } \\
\text { iguales y afrontar interacciones } \\
\text { sociales. Tendrían dificultades para } \\
\text { defender sus derechos frente a otros, } \\
\text { para hablar en público o para } \\
\text { interaccionar con el otro sexo. }\end{array}$ \\
\hline
\end{tabular}

Figura 1. Cuadro comparativo entre tipologías 


\section{Estado actual de la investigación. Objetivos e hipótesis}

Una vez expuesto los antecedentes de referencia en que se circunscribe nuestro trabajo es obligado señalar cuál es el estado de la investigación del que partimos relacionado con el constructo de la personalidad eficaz.

Cabe señalar que en contextos chilenos los estudios en torno al constructo personalidad eficaz se han centrado de forma preferente en contextos adolescentes (Muñoz Rojo, 2013; Arraño (2014) en contextos universitarios (Bernal, 2014) en contextos adultos (Ramírez, 2012) pero nunca en contextos de la tercera edad o edad superior a los 60 años.

En base a este hecho la investigación nuestra se propone estudiar esta carencia y completar con ello, una aspiración legítima del grupo GOYAD, la totalidad del ciclo vital.

En este contexto y respondiendo al título del trabajo que se presenta el objetivo del mismo es el establecimiento de tipologías modales multivariados en edades comprendidas entre los 60 a 90 años de edad en población chilena.

Este objetivo general se concreta en los siguientes apartados: 
Verificación de las características psicométricas del instrumento empleados en lo referente a fiabilidad, validez y normalización del mismo en la población/muestra objeto de nuestro estudio.

Análisis de las diferencias existentes en la población/muestra empleadas en función de las distintas variables que se recogen tales como género, edad, nivel formativo y situación ocupacional en la que se encuentran.

Análisis de las diferencias existentes con carácter general con edades precedentes comprendidas entre los 30 a 59 años de edad.

Obtención de tipologías modales multivariadas en la población/muestra estudiada.

Comparativa de las tipologías modales obtenidas con las tipologías obtenidas en esas misma edades previas indicadas.

Las hipótesis subyacentes a este objetivo son las siguientes que se fundamentan en estudios previos obtenidos en otras edades.

Hipótesis 1: En el periodo de edad comprendido entre los 60 y 90 años de edad se da una tipología modal multivariada en torno a la personalidad eficaz alta en todas las dimensiones que la integran. 
Hipótesis 2: En el, periodo de edad comprendido entre los 60 y 90 años de edad se da una tipología modal multivariada en torno a la personalidad eficaz baja en todas las dimensiones que la integran.

Hipótesis 3: En el periodo de edad comprendido entre los 60 y 90 años de edad se da una tipología modal multivariada en torno a la personalidad eficaz oscilante en todas las dimensiones que la integran. 
II. MARCO EMPIRICO 


\section{Metodología}

La metodología empleada en este trabajo es empírica y no experimental.

Esto significa que se ha procedido a la elección de un instrumento que reúna los requisitos de fiabilidad, validez y normalización que permitan explorar las dimensiones objeto del estudio. Se ha seleccionado una muestra lo suficientemente representativa de la población objeto de nuestro estudio. Se han aplicado con las suficientes garantías de veracidad los instrumentos. Se ha utilizados el oportuno programa de análisis de datos. Se han realizados los análisis estadísticos pertinentes. Se han discutido los resultados obtenidos y finalmente se han formulados las conclusiones.

\subsection{Participantes}

Para la elección de la muestra hemos establecido como únicos criterios discriminadores a personas comprendidas en edad comprendida a partir de los 60 años que se encuentre gozando de un estado de salud adecuado a la edad, autonomía total para su desempeño personal y no padezca síntomas de deterioro especifico en los procesos mentales.

Se ha tenido en cuenta las variables edad, genero, nivel de estudios y situación ocupacional en el momento de la ejecución del cuestionario. 
La muestra obtenida ciertamente no es abundante pues el método de aplicación empleado ha sido personal e individualizado. En consecuencia los resultados que de ello se obtienen tienen esta limitación a la hora de universalizarlos o extenderlos a la totalidad de la población.

Se han realizado un total de 76 entrevistas.

Se presenta en la tabla 1 los estadísticos básicos de la muestra recogida

Tabla 1. Estadísticos descriptivos de la muestra

\begin{tabular}{lc} 
& $\begin{array}{c}\text { Numero y media de } \\
\text { edad }\end{array}$ \\
\hline Validos & 76 \\
Perdidos & 0 \\
Media & 71,80 \\
Desv. típ. & 8,468 \\
Mínimo & 60 \\
Máximo & 96 \\
\hline
\end{tabular}

Se presenta en la tabla 2, 3, 4, 5 la distribución de la muestra en función de las variables género, periodos de edad, nivel de formación y situación ocupacional actual. 
Se acompaña a modo de facilitar la información expresada en las tablas los gráficos correspondientes a las mismas

Tabla 2. Descriptivos de la variable género

Frecuencia Porcentaje Porcentaje acumulado

\begin{tabular}{llccc}
\hline Válidos & Hombre & 23 & 30,3 & 30,3 \\
& Mujer & 53 & 69,7 & 100,0 \\
& Total & 76 & 100,0 & \\
\hline
\end{tabular}

En la Figura 2 se muestra la representación gráfica de esta variable.

\section{Distribución por género}

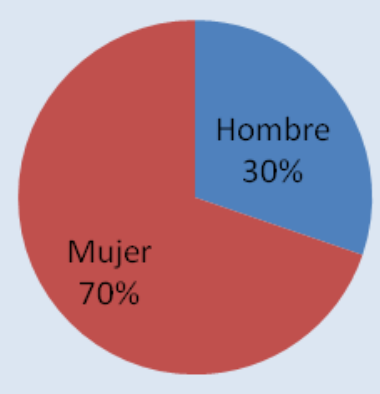

Figura 2. Distribución por género 
Tabla 3. Descriptivos de la variable edad

\begin{tabular}{llcccc} 
& & Frecuencia & Porcentaje & $\begin{array}{c}\text { Porcentaje } \\
\text { válido }\end{array}$ & $\begin{array}{c}\text { Porcentaje } \\
\text { acumulado }\end{array}$ \\
\hline Válidos & 60 a 69 años & 32 & 42,1 & 42,1 & 42,1 \\
& 70 a 79 años & 27 & 35,5 & 35,5 & 77,6 \\
& mayores de 80 & 17 & 22,4 & 22,4 & 100,0 \\
& & 76 & 100,0 & 100,0 & \\
\hline
\end{tabular}

En la Figura 3 se muestra la representación gráfica de la variable edad.

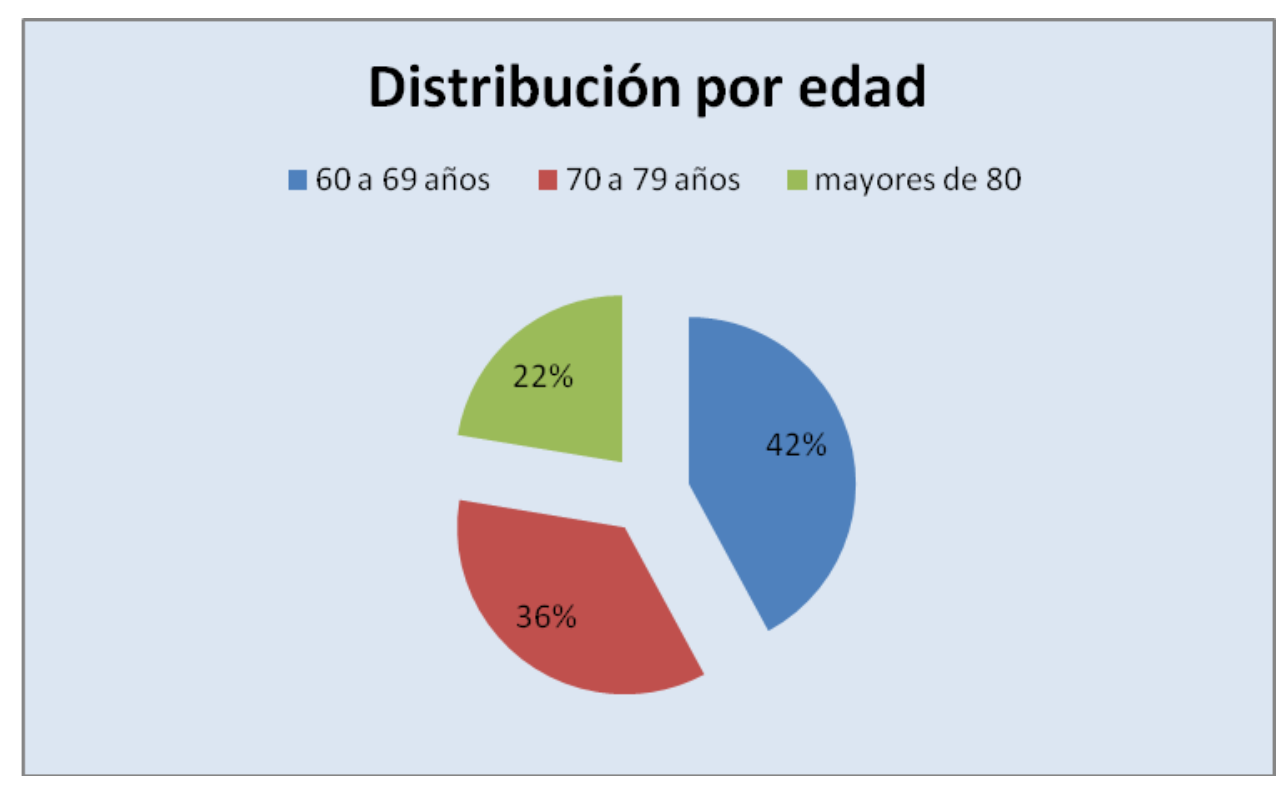

Figura 3. Distribución por edad 
Tabla 4. Descriptivos de la variable situación ocupacional actual

\begin{tabular}{cccccc} 
& & Frecuencia & Porcentaje & $\begin{array}{c}\text { Porcentaje } \\
\text { válido }\end{array}$ & $\begin{array}{c}\text { Porcentaje } \\
\text { acumulado }\end{array}$ \\
\hline \multirow{4}{*}{ Válidos } & En activo & 29 & 38,2 & 38,2 & 38,2 \\
& Jubilado & 9 & 11,8 & 11,8 & 50,0 \\
& Ama de casa & 38 & 50,0 & 50,0 & 100,0 \\
& Total & 76 & 100,0 & 100,0 & \\
\hline
\end{tabular}

En la Figura 4 se muestra una representación gráfica de la variable situación ocupacional actual.

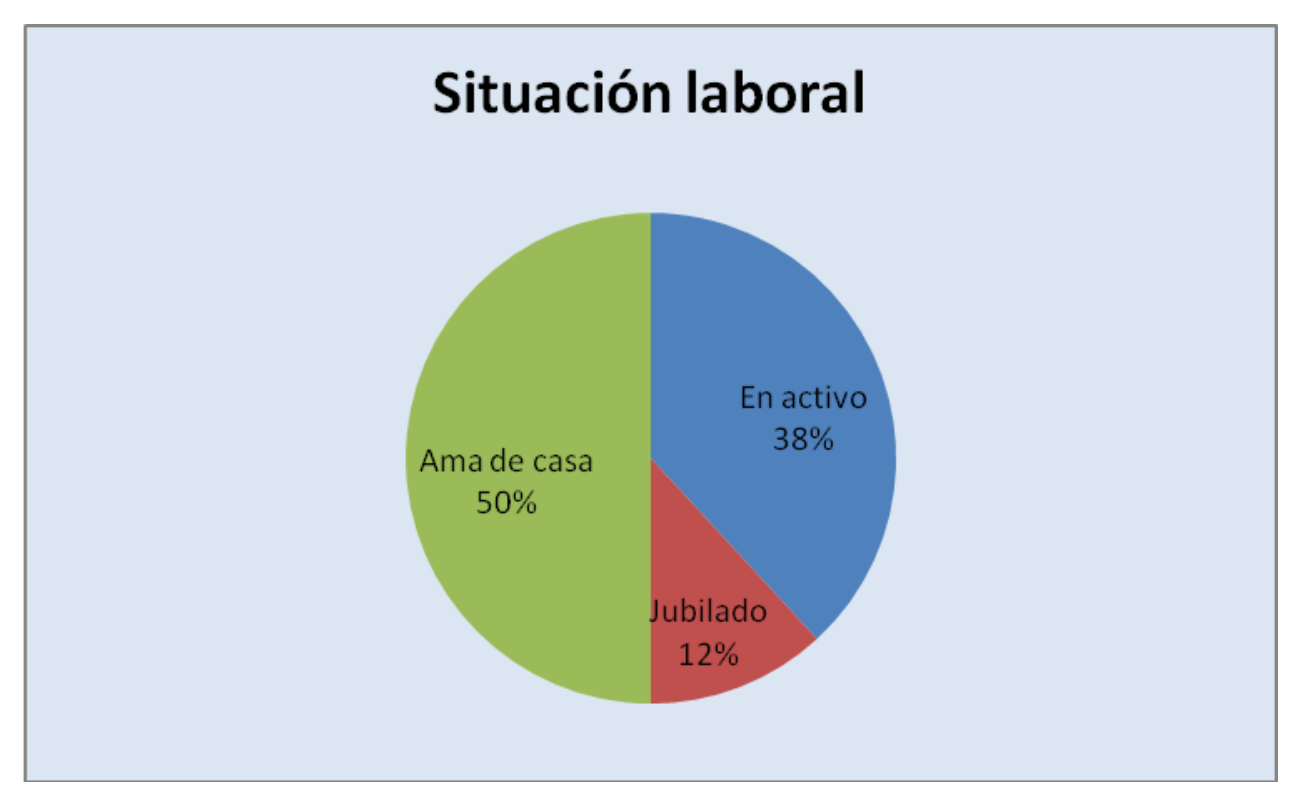

Figura 4. Distribución de la variable situación laboral actual 
Tabla 5. Descriptivos de la variable estudios

\begin{tabular}{llcccc} 
& Frecuencia & Porcentaje & $\begin{array}{c}\text { Porcentaje } \\
\text { válido }\end{array}$ & $\begin{array}{c}\text { Porcentaje } \\
\text { acumulado }\end{array}$ \\
\hline Válidos & BASICOS & 34 & 44,7 & 44,7 & 44,7 \\
& MEDIOS & 20 & 26,3 & 26,3 & 71,1 \\
& TECINCOS & 6 & 7,9 & 7,9 & 78,9 \\
UNIVERSITARI & 16 & 21,1 & 21,1 & 100,0 \\
OS & 76 & 100,0 & 100,0 & \\
Total & & & &
\end{tabular}

En la Figura 5 se muestra la distribución por niveles de estudio.

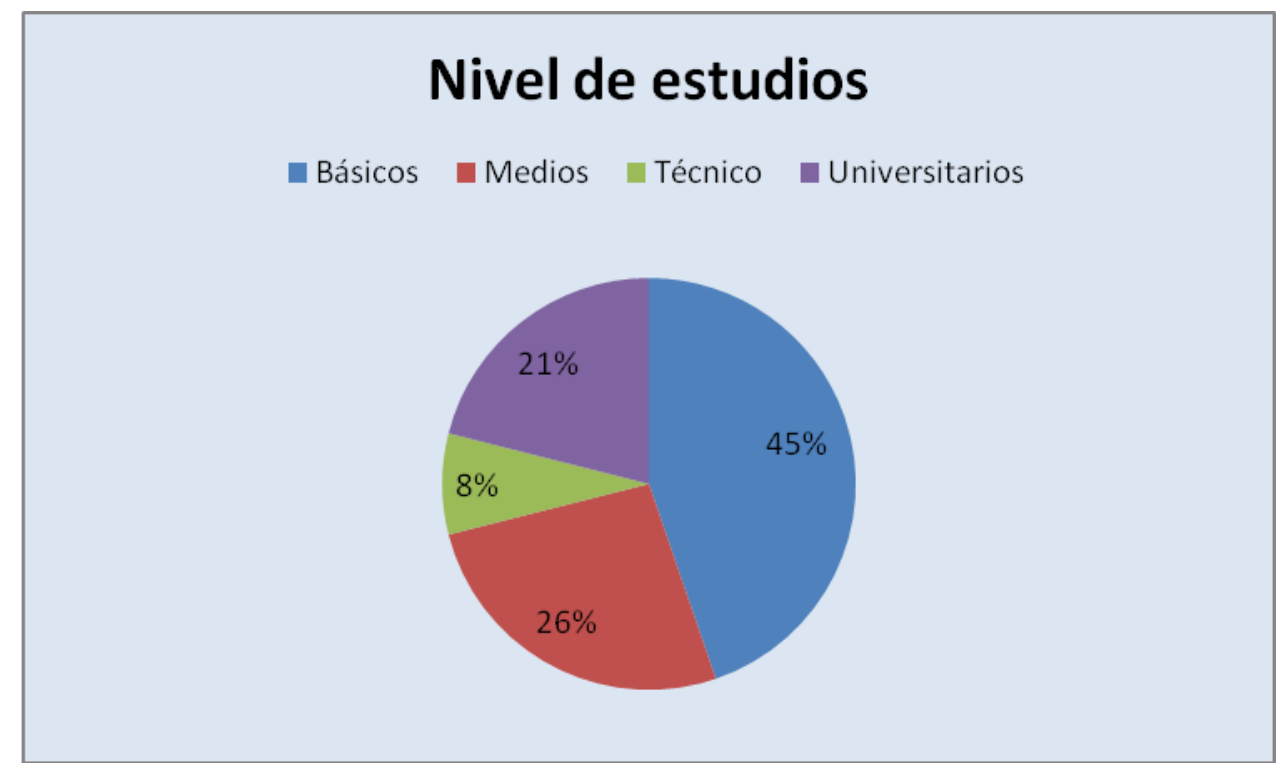

Figura 5. Distribución por nivel de estudios

A modo de síntesis, se puede indicar que si bien la equiparidad respecto al género no es muy ajustada aunque si esperada en base a los índices demográficos existentes si parece más equitativa la distribución en función de las otras variables edad, situación laboral y nivel de estudios 
esta aceptablemente distribuida y ajustada a los porcentajes existentes en este tipo de población.

\subsection{Instrumento}

Para la realización de esta investigación se ha empleado el "Cuestionario de Personalidad eficaz en población adulta Chilena de 30 a 60 años de edad" de Ramírez (2013) que presenta las siguientes características. Ver el protocolo en el anexo 1.

Numero de ítems: 30 ítems.

Presenta un coeficiente global (Alfa de Cronbach) de 0.863.

Los índices alfa de consistencia interna de cada ítem oscilan entre .854 y .864

Presenta cuatro factores:

Fortalezas del Yo, puesto que integra ítems que miden indicadores de autoconcepto y autoestima.

Dado que este componente integra aspectos valorativos de la persona, un sujeto que puntuara alto tendría un buen conocimiento y aprecio de su físico, una alta valoración y confianza en sus recursos cognitivomotivacionales y sociales y un ajustado reconocimiento de sus limitaciones. Consta de ocho ítems: 3, 7, 11, 15, 19, 23, 26 у 29. 
3 Me siento muy bien con mi aspecto físico

7 Hay muchas cosas acerca de mí mismo que me gustaría cambiar si pudiera

11 En general me siento satisfecho conmigo mismo

15 Me acepto tal y como soy, con mis cualidades, limitaciones y defectos

19 Tengo muchas cualidades para estar orgulloso y satisfecho de mi mismo

23 Logro que casi todas las cosas me resulten bien

26 Creo que soy una persona valiosa para los otros

29 Creo que tengo el talento para hacer que las cosas funcionen

Demandas del Yo: Este factor pone de manifiesto la relación entre el conocimiento personal y la atribución de éxito a una definida y positiva capacidad y esfuerzo, la motivación intrínseca y el logro en las actividades que desarrolle en su vida cotidiana. El sujeto que puntuara alto en este factor sería aquel que valora positivamente sus recursos a la hora de enfrentarse a determinadas tareas o retos, cuyas motivaciones cotidianas son principalmente de carácter interno; valora positivamente su capacidad para superar retos y ejercer su autonomía y control personal. Realiza atribuciones de capacidad y esfuerzo y tiene expectativas, próxima y lejanas, de éxito. Consta de ocho ítems: 1, 5, 9, 13, 17, 21, 24 y 27. 
1 Mis éxitos en mi profesión se deben a mi esfuerzo y dedicación

$5 \mathrm{Mi}$ éxito en una tarea se debe a que me esmero por realizar un buen trabajo

9 Tengo buena capacidad para trabajar

13 Me considero un buen trabajador

17 Trabajo porque me gusta superar los retos que me presentan las tareas

21 Mi éxito en el trabajo se debe a mi capacidad personal

24 Cuando tengo un problema dedico tiempo y esfuerzo para resolverlo

27 Estoy convencido de que tendré éxito cuando trabaje

Retos del Yo: Mide variables que apoyan un afrontamiento eficaz a los retos que puedan surgir en todos los ámbitos. Conjuga ítems que miden indicadores relativos a la toma de decisiones y al afrontamiento de problemas. Por tanto, un sujeto que puntuara alto en este factor planificaría cuidadosamente las decisiones que tuviera que tomar ajustándose a las demandas propias de cada situación, reuniendo la mayor cantidad de información que pueda encontrar y analizando las posibles consecuencias de sus decisiones, con una actitud positiva y capacidad para aprender de la experiencia. Consta de cinco ítems: 4, 8, 12, 16 y 20. 
4 Cuando tengo que tomar una decisión, planifico cuidadosamente lo que voy a hacer

8 Cuando tengo un problema trato de ver el lado positivo que posee

12 Para tomar una decisión reúno toda la información que puedo encontrar

16 Controlo bien mis emociones

20 Cuando experimento un fracaso intento aprender de esa experiencia

Relaciones del Yo, puesto que involucra habilidades de comunicación, empatía y asertividad. Este factor pone de manifiesto la vinculación entre la autopercepción de capacidad o competencia para establecer y mantener relaciones con los otros y las expectativas de éxito en sus relaciones sociales futuras. Dado que este factor incluye variables que apoyan una ejecución social eficaz, un sujeto que puntuara alto tendría confianza y aprecio en sus recursos para construir vínculos, realizaría atribuciones de sus relaciones sociales en función de su habilidad para relacionarse y tendría expectativas de éxito en sus relaciones sociales. Consta de nueve ítems: 2, 6, 10, 14, 18, 22, 25, 28 y 30.

2 Tengo pocos amigos porque me cuesta tratar con los demás

6 Hago amigos con facilidad 
10 Mis fracasos en las relaciones con los demás se deben a mi falta de habilidad para hacer amigos

14 Creo que, conociéndome como soy, tendré problemas en mis relaciones con los demás

18 Creo, con toda seguridad, que tendré éxito en mis relaciones con los demás

22 Mis éxitos en las relaciones con los demás se deben a mi habilidad para hacer amigos

25 Mis éxitos en las relaciones con los demás se deben a que son ellos los que toman la iniciativa

28 Pienso que mi fracaso en las relaciones con los demás se deben a que no le agrado a la mayoría de las personas

$30 \mathrm{Me}$ siento a gusto compartiendo con otras personas

El índice de fiabilidad de cada uno de los factores se presenta en la tabla 6, en base al estadístico Alfa de Cronbach (1951). Siendo Retos del yo el que menor consistencia interna presenta de los cuatro.

Tabla 6. Estadísticos de fiabilidad de las dimensiones

FACTORES

ALFA DE CRONBACH N DE ELEMENTOS

Fortalezas del Yo

Demandas del Yo

.758

Retos del Yo

.643 
Presenta los siguientes baremos generales y específicos en función de las diferencias encontradas en Fortalezas, Retos y Relaciones en alguna de las variables. Los baremos generales se presentan en la tabla 7.

Tabla 7. Baremos generales

\begin{tabular}{|c|c|c|c|c|c|}
\hline & & Fortalezas & Demandas & Retos & Relaciones \\
\hline \multirow[t]{2}{*}{$\mathrm{N}$} & Válidos & 561 & 561 & 561 & 561 \\
\hline & Perdidos & 0 & 0 & 0 & 0 \\
\hline \multicolumn{2}{|l|}{ Media } & 51,1426 & 52,2068 & 20,6417 & 54,8752 \\
\hline \multicolumn{2}{|l|}{ Desv. típ. } & 3,94846 & 3,23320 & 2,85575 & 4,95070 \\
\hline \multicolumn{2}{|l|}{ Varianza } & 15,590 & 10,454 & 8,155 & 24,509 \\
\hline \multicolumn{2}{|l|}{ Asimetría } &,- 486 &,- 949 &,- 626 &,- 602 \\
\hline \multicolumn{2}{|c|}{ Error típ. de asimetría } &, 103 &, 103 &, 103 &, 103 \\
\hline \multicolumn{2}{|l|}{ Curtosis } &,- 138 & ,770 &, 547 &,- 334 \\
\hline \multicolumn{2}{|c|}{ Error típ. de curtosis } & ,206 & ,206 & ,206 & ,206 \\
\hline \multicolumn{2}{|l|}{ Mínimo } & 38,00 & 39,00 & 9,00 & 37,00 \\
\hline \multicolumn{2}{|l|}{ Máximo } & 58,00 & 56,00 & 25,00 & 62,00 \\
\hline \multirow[t]{11}{*}{ Percentiles } & 10 & 46,0000 & 48,0000 & 17,0000 & 47,0000 \\
\hline & 20 & 48,0000 & 50,0000 & 18,0000 & 50,0000 \\
\hline & 25 & 49,0000 & 50,0000 & 19,0000 & 51,0000 \\
\hline & 30 & 49,0000 & 51,0000 & 19,0000 & 52,0000 \\
\hline & 40 & 50,0000 & 52,0000 & 20,0000 & 54,0000 \\
\hline & 50 & 51,0000 & 53,0000 & 21,0000 & 56,0000 \\
\hline & 60 & 52,0000 & 54,0000 & 22,0000 & 57,0000 \\
\hline & 70 & 54,0000 & 54,0000 & 22,0000 & 58,0000 \\
\hline & 75 & 54,0000 & 55,0000 & 23,0000 & 59,0000 \\
\hline & 80 & 55,0000 & 55,0000 & 23,0000 & 60,0000 \\
\hline & 90 & 56,0000 & 56,0000 & 24,0000 & 61,0000 \\
\hline
\end{tabular}


A raíz de las de diferencias de medias encontrados en el factor Relaciones en relación al nivel de estudio y de Fortalezas y Retos a nivel de edad el cuestionario ofrece baremos diferenciados presentan en las tablas $8,9,10$.

Tabla 8. Baremos de Relaciones en función del nivel de estudios

\begin{tabular}{|c|c|c|c|c|c|}
\hline & & Educación Básica & Educación Media & $\begin{array}{c}\text { Técnicos } \\
\text { Universitarios }\end{array}$ & $\begin{array}{l}\text { Profesionales } \\
\text { Universitarios }\end{array}$ \\
\hline \multirow[t]{2}{*}{$\overline{\mathrm{N}}$} & Válidos & 8 & 91 & 54 & 408 \\
\hline & Perdidos & 0 & 0 & 0 & 0 \\
\hline \multicolumn{2}{|l|}{ Media } & 48,8750 & 48,8750 & 53,7582 & 54,6111 \\
\hline \multicolumn{2}{|l|}{ Desv. típ. } & 3,68152 & 3,68152 & 5,58637 & 5,44758 \\
\hline \multicolumn{2}{|l|}{ Varianza } & 13,554 & 13,554 & 31,208 & 29,676 \\
\hline \multicolumn{2}{|l|}{ Asimetría } & 063 & ,063 &,- 231 &,- 692 \\
\hline \multicolumn{2}{|c|}{ Error típ. de asimetría } &, 752 &, 752 &, 253 &, 325 \\
\hline \multicolumn{2}{|l|}{ Curtosis } & $-1,431$ & $-1,431$ &,- 939 &,- 460 \\
\hline \multicolumn{2}{|c|}{ Error típ. de curtosis } & 1,481 & 1,481 &, 500 & ,639 \\
\hline \multicolumn{2}{|l|}{ Mínimo } & 44,00 & 44,00 & 40,00 & 41,00 \\
\hline \multicolumn{2}{|l|}{ Máximo } & 54,00 & 54,00 & 62,00 & 62,00 \\
\hline \multirow[t]{11}{*}{ Percentiles } & 10 & 44,0000 & 46,0000 & 46,0000 & 48,9000 \\
\hline & 20 & 44,8000 & 48,4000 & 49,0000 & 51,0000 \\
\hline & 25 & 45,2500 & 49,0000 & 52,0000 & 52,0000 \\
\hline & 30 & 45,7000 & 50,0000 & 52,0000 & 53,0000 \\
\hline & 40 & 47,8000 & 52,0000 & 54,0000 & 55,0000 \\
\hline & 50 & 49,0000 & 54,0000 & 56,0000 & 56,0000 \\
\hline & 60 & 49,8000 & 56,0000 & 58,0000 & 57,0000 \\
\hline & 70 & 51,6000 & 57,4000 & 58,0000 & 58,3000 \\
\hline & 75 & 52,5000 & 58,0000 & 59,0000 & 59,0000 \\
\hline & 80 & 53,2000 & 59,6000 & 60,0000 & 60,0000 \\
\hline & 90 & 54,0000 & 61,0000 & 60,0000 & 61,0000 \\
\hline
\end{tabular}


Tabla 9. Baremos de Fortalezas en función del rango de edad

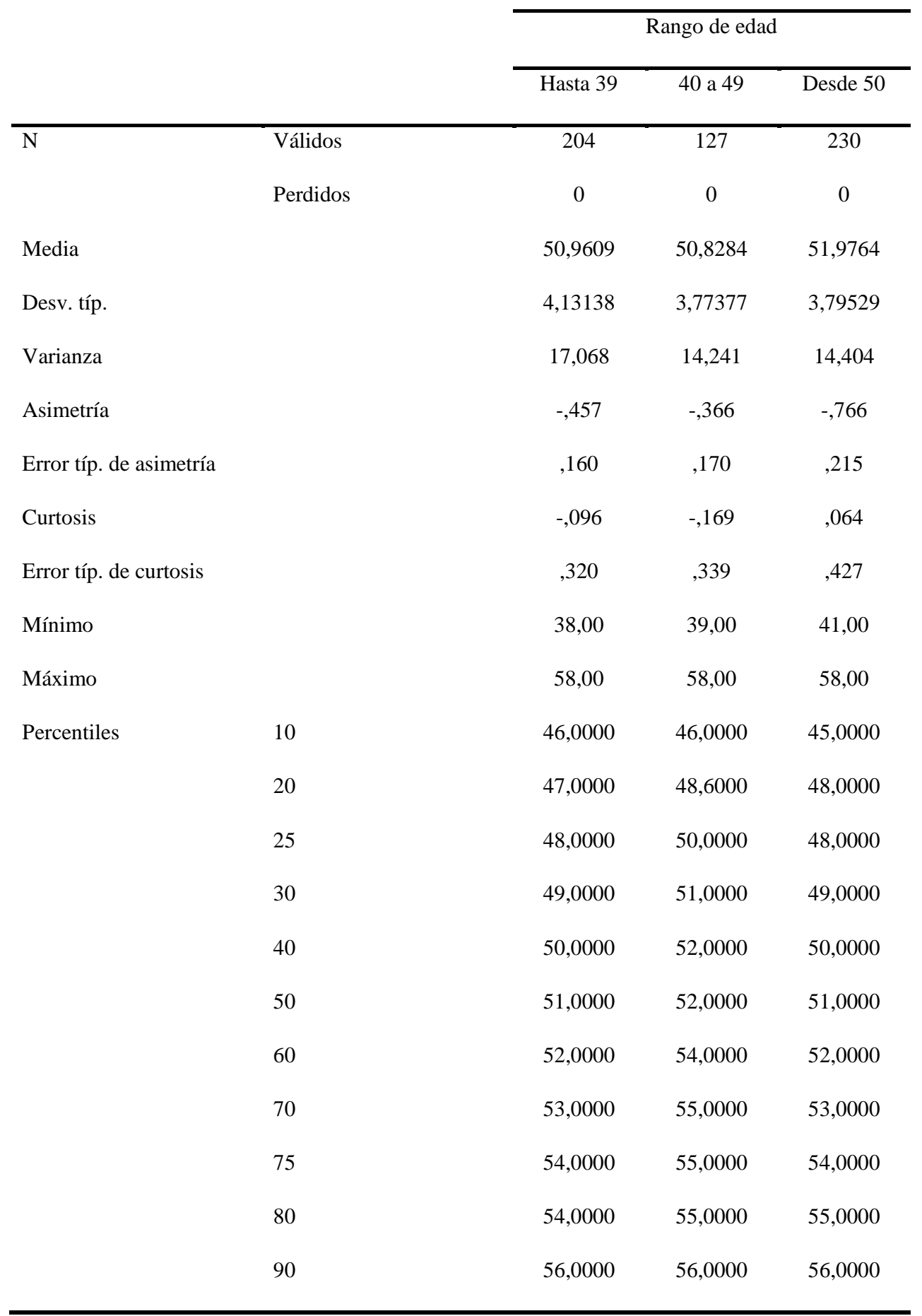


Tabla 10. Baremos de Retos en función del rango de edad

\begin{tabular}{|c|c|c|c|c|}
\hline & & \multicolumn{3}{|c|}{ Rango de edad } \\
\hline & & Hasta 39 & 40 a 49 & Desde 50 \\
\hline \multirow[t]{2}{*}{$\mathrm{N}$} & Válidos & 204 & 127 & 230 \\
\hline & Perdidos & 0 & 0 & 0 \\
\hline Media & & 20,4609 & 20,3922 & 21,3701 \\
\hline Desv. típ. & & 2,95464 & 2,84633 & 2,57523 \\
\hline Varianza & & 8,730 & 8,102 & 6,632 \\
\hline Asimetría & &,- 717 &,- 490 &,- 575 \\
\hline Error típ. de asimetría & & 160 & , 170 & ,215 \\
\hline Curtosis & & ,825 & 406 &,- 141 \\
\hline Error típ. de curtosis & & ,320 & ,339 & ,427 \\
\hline Mínimo & & 9,00 & 10,00 & 14,00 \\
\hline Máximo & & 25,00 & 25,00 & 25,00 \\
\hline \multirow[t]{11}{*}{ Percentiles } & 10 & 17,0000 & 17,8000 & 45,0000 \\
\hline & 20 & 18,0000 & 19,0000 & 48,0000 \\
\hline & 25 & 18,2500 & 20,0000 & 48,0000 \\
\hline & 30 & 19,0000 & 20,0000 & 49,0000 \\
\hline & 40 & 20,0000 & 21,0000 & 50,0000 \\
\hline & 50 & 21,0000 & 22,0000 & 51,0000 \\
\hline & 60 & 21,0000 & 22,0000 & 52,0000 \\
\hline & 70 & 22,0000 & 23,0000 & 53,0000 \\
\hline & 75 & 22,0000 & 23,0000 & 54,0000 \\
\hline & 80 & 23,0000 & 24,0000 & 55,0000 \\
\hline & 90 & 24,0000 & 25,0000 & 56,0000 \\
\hline
\end{tabular}




\subsection{Aplicación}

La recolección de la información se realiza a partir de la aplicación del Cuestionario de Personalidad Eficaz Adultos (CPE-A) (Equipo Interuniversitario de Orientación y Atención a la Diversidad (GOYAD), 2012) por parte de un grupo de profesionales y estudiantes de último año de la carrera de Terapia Ocupacional, previamente entrenados, en la técnica de entrevista y en la forma de aplicación del instrumento seleccionado.

En diciembre de 2013, se recluta un grupo de 5 estudiantes y 2 profesionales voluntarios, a los cuales se les capacita en la técnica de entrevista y en las características del instrumento, el que contempla una parte introductoria que permite descartar compromiso cognitivo y ánimo depresivo, a través de las pruebas Test Minimental State (Folstein, Folstein, \& P.R., 1975) y la Escala de Depresión Geriátrica de Yesavage, (Yesavage y Sheikh, 1986) abreviada. En paralelo, se contactan personas mayores residentes en la región de Valparaíso, que acepten participar en el presente estudio y que suscriben consentimiento informado, posteriormente, se entrega a cada estudiante un listado de las personas mayores contactadas para que las entrevisten y apliquen el instrumento, actividad que se realiza entre los meses de enero y febrero 2014.

Se elabora una base de datos en Excel, que considera cada uno de los ítems contemplados en el cuestionario, lo que permite sistematizar la 
información y el procesamiento de los datos recogidos. A medida que se realizan las entrevistas, se ingresan los datos obtenidos en el archivo electrónico, aplicando posteriormente estadísticos básicos.

En el caso de este estudio, considerando que previo a su aplicación se descartó compromiso cognitivo y del ánimo, esta aplicación se realizó en forma individual. El tiempo promedio de aplicación fue de entre 15 y 20 minutos por persona.

Este cuestionario pretende obtener información acerca la personalidad en general y cómo se desenvuelven las personas adultas en algunos aspectos de su vida diaria. Todos los datos fueron tratados de forma absolutamente confidencial, ofreciéndose a los encuestados la posibilidad de recibir un informe con los resultados obtenidos.

En la primera parte, se solicitaron algunos datos personales, seguidos del cuestionario. El cuestionario consta de 30 ítems a los que se debe responder escribiendo, en la casilla en blanco, el número que mejor representa la opinión del encuestado en cada respuesta. Estos números pertenecen a una escala de Likert en que 1 corresponde a nunca y 5 a siempre. Los tramos intermedios, 2,3 y 4 se consignan cuando existe duda considerando lo que suceda el mayor número de veces, según la siguiente definición: 
NUNCA

POCAS VECES

ALGUNA VEZ

MUCHAS VECES

SIEMPRE

La información recogida se clasifica en 4 dimensiones relacionadas entre sí, de acuerdo al modelo teórico utilizado como fundamento por los autores del instrumento.

Para el análisis de los datos, se calcula el puntaje obtenido en cada una de las dimensiones realizando la sumatoria de cada columna, la que corresponde a cada una de las siguientes dimensiones:

- Autoestima (A): Se conforma principalmente por variables propias de la esfera Fortalezas del Yo, puesto que integra ítems que miden indicadores de autoconcepto y autoestima. Dado que este componente integra aspectos valorativos de la persona, un sujeto que puntuara alto tendría un buen conocimiento y aprecio de su físico, una alta valoración y confianza en sus recursos cognitivo-motivacionales y sociales y un ajustado reconocimiento de sus limitaciones.

- Autorrealización Laboral (A. L.) En este componente aparecen conjugados ítems referidos a Demandas del Yo: motivación intrínseca, expectativas y atribuciones de desempeño laboral e ítems que miden 
indicadores de Fortalezas del Yo: autoconcepto, y autoestima. Este factor pone de manifiesto la relación entre el conocimiento personal y la atribución de éxito a una definida y positiva capacidad y esfuerzo, la motivación intrínseca y el logro en las actividades que desarrolle en su vida cotidiana. El sujeto que puntuara alto en este factor sería aquel que valora positivamente sus recursos a la hora de enfrentarse a determinadas tareas o retos, cuyas motivaciones cotidianas son principalmente de carácter interno; valora positivamente su capacidad para superar retos y ejercer su autonomía y control personal. Realiza atribuciones de capacidad y esfuerzo y tiene expectativas, próxima y lejanas, de éxito.

- Autoeficacia Resolutiva (A.R.): Este componente corresponde a la Esfera Retos del Yo ya que mediría variables que apoyan un afrontamiento eficaz a los retos que puedan surgir en todos los ámbitos. Conjuga ítems que miden indicadores relativos a la toma de decisiones y al afrontamiento de problemas. Por tanto, un sujeto que puntuara alto en este factor planificaría cuidadosamente las decisiones que tuviera que tomar ajustándose a las demandas propias de cada situación, reuniendo la mayor cantidad de información que pueda encontrar y analizando las posibles consecuencias de sus decisiones, con una actitud positiva y capacidad para aprender de la experiencia.

- Autorrealización Social (A.S.): Este componente responde a la esfera de Relaciones del Yo, puesto que involucra habilidades de 
comunicación, empatía y asertividad. Este factor pone de manifiesto la vinculación entre la autopercepción de capacidad o competencia para establecer y mantener relaciones con los otros y las expectativas de éxito en sus relaciones sociales futuras. Dado que este factor incluye variables que apoyan una ejecución social eficaz, un sujeto que puntuara alto tendría confianza y aprecio en sus recursos para construir vínculos, realizaría atribuciones de sus relaciones sociales en función de su habilidad para relacionarse y tendría expectativas de éxito en sus relaciones sociales.

Los ítems correspondientes a cada una de las dimensiones son los siguientes:

\begin{tabular}{|c|}
\hline Autoestima (A.) $=3,7,11,15,19,23,26$ y 29 \\
\hline Autorrealización Laboral (A. L.) = 1, 5, 9, 13, 17, 21, 24 y \\
\hline Autoeficacia Resolutiva (A. R.) $=4,8,12,16$ y 20 \\
\hline $\begin{array}{l}\text { Autorrealización Social (A. S.) = 2, 6, 10, 14, 18, 22, 25, } \\
28 \text { у } 30\end{array}$ \\
\hline
\end{tabular}

\subsection{Procedimiento}

En este trabajo se han realizados los siguientes análisis de datos:

Fiabilidad del Cuestionario

Fiabilidad de los factores de segundo orden 
Correlaciones entre los factores

Análisis de diferencias intragrupales en función de las variables genero, edad, nivel formativo y situación ocupacional actual

Análisis de diferencias intergrupales con grupo de edad adulta comprendida entre los 30 a 59 años de edad.

Baremos generales

Análisis de cluster

\subsection{Análisis de datos}

Para el análisis de los datos se han utilizado el paquete estadístico SPSS versión 18.0 y el Amos 18.

\subsubsection{Análisis de fiabilidad}

Se procedió a calcular el Análisis de la fiabilidad para conocer las propiedades métricas de los ítems y obtener información sobre la fiabilidad del cuestionario.

El cuestionario presenta una fiabilidad de .852 . como figura en la tabla 11. 

Alfa de Cronbach
$\mathrm{N}$ de elementos

, 852

30

La correlación elemento-total corregida arroja coeficientes superiores

a .20 , satisfaciendo así el criterio mínimo de .20 , considerado como el más adecuado para este tipo de escalas. Ver tabla 12.

Tabla 12. Estadísticos total-elemento

\begin{tabular}{|c|c|c|c|c|}
\hline & $\begin{array}{c}\text { Media de la } \\
\text { escala si se } \\
\text { elimina el } \\
\text { elemento }\end{array}$ & $\begin{array}{l}\text { Varianza de la } \\
\text { escala si se } \\
\text { elimina el } \\
\text { elemento }\end{array}$ & $\begin{array}{l}\text { Correlación } \\
\text { elemento-total } \\
\text { corregida }\end{array}$ & $\begin{array}{c}\text { Alfa de } \\
\text { Cronbach si se } \\
\text { eleimina el } \\
\text { elemento }\end{array}$ \\
\hline $\begin{array}{l}1 \text { Mis éxitos en mi profesión se } \\
\text { deben a mi esfuerzo y } \\
\text { dedicación }\end{array}$ & 119,37 & 161,702 & ,669 & ,841 \\
\hline $\begin{array}{l}2 \text { Tengo pocos amigos porque } \\
\text { me cuesta tratar con los demás }\end{array}$ & 119,99 & 169,720 & ,185 & ,854 \\
\hline $\begin{array}{l}3 \text { Me siento muy bien con mi } \\
\text { aspecto físico }\end{array}$ & 119,76 & 163,436 & ,453 & ,845 \\
\hline $\begin{array}{l}4 \text { Cuando tengo que tomar una } \\
\text { decisión, planifico } \\
\text { cuidadosamente lo que voy a } \\
\text { hacer }\end{array}$ & 119,91 & 169,711 & ,174 & ,855 \\
\hline $\begin{array}{l}5 \text { Mi éxito en una tarea se debe } \\
\text { a que me esmero por realizar } \\
\text { un buen trabajo }\end{array}$ & 119,26 & 169,370 & ,409 & ,848 \\
\hline 6 Hago amigos con facilidad & 120,20 & 164,001 & ,358 & ,849 \\
\hline $\begin{array}{l}7 \text { Hay muchas cosas acerca de } \\
\text { mí mismo que me gustaría } \\
\text { cambiar si pudiera }\end{array}$ & 120,71 & 163,168 & ,359 & ,849 \\
\hline $\begin{array}{l}8 \text { Cuando tengo un problema } \\
\text { trato de ver el lado positivo que } \\
\text { posee }\end{array}$ & 119,84 & 159,361 &, 563 & ,842 \\
\hline
\end{tabular}


9 Tengo buena capacidad para trabajar

10 Mis fracasos en las relaciones con los demás se deben a mi falta de habilidad para hacer amigos

11 En general me siento satisfecho conmigo mismo

12 Para tomar una decisión reúno toda la información que puedo encontrar

13 Me considero un buen trabajador

14 Creo que, conociéndome como soy, tendré problemas en mis relaciones con los demás

15 Me acepto tal y como soy, con mis cualidades,

limitaciones y defectos

16 Controlo bien mis emociones

17 Trabajo porque me gusta superar los retos que me presentan las tareas

18 Creo, con toda seguridad, que tendré éxito en mis relaciones con los demás

19 Tengo muchas cualidades para estar orgulloso y satisfecho de mi mismo

20 Cuando experimento un fracaso intento aprender de esa experiencia

$21 \mathrm{Mi}$ éxito en el trabajo se debe a mi capacidad personal

22 Mis éxitos en las relaciones con los demás se deben a mi habilidad para hacer amigos

23 Logro que casi todas las cosas me resulten bien 
Si se eliminan los ítems 2, 4, 9, 25 y 28 aumentaría ligeramente la fiabilidad pero se mantiene para no perder información usando un criterio más psicológico que estadístico.

\subsubsection{Fiabilidad de los factores}

Se ha comprobado la fiabilidad de los cuatro factores una vez que el análisis confirmatorio los considera adecuados y ajustados al modelo.

Todos los índices son superiores al .7.

No se ha eliminado ningún ítems siguiendo nuevamente el criterio psicológico (no perder información) frente al criterio estadístico, una vez 
que manteniendo los ítems no se piéride los índices de fiabilidad dados de forma sustantivamente importante.

\section{Fortalezas}

En cuanto al factor Fortalezas se presentan en las tablas 13 y 14 los estadísticos de fiabilidad y estadísticos total-elemento.

Tabla 13. Estadísticos de fiabilidad del factor Fortalezas

\begin{tabular}{rr}
\hline $\begin{array}{c}\text { Alfa de } \\
\text { Cronbach }\end{array}$ & $\begin{array}{c}\mathrm{N} \text { de } \\
\text { elementos }\end{array}$ \\
\hline, 792 & 8 \\
\hline
\end{tabular}

Tabla 14. Estadísticos total-elemento del factor Fortalezas

$\begin{array}{cccc}\text { Media de la } & \text { Varianza de } & \text { Correlación } & \text { Alfa de } \\ \text { escala si se } & \text { la escala si } & \text { elemento- } & \text { Cronbach } \\ \text { elimina el } & \text { se elimina } & \text { total } & \text { si se } \\ \text { elemento } & \text { el elemento } & \text { corregida } & \begin{array}{c}\text { eleimina el } \\ \text { elemento }\end{array}\end{array}$

\begin{tabular}{lcccc}
\hline $\begin{array}{l}3 \text { Me siento muy bien } \\
\text { con mi aspecto físico }\end{array}$ & 29,62 & 16,932 &, 345 &, 798 \\
$\begin{array}{l}7 \text { Hay muchas cosas } \\
\text { acerca de mí mismo } \\
\text { que me gustaría } \\
\text { cambiar si pudiera }\end{array}$ & 30,57 & 15,849 &, 339 &, 814 \\
$\begin{array}{l}11 \text { En general me } \\
\text { siento satisfecho } \\
\text { conmigo mismo }\end{array}$ & 29,18 & 16,499 &, 665 &, 748 \\
$\begin{array}{l}15 \text { Me acepto tal y } \\
\text { como soy, con mis } \\
\text { cualidades, }\end{array}$ & 29,26 & 16,010 &, 639 &, 747 \\
\end{tabular}


limitaciones y

defectos

19 Tengo muchas

29,32

16,326

,638

, 750

cualidades para estar

orgulloso y satisfecho

de mi mismo

23 Logro que casi

29,59

16,138

, 625

, 750

todas las cosas me

resulten bien

26 Creo que soy una

29,41

17,045

, 526

,766

persona valiosa para

los otros

29 Creo que tengo el

29,30

17,761

,452

,776

talento para hacer

que las cosas

funcionen

\section{Demandas}

En cuanto al factor Demandas se presentan en las tablas 15 y 16 los estadísticos de fiabilidad y estadísticos total-elemento.

Tabla 15. Estadísticos de fiabilidad del factor Demandas

$$
\text { Alfa de } \quad \mathrm{N} \text { de }
$$

Cronbach elementos

\begin{tabular}{rr}
\hline, 728 & 8 \\
\hline
\end{tabular}


Tabla 16. Estadísticos total-elemento del factor Demandas

$\begin{array}{cccc}\text { Media de la } & \text { Varianza de } & \text { Correlación } & \text { Alfa de } \\ \text { escala si se } & \text { la escala si } & \text { elemento- } & \text { Cronbach } \\ \text { elimina el } & \text { se elimina } & \text { total } & \text { si se } \\ \text { elemento } & \text { el elemento } & \text { corregida } & \begin{array}{c}\text { elimina el } \\ \text { elemento }\end{array}\end{array}$

\begin{tabular}{lllll}
\hline $\begin{array}{l}1 \text { Mis éxitos en mi } \\
\text { profesión se deben a } \\
\text { mi esfuerzo y } \\
\text { dedicación }\end{array}$ & 30,51 & 15,453 &, 293 &, 725 \\
$\begin{array}{l}5 \text { Mi éxito en una } \\
\text { tarea se debe a que me } \\
\text { esmero por realizar un } \\
\text { buen trabajo }\end{array}$ & 30,41 & 15,018 &, 526 &, 690 \\
$\begin{array}{l}\text { 9 Tengo buena } \\
\text { capacidad para } \\
\text { trabajar }\end{array}$ & 30,78 & 13,909 &, 437 &, 698 \\
$\begin{array}{l}13 \text { Me considero un } \\
\text { buen trabajador }\end{array}$ & 30,51 & 13,986 &, 513 &, 683 \\
$\begin{array}{l}17 \text { Trabajo porque me } \\
\text { gusta superar los retos } \\
\text { que me presentan las } \\
\text { tareas }\end{array}$ & 30,75 & 14,110 &, 422 &, 701 \\
$\begin{array}{l}21 \text { Mi éxito en el } \\
\text { trabajo se debe a mi } \\
\text { capacidad personal }\end{array}$ & & & & \\
$\begin{array}{l}24 \text { Cuando tengo un } \\
\text { problema dedico } \\
\text { tiempo y esfuerzo para } \\
\text { resolverlo }\end{array}$ & 30,54 & 14,838 &, 445 &, 698 \\
$\begin{array}{l}27 \text { Estoy convencido } \\
\text { de que tendré éxito } \\
\text { cuando trabaje }\end{array}$ & 30,93 & 13,209 &, 441 & \\
\hline & & & & \\
\hline
\end{tabular}




\section{Retos}

En cuanto al factor Retos se presentan en las tablas 17 y 18 los estadísticos de fiabilidad y estadísticos total-elemento.

Tabla 17. Estadísticos de fiabilidad del factor Retos

Alfa de Cronbach

$\mathrm{N}$ de elementos

Tabla 18. Estadísticos total-elemento del factor Retos

$\begin{array}{cccc}\text { Media de la } & \text { Varianza de } & \text { Correlación } & \text { Alfa de } \\ \text { escala si se } & \text { la escala si } & \text { elemento- } & \text { Cronbach } \\ \text { elimina el } & \text { se elimina } & \text { total } & \text { si se } \\ \text { elemento } & \text { el elemento } & \text { corregida } & \begin{array}{c}\text { elimina el } \\ \text { elemento }\end{array}\end{array}$

\begin{tabular}{lllll}
\hline $\begin{array}{l}\text { 4 Cuando tengo que } \\
\text { tomar una decisión, } \\
\text { planifico } \\
\text { cuidadosamente lo que } \\
\text { voy a hacer }\end{array}$ & 16,08 & 10,420 &, 374 &, 719 \\
$\begin{array}{l}8 \text { Cuando tengo un } \\
\text { problema trato de ver } \\
\text { el lado positivo que } \\
\text { posee }\end{array}$ & 16,01 & 9,773 &, 536 &, 651 \\
$\begin{array}{l}12 \text { Para tomar una } \\
\text { decisión reúno toda la } \\
\text { información que } \\
\text { puedo encontrar }\end{array}$ & 16,01 & 9,506 &, 562 &, 639 \\
$\begin{array}{l}16 \text { Controlo bien mis } \\
\text { emociones }\end{array}$ & 16,30 & 11,361 &, 316 &, 734 \\
\end{tabular}


20 Cuando

15,86

9,725

, 648

, 613

experimento un

fracaso intento

aprender de esa

experiencia

\section{Relaciones}

En cuanto al factor Fortalezas se presentan en las tablas 19 y 20 los estadísticos de fiabilidad y estadísticos total-elemento.

Tabla 19. Estadísticos de fiabilidad del factor Relaciones
Alfa de Cronbach
$\mathrm{N}$ de elementos

Tabla 20. Estadísticos total-elemento del factor Relaciones

$\begin{array}{cccc}\text { Media de la } & \text { Varianza de } & \text { Correlación } & \text { Alfa de } \\ \text { escala si se } & \text { la escala si } & \text { elemento- } & \text { Cronbach } \\ \text { elimina el } & \text { se elimina } & \text { total } & \text { si se } \\ \text { elemento } & \text { el elemento } & \text { corregida } & \begin{array}{c}\text { elimina el } \\ \text { elemento }\end{array}\end{array}$

\begin{tabular}{lcccc}
\hline $\begin{array}{l}\text { 2 Tengo pocos amigos } \\
\text { porque me cuesta } \\
\text { tratar con los demás }\end{array}$ & 31,13 & 27,129 &, 442 &, 702 \\
$\begin{array}{l}\text { 6 Hago amigos con } \\
\text { facilidad }\end{array}$ & 31,34 & 25,508 &, 557 &, 679 \\
$\begin{array}{l}10 \text { Mis fracasos en las } \\
\text { relaciones con los } \\
\text { demás se deben a mi }\end{array}$ & 31,20 & 25,947 &, 517 &, 687 \\
\end{tabular}


falta de habilidad para hacer amigos

14 Creo que,

31,04

27,132

,413

,707

conociéndome como

soy, tendré problemas

en mis relaciones con

los demás

$18 \mathrm{Creo}$, con toda

30,79

29,715

,313

,723

seguridad, que tendré

éxito en mis relaciones

con los demás

22 Mis éxitos en las

31,16

29,388

, 294

, 726

relaciones con los

demás se deben a mi

habilidad para hacer

amigos

25 Mis éxitos en las

31,74

27,370

,398

, 710

relaciones con los

demás se deben a que

son ellos los que

toman la iniciativa

28 Pienso que mi

fracaso en las

relaciones con los

demás se deben a que

no le agrado a la

mayoría de las

personas

$30 \mathrm{Me}$ siento a gusto

30,47

30,946

, 239

, 732

compartiendo con

otras personas 


\subsubsection{Correlaciones entre los factores}

En la tabla 21 aparecen que las Fortalezas del yo están relacionadas con las Demandas, los retos y las relaciones del yo. No obstante, las demandas y los retos no aparecen relacionados con las relaciones del yo. Esta dimensión únicamente aparece relacionada con las Fortalezas.

\section{Tabla 21. Correlaciones}

Fortalezas Demandas Retos Relaciones

\begin{tabular}{llcccc}
\hline Fortalezas & Correlación de Pearson & 1 &, $550(* *)$ &, $539(* *)$ &, $433(* *)$ \\
& Sig. (bilateral) & &, 000 &, 000 &, 000 \\
& $\mathrm{~N}$ & 76 & 76 & 76 & 76 \\
\multirow{5}{*}{ Demandas } & Correlación de Pearson &, $550(* *)$ & 1 & $362(* *)$ &, 152 \\
& Sig. (bilateral) &, 000 & &, 001 &, 191 \\
& N & 76 & 76 & 76 & 76 \\
\multirow{5}{*}{ Retos } & Correlación de Pearson &, $539(* *)$ &, $362(* *)$ & 1 &,- 050 \\
& Sig. (bilateral) &, 000 &, 001 & &, 670 \\
& N & 76 & 76 & 76 & 76 \\
Relaciones & Correlación de Pearson &, $433(* *)$ &, 152 &,- 050 & 1 \\
& Sig. (bilateral) &, 000 &, 191 &, 670 & \\
& N & 76 & 76 & 76 & 76 \\
\hline
\end{tabular}

** La correlación es significativa al nivel 0,01 (bilateral). 


\subsubsection{Análisis de diferencias}

Se han realizado dos tipos de análisis de diferencias.

El primer tipo de análisis corresponde a las diferencias internas en la muestra obtenida. Estas diferencias han sido en función de las variables género, edad, nivel de estudios y situación profesional actual.

El segundo tipo de análisis corresponde a las diferencias en relación a la muestra obtenida en otros trabajos en edades comprendidas entre los 30 y 60 años de edad.

Se utilizó la técnica multivariada de la varianza (MANOVA) para analizar el efecto de las variables sobre las dimensiones de la Personalidad eficaz.

Se optó por la utilización de esta técnica puesto que tiene en cuenta el aumento del error tipo I que se produciría al utilizar múltiples anovas y porque podría mostrar diferencias debidas a pequeñas diferencias en algunas de las variables que al combinarse pudiesen dar lugar a diferencias significativas entre los grupos.

Se usó un contraste repetido puesto que nos interesa ver como varían las puntuaciones en función del grupo de pertenencia. 


\subsubsection{Diferencias de medias intragrupo}

Para ello se ha comprobado previamente el ajuste de los datos con la curva de normalidad para proceder a su cálculo. Ver tabla 22.

Tabla 22. Comprobación de supuestos

\begin{tabular}{|c|c|c|c|c|c|}
\hline & & Fortalezas & Demandas & Retos & Relaciones \\
\hline \multirow[t]{2}{*}{$\mathrm{N}$} & Válidos & 76 & 76 & 76 & 76 \\
\hline & Perdidos & 0 & 0 & 0 & 0 \\
\hline Asimetría & &,- 784 &,- 805 &,- 737 &,- 602 \\
\hline Error típ. de asimetría & & ,276 & ,276 & ,276 & ,276 \\
\hline Curtosis & & ,422 & ,366 &,- 156 & 1,148 \\
\hline Error típ. de curtosis & &, 545 &, 545 &, 545 &, 545 \\
\hline
\end{tabular}

\section{Diferencias en función del género}

En la tabla 23 aparece los estadísticos básicos en función de la variable género.

Tabla 23. Estadísticos descriptivos en función del género

\begin{tabular}{llccc} 
& Genero & Media & Desv. típ. & $\mathrm{N}$ \\
\hline Fortalezas & Hombres & 53,3913 & 3,07097 & 23 \\
& Mujeres & 52,2453 & 4,34523 & 53 \\
& Total & 52,5921 & 4,01722 & 76 \\
Demanadas & Hombres & 51,6957 & 3,99357 & 23 \\
& Mujeres & 51,4717 & 3,82604 & 53
\end{tabular}




\begin{tabular}{lllll} 
& Total & 51,5395 & 3,85207 & 76 \\
Retos & Hombres & 20,3043 & 3,13970 & 23 \\
& Mujeres & 19,9623 & 4,14619 & 53 \\
\multirow{2}{*}{ Relaciones } & Total & 20,0658 & 3,85170 & 76 \\
& Hombres & 54,1304 & 4,74154 & 23 \\
& Mujeres & 52,7358 & 5,68111 & 53 \\
& Total & 53,1579 & 5,42108 & 76 \\
\hline
\end{tabular}

En la tabla 24 aparecen los datos obtenidos en el análisis de contrastes multivariados. Se observa que las diferencias encontradas no son significativas.

Tabla 24. Contrastes multivariados en función del género

\begin{tabular}{|c|c|c|c|c|c|c|c|}
\hline Efecto & & Valor & $\mathrm{F}$ & $\begin{array}{l}\text { Gl de la } \\
\text { hipótesis }\end{array}$ & Gl del error & Significación & $\begin{array}{c}\text { Eta al } \\
\text { cuadrado } \\
\text { parcial }\end{array}$ \\
\hline \multirow[t]{4}{*}{ Intersección } & Traza de Pillai & ,996 & 3967,951 (a) & 4,000 & 71,000 &, 000 & 996 \\
\hline & Lambda de Wilks & ,004 & 3967,951(a) & 4,000 & 71,000 & ,000 & ,996 \\
\hline & Traza de Hotelling & 223,547 & 3967,951(a) & 4,000 & 71,000 &, 000 & ,996 \\
\hline & Raíz mayor de Roy & 223,547 & 3967,951(a) & 4,000 & 71,000 & ,000 & ,996 \\
\hline \multirow[t]{4}{*}{ genero } & Traza de Pillai &, 024 & ,444(a) & 4,000 & 71,000 &, 776 &, 024 \\
\hline & Lambda de Wilks & ,976 & ,444(a) & 4,000 & 71,000 &, 776 &, 024 \\
\hline & Traza de Hotelling &, 025 & ,444(a) & 4,000 & 71,000 & ,776 &, 024 \\
\hline & Raíz mayor de Roy & ,025 & ,444(a) & 4,000 & 71,000 &, 776 & 024 \\
\hline
\end{tabular}

a Estadístico exacto

b Diseño: Intersección+generoRECOD 


\section{Diferencias en función de la edad}

Para ello se han establecido tres grupos: 60-69, 70-79 y 80 en adelante.

Se presenta en la Tabla 25 los estadísticos descriptivos en función de estos grupos: Edad 60 a 69 con 70 a 79 y con mayores de 80 .

Tabla 25. Estadísticos descriptivos en función de la edad

\begin{tabular}{|c|c|c|c|c|}
\hline & Grupos de edad & Media & Desv. típ. & $\mathrm{N}$ \\
\hline \multirow[t]{4}{*}{ FORTALEZAS } & 60 a 69 años & 53,2500 & 3,87715 & 32 \\
\hline & 70 a 79 años & 52,3704 & 4,29802 & 27 \\
\hline & mayores de 80 & 51,7059 & 3,83674 & 17 \\
\hline & Total & 52,5921 & 4,01722 & 76 \\
\hline \multirow[t]{4}{*}{ DEMANDAS } & 60 a 69 años & 51,9063 & 3,57734 & 32 \\
\hline & 70 a 79 años & 51,7037 & 4,12138 & 27 \\
\hline & mayores de 80 & 50,5882 & 3,98527 & 17 \\
\hline & Total & 51,5395 & 3,85207 & 76 \\
\hline \multirow[t]{4}{*}{ RETOS } & 60 a 69 años & 19,9688 & 3,57847 & 32 \\
\hline & 70 a 79 años & 20,4074 & 4,31687 & 27 \\
\hline & mayores de 80 & 19,7059 & 3,75441 & 17 \\
\hline & Total & 20,0658 & 3,85170 & 76 \\
\hline \multirow[t]{4}{*}{ RELACIONES } & 60 a 69 años & 53,0625 & 5,10495 & 32 \\
\hline & 70 a 79 años & 53,4444 & 6,27776 & 27 \\
\hline & mayores de 80 & 52,8824 & 4,79430 & 17 \\
\hline & Total & 53,1579 & 5,42108 & 76 \\
\hline
\end{tabular}


En la tabla 26 aparecen los datos obtenidos en el análisis de contrastes multivariados. Se observa que las diferencias encontradas no son significativas.

Tabla 26. Contrastes multivariados en función de la edad

\begin{tabular}{|c|c|c|c|c|c|c|c|}
\hline Efecto & & Valor & $F$ & $\begin{array}{l}\text { Gl de la } \\
\text { hipótesis }\end{array}$ & $\begin{array}{l}\text { Gl del } \\
\text { error }\end{array}$ & Significación & $\begin{array}{c}\text { Eta al } \\
\text { cuadrado } \\
\text { parcial }\end{array}$ \\
\hline \multirow[t]{4}{*}{ Intersección } & Traza de Pillai & ,996 & $4308,718(a)$ & 4,000 & 70,000 & ,000 & ,996 \\
\hline & $\begin{array}{l}\text { Lambda de } \\
\text { Wilks }\end{array}$ & ,004 & $4308,718(a)$ & 4,000 & 70,000 & ,000 & ,996 \\
\hline & $\begin{array}{l}\text { Traza de } \\
\text { Hotelling }\end{array}$ & 246,212 & $4308,718(a)$ & 4,000 & 70,000 & ,000 & ,996 \\
\hline & $\begin{array}{l}\text { Raíz mayor de } \\
\text { Roy }\end{array}$ & 246,212 & $4308,718(a)$ & 4,000 & 70,000 & ,000 & ,996 \\
\hline \multirow[t]{4}{*}{ edad } & Traza de Pillai & ,066 & ,609 & 8,000 & 142,000 & ,769 & ,033 \\
\hline & $\begin{array}{l}\text { Lambda de } \\
\text { Wilks }\end{array}$ & ,934 &, $604(a)$ & 8,000 & 140,000 & ,773 & ,033 \\
\hline & $\begin{array}{l}\text { Traza de } \\
\text { Hotelling }\end{array}$ & ,069 & ,599 & 8,000 & 138,000 & ,778 & ,034 \\
\hline & $\begin{array}{l}\text { Raíz mayor de } \\
\text { Roy }\end{array}$ & ,055 &, $976(b)$ & 4,000 & 71,000 & ,426 & ,052 \\
\hline
\end{tabular}

a Estadístico exacto

b El estadístico es un límite superior para la $\mathrm{F}$ el cual ofrece un límite inferior para el nivel de significación.

c Diseño: Intersección+edadRECOD

\section{Diferencias en función del nivel de estudios}

Se presenta en la tabla 27 los estadísticos básicos en función de la variable estudios o formación. 
Tabla 27. Estadísticos descriptivos en función de la variable formación

\begin{tabular}{|c|c|c|c|c|}
\hline & Estudios & Media & Desv. típ. & $\mathrm{N}$ \\
\hline \multirow[t]{5}{*}{ Fortalezas } & Basicos & 51,2059 & 4,06597 & 34 \\
\hline & Medios & 53,5000 & 4,22399 & 20 \\
\hline & Tecnicos & 55,5000 & 1,87083 & 6 \\
\hline & Universitarios & 53,3125 & 3,34103 & 16 \\
\hline & Total & 52,5921 & 4,01722 & 76 \\
\hline \multirow[t]{5}{*}{ Demandas } & Basicos & 50,7941 & 4,07341 & 34 \\
\hline & Medios & 51,5000 & 4,09750 & 20 \\
\hline & Tecnicos & 53,5000 & 2,42899 & 6 \\
\hline & Universitarios & 52,4375 & 3,28570 & 16 \\
\hline & Total & 51,5395 & 3,85207 & 76 \\
\hline \multirow[t]{5}{*}{ Retos } & Basicos & 19,4412 & 4,11348 & 34 \\
\hline & Medios & 19,7000 & 4,18141 & 20 \\
\hline & Tecnicos & 22,1667 & 3,71035 & 6 \\
\hline & Universitarios & 21,0625 & 2,51578 & 16 \\
\hline & Total & 20,0658 & 3,85170 & 76 \\
\hline \multirow[t]{5}{*}{ Relaciones } & Basicos & 51,0588 & 5,87723 & 34 \\
\hline & Medios & 55,4000 & 4,33347 & 20 \\
\hline & Tecnicos & 55,6667 & 4,71876 & 6 \\
\hline & Universitarios & 53,8750 & 4,47027 & 16 \\
\hline & Total & 53,1579 & 5,42108 & 76 \\
\hline
\end{tabular}


En la tabla 28 aparecen los datos obtenidos en el análisis de contrastes multivariados. Se observa que las diferencias encontradas no son significativas.

Tabla 28. Contrastes multivariados en función de la variable formación

\begin{tabular}{|c|c|c|c|c|c|c|c|}
\hline Efecto & & Valor & $\mathrm{F}$ & $\begin{array}{c}\text { Gl de la } \\
\text { hipótesis }\end{array}$ & $\begin{array}{l}\text { Gl del } \\
\text { error }\end{array}$ & Significación & $\begin{array}{c}\text { Eta al } \\
\text { cuadrado } \\
\text { parcial }\end{array}$ \\
\hline \multirow[t]{4}{*}{ Intersección } & $\begin{array}{l}\text { Traza de } \\
\text { Pillai }\end{array}$ & ,995 & $3628,223(a)$ & 4,000 & 69,000 & ,000 & ,995 \\
\hline & $\begin{array}{l}\text { Lambda de } \\
\text { Wilks }\end{array}$ & ,005 & $3628,223(a)$ & 4,000 & 69,000 & ,000 &, 995 \\
\hline & $\begin{array}{l}\text { Traza de } \\
\text { Hotelling }\end{array}$ & 210,332 & $3628,223(a)$ & 4,000 & 69,000 & ,000 & ,995 \\
\hline & $\begin{array}{l}\text { Raíz mayor } \\
\text { de Roy }\end{array}$ & 210,332 & $3628,223(a)$ & 4,000 & 69,000 & ,000 & ,995 \\
\hline \multirow[t]{4}{*}{ nivel_estudios } & $\begin{array}{l}\text { Traza de } \\
\text { Pillai }\end{array}$ & ,219 & 1,397 & 12,000 & 213,000 & ,169 & ,073 \\
\hline & $\begin{array}{l}\text { Lambda de } \\
\text { Wilks }\end{array}$ & ,789 & 1,428 & 12,000 & 182,848 & , 156 &, 076 \\
\hline & $\begin{array}{l}\text { Traza de } \\
\text { Hotelling }\end{array}$ & 258 & 1,453 & 12,000 & 203,000 & ,145 & ,079 \\
\hline & $\begin{array}{l}\text { Raíz mayor } \\
\text { de Roy }\end{array}$ & 212 & $3,755(b)$ & 4,000 & 71,000 & ,008 & 175 \\
\hline
\end{tabular}

a Estadístico exacto

b El estadístico es un límite superior para la F el cual ofrece un límite inferior para el nivel de significación.

c Diseño: Intersección+nivel_estudiosRECOD 


\section{Diferencia en función de la ocupación actual}

Se presenta en la tabla 29 los estadísticos básicos en función de la variable ocupación actual

Tabla 29. Estadísticos descriptivos en función de la variable ocupación actual

\begin{tabular}{|c|c|c|c|c|}
\hline & profesiónRECOD & Media & Desv. típ. & $\mathrm{N}$ \\
\hline \multirow[t]{4}{*}{ Fortalezas } & En activo & 52,8966 & 3,12072 & 29 \\
\hline & Jubilado & 54,8889 & 2,36878 & 9 \\
\hline & Ama de casa & 51,8158 & 4,70684 & 38 \\
\hline & Total & 52,5921 & 4,01722 & 76 \\
\hline \multirow[t]{4}{*}{ Demandas } & En activo & 52,5517 & 3,32293 & 29 \\
\hline & Jubilado & 50,1111 & 4,59468 & 9 \\
\hline & Ama de casa & 51,1053 & 3,95781 & 38 \\
\hline & Total & 51,5395 & 3,85207 & 76 \\
\hline \multirow[t]{4}{*}{ Retos } & En activo & 20,6207 & 2,84622 & 29 \\
\hline & Jubilado & 20,7778 & 4,29470 & 9 \\
\hline & Ama de casa & 19,4737 & 4,38509 & 38 \\
\hline & Total & 20,0658 & 3,85170 & 76 \\
\hline \multirow[t]{4}{*}{ Relaciones } & En activo & 53,3793 & 4,86543 & 29 \\
\hline & Jubilado & 54,7778 & 4,35252 & 9 \\
\hline & Ama de casa & 52,6053 & 6,04729 & 38 \\
\hline & Total & 53,1579 & 5,42108 & 76 \\
\hline
\end{tabular}


En la tabla 30 aparecen los datos obtenidos en el análisis de contrastes multivariados. Se observa que las diferencias encontradas no son significativas.

Tabla 30. Contrastes multivariados en función de la variable ocupación actual

\begin{tabular}{|c|c|c|c|c|c|c|c|}
\hline Efecto & & Valor & $\mathrm{F}$ & $\begin{array}{c}\text { Gl de la } \\
\text { hipótesis }\end{array}$ & $\begin{array}{l}\text { Gl del } \\
\text { error }\end{array}$ & Significación & $\begin{array}{c}\text { Eta al } \\
\text { cuadrado } \\
\text { parcial }\end{array}$ \\
\hline \multirow[t]{4}{*}{ Intersección } & $\begin{array}{l}\text { Traza de } \\
\text { Pillai }\end{array}$ & ,995 & $3247,624(a)$ & 4,000 & 70,000 & ,000 & ,995 \\
\hline & $\begin{array}{l}\text { Lambda de } \\
\text { Wilks }\end{array}$ & ,005 & $3247,624(a)$ & 4,000 & 70,000 & ,000 & ,995 \\
\hline & $\begin{array}{l}\text { Traza de } \\
\text { Hotelling }\end{array}$ & 185,579 & $3247,624(a)$ & 4,000 & 70,000 & ,000 & ,995 \\
\hline & $\begin{array}{l}\text { Raíz mayor } \\
\text { de Roy }\end{array}$ & 185,579 & $3247,624(a)$ & 4,000 & 70,000 & ,000 & ,995 \\
\hline \multirow[t]{4}{*}{ profesiónRECOD } & $\begin{array}{l}\text { Traza de } \\
\text { Pillai }\end{array}$ & 179 & 1,741 & 8,000 & 142,000 & ,094 & 089 \\
\hline & $\begin{array}{l}\text { Lambda de } \\
\text { Wilks }\end{array}$ & ,827 & $1,746(a)$ & 8,000 & 140,000 & ,093 & 091 \\
\hline & $\begin{array}{l}\text { Traza de } \\
\text { Hotelling }\end{array}$ & 203 & 1,751 & 8,000 & 138,000 & ,092 & ,092 \\
\hline & $\begin{array}{l}\text { Raíz mayor } \\
\text { de Roy }\end{array}$ & 163 & $2,889(b)$ & 4,000 & 71,000 & ,028 & , 140 \\
\hline
\end{tabular}

a Estadístico exacto

b El estadístico es un límite superior para la F el cual ofrece un límite inferior para el nivel de significación.

c Diseño: Intersección+profesiónRECOD 


\subsubsection{Diferencias de medias intergrupos}

Para el análisis de estas diferencias hemos acudido a la base de datos cedidas por Ramírez (2013) realizada con población adulta en edades comprendidas entre los 30 a 59 años de edad.

En la tabla 31 se presentan los estadísticos básicos de esta muestra en cada factor.

Tabla 31. Estadísticos de la muestra en cada factor

\begin{tabular}{lccccc} 
& & FORTALEZAS & DEMANDAS & RETOS & RELACIONES \\
\hline $\mathrm{N}$ & Válidos & 637 & 637 & 637 & 637 \\
& Perdidos & 0 & 0 & 0 & 0 \\
Asimetría & &,- 504 &,- 944 &,- 703 &,- 612 \\
Error típ. de asimetría &, 097 &, 097 &, 097 &, 097 \\
Curtosis &,- 123 &, 752 &, 588 &,- 074 \\
Error típ. de curtosis &, 193 &, 193 &, 193 &, 193 \\
\hline
\end{tabular}

En la tabla 32 se presenta los estadísticos descriptivos entre ambas muestras generacionales. En ella aparecen diferencias en las dimensiones Fortalezas y relaciones del yo. 
Tabla 32. Estadísticos descriptivos en las muestras generacionales

\begin{tabular}{llccr} 
& Generación & Media & Desv. típ. & N \\
\hline Fortalezas & de 30 a 59 & 51,1426 & 3,94846 & 561 \\
& mayores de 60 & 52,5921 & 4,01722 & 76 \\
& Total & 51,3155 & 3,98140 & 637 \\
Demandas & de 30 a 59 & 52,2068 & 3,23320 & 561 \\
& mayores de 60 & 51,5395 & 3,85207 & 76 \\
Retos & Total & 52,1272 & 3,31679 & 637 \\
& de 30 a 59 & 20,6417 & 2,85575 & 561 \\
& mayores de 60 & 20,0658 & 3,85170 & 76 \\
Relaciones & Tetal 30 a 59 & 20,5730 & 2,99419 & 637 \\
& mayores de 60 & 54,8752 & 4,95070 & 561 \\
& Total & 53,1579 & 5,42108 & 76
\end{tabular}

En la tabla 33 se presentan los resultados de contraste multivariados al objeto de conocer el grado de significación que tienen estas diferencias. 
Tabla 33. Contrastes multivariados en función de la muestra generacional

\begin{tabular}{|c|c|c|c|c|c|c|c|}
\hline Efecto & & Valor & $\mathrm{F}$ & $\begin{array}{l}\text { Gl de la } \\
\text { hipótesis }\end{array}$ & $\begin{array}{l}\text { Gl del } \\
\text { error }\end{array}$ & Significación & $\begin{array}{c}\text { Eta al } \\
\text { cuadrado } \\
\text { parcial }\end{array}$ \\
\hline \multirow[t]{4}{*}{ Intersección } & Traza de Pillai & ,993 & $21233,960(a)$ & 4,000 & 632,000 & ,000 & ,993 \\
\hline & $\begin{array}{l}\text { Lambda de } \\
\text { Wilks }\end{array}$ & ,007 & 21233,960 (a) & 4,000 & 632,000 & ,000 & ,993 \\
\hline & $\begin{array}{l}\text { Traza de } \\
\text { Hotelling }\end{array}$ & 134,392 & $21233,960(a)$ & 4,000 & 632,000 & ,000 & ,993 \\
\hline & $\begin{array}{l}\text { Raíz mayor de } \\
\text { Roy }\end{array}$ & 134,392 & $21233,960(a)$ & 4,000 & 632,000 & ,000 & ,993 \\
\hline \multirow[t]{4}{*}{ Generación } & Traza de Pillai & ,069 & $11,703(a)$ & 4,000 & 632,000 & ,000 & ,069 \\
\hline & $\begin{array}{l}\text { Lambda de } \\
\text { Wilks }\end{array}$ & ,931 & $11,703(a)$ & 4,000 & 632,000 & ,000 & ,069 \\
\hline & $\begin{array}{l}\text { Traza de } \\
\text { Hotelling }\end{array}$ & ,074 & $11,703(a)$ & 4,000 & 632,000 & ,000 & ,069 \\
\hline & $\begin{array}{l}\text { Raíz mayor de } \\
\text { Roy }\end{array}$ & , 074 & $11,703(a)$ & 4,000 & 632,000 & ,000 & ,069 \\
\hline
\end{tabular}

a Estadístico exacto

b Diseño: Intersección+Generación

Al obtenerse en la Traza de Pillai que estas diferencias encontradas sosn significativas se ha procedido a las pruebas de los efectos inter-sujetos cuyos resultados se presentan en la tabla 34 donde se confirman que estas diferencias en Fortalezas a favor del grupo de mayores de 60 y en Relaciones a favor del grupo 30-59 no son debidas al azar. 
Tabla 34. Pruebas de los efectos inter-sujetos

\begin{tabular}{|c|c|c|c|c|c|c|c|}
\hline Fuente & $\begin{array}{l}\text { Variable } \\
\text { dependiente }\end{array}$ & $\begin{array}{c}\text { Suma de } \\
\text { cuadrados } \\
\text { tipo III }\end{array}$ & gl & $\begin{array}{c}\text { Media } \\
\text { cuadrática }\end{array}$ & $F$ & Significación & $\begin{array}{c}\text { Eta al } \\
\text { cuadrado } \\
\text { parcial }\end{array}$ \\
\hline \multirow[t]{4}{*}{$\begin{array}{l}\text { Modelo } \\
\text { corregido }\end{array}$} & Fortalezas & $140,629(a)$ & 1 & 140,629 & 8,983 & ,003 & ,014 \\
\hline & Demandas & $29,804(b)$ & 1 & 29,804 & 2,717 & , 100 & ,004 \\
\hline & Retos & $22,201(c)$ & 1 & 22,201 & 2,482 & ,116 & ,004 \\
\hline & Relaciones & $197,398(d)$ & 1 & 197,398 & 7,869 & ,005 & ,012 \\
\hline \multirow[t]{4}{*}{ Intersección } & Fortalezas & 720253,201 & 1 & 720253,201 & 46007,768 & ,000 & ,986 \\
\hline & Demandas & 720413,453 & 1 & 720413,453 & 65662,320 & ,000 & ,990 - l \\
\hline & Retos & 110913,880 & 1 & 110913,880 & 12400,456 & ,000 & ,951 \\
\hline & Relaciones & 781179,502 & 1 & 781179,502 & 31140,526 & , 000 & ,980 \\
\hline \multirow[t]{4}{*}{ Generación } & Fortalezas & 140,629 & 1 & 140,629 & 8,983 & ,003 & ,014 \\
\hline & Demandas & 29,804 & 1 & 29,804 & 2,717 & ,100 & ,004 \\
\hline & Retos & 22,201 & 1 & 22,201 & 2,482 & ,116 & ,004 \\
\hline & Relaciones & 197,398 & 1 & 197,398 & 7,869 & ,005 & ,012 \\
\hline \multirow[t]{4}{*}{ Error } & Fortalezas & 9940,947 & 635 & 15,655 & & & \\
\hline & Demandas & 6966,896 & 635 & 10,971 & & & \\
\hline & Retos & 5679,655 & 635 & 8,944 & & & \\
\hline & Relaciones & 15929,371 & 635 & 25,086 & & & \\
\hline \multirow[t]{4}{*}{ Total } & Fortalezas & 1687484,000 & 637 & & & & \\
\hline & Demandas & 1737879,000 & 637 & & & & \\
\hline & Retos & 275311,000 & 637 & & & & \\
\hline & Relaciones & 1920021,000 & 637 & & & & \\
\hline \multirow[t]{3}{*}{$\begin{array}{l}\text { Total } \\
\text { corregida }\end{array}$} & Fortalezas & 10081,576 & 636 & & & & \\
\hline & Demandas & 6996,700 & 636 & & & & \\
\hline & Retos & 5701,856 & 636 & & & & \\
\hline
\end{tabular}


a $\mathrm{R}$ cuadrado $=, 014$ ( $\mathrm{R}$ cuadrado corregida $=, 012)$

b $\mathrm{R}$ cuadrado $=, 004(\mathrm{R}$ cuadrado corregida $=, 003)$

C $\mathrm{R}$ cuadrado $=, 004$ ( $\mathrm{R}$ cuadrado corregida $=, 002)$

d $\mathrm{R}$ cuadrado $=, 012(\mathrm{R}$ cuadrado corregida $=, 011)$

\subsubsection{Baremos o referencias de normalización de la escala}

Se presenta en la tabla 35 los baremos generales expresados en puntuaciones centiles de la escala para las personas comprendidas en estas edades.

Tabla 35. Baremos generales de la escala

\begin{tabular}{|c|c|c|c|c|c|}
\hline & & FORTALEZAS & DEMANDAS & RETOS & RELACIONES \\
\hline \multirow[t]{2}{*}{$\mathrm{N}$} & Válidos & 76 & 76 & 76 & 76 \\
\hline & Perdidos & 0 & 0 & 0 & 0 \\
\hline Media & & 52,5921 & 51,5395 & 20,0658 & 53,1579 \\
\hline Desv. típ. & & 4,01722 & 3,85207 & 3,85170 & 5,42108 \\
\hline Varianza & & 16,138 & 14,838 & 14,836 & 29,388 \\
\hline Asimetría & &,- 784 &,- 805 &,- 737 &,- 602 \\
\hline Error típ. de asimetría & & 276 & ,276 & ,276 & 276 \\
\hline Curtosis & & ,422 & ,366 &,- 156 & 1,148 \\
\hline Error típ. de curtosis & &, 545 &, 545 &, 545 &, 545 \\
\hline Mínimo & & 42,00 & 39,00 & 9,00 & 33,00 \\
\hline Máximo & & 58,00 & 56,00 & 25,00 & 62,00 \\
\hline \multirow[t]{5}{*}{ Percentiles } & 10 & 47,4000 & 46,0000 & 15,0000 & 46,7000 \\
\hline & 20 & 50,0000 & 48,4000 & 16,4000 & 49,0000 \\
\hline & 25 & 50,0000 & 49,0000 & 17,2500 & 49,2500 \\
\hline & 30 & 51,0000 & 49,0000 & 18,0000 & 50,1000 \\
\hline & 40 & 52,0000 & 51,0000 & 20,0000 & 51,8000 \\
\hline
\end{tabular}




\begin{tabular}{lllll}
50 & 53,0000 & 52,0000 & 21,0000 & 53,0000 \\
60 & 54,0000 & 53,2000 & 22,0000 & 55,0000 \\
70 & 55,0000 & 54,0000 & 23,0000 & 57,0000 \\
75 & 56,0000 & 55,0000 & 23,0000 & 58,0000 \\
80 & 56,6000 & 55,6000 & 23,0000 & 58,0000 \\
90 & 57,3000 & 56,0000 & 25,0000 & 60,3000 \\
\hline
\end{tabular}

\subsubsection{Análisis de tipologías- conglomerados}

Se ha realizado un Análisis de Conglomerados mediante el método K-medias con la finalidad de agrupar a los sujetos en función de sus puntuaciones directas en los cuatro factores (Fortalezas, Demandas, Retos y Relaciones) que conforman el c constructo de Personalidad Eficaz.

Se trata de un método de partición u optimización que permite asignar elementos a grupos especificando de antemano el número de clusters que se desea obtener y obteniendo tipos independientes entre sí.

Se han realizado exploraciones de modelos de agrupaciones desde 3 hasta 8 grupos. Finalmente, hemos optado por presentar el modelo de cuatro grupos por ser el modelo frecuentemente usado en los trabajos sobre tipologías realizados previamente en el entorno de la personalidad eficaz

\section{Obtención de cuatro grupos}

En la tabla 36 se presenta los centros de los cuatro conglomerados finales en función de las medias que obtienen en las cuatro dimensiones. 
Tabla 36. Centros de los conglomerados finales

Conglomerado

\begin{tabular}{lcccc}
\hline & 1 & 2 & 3 & 4 \\
\hline Fortalezas & 53,19 & 54,62 & 47,38 & 44,00 \\
Demandas & 52,41 & 52,50 & 47,85 & 47,50 \\
Retos & 22,15 & 20,47 & 14,62 & 20,50 \\
Relaciones & 49,15 & 57,82 & 51,54 & 38,50 \\
\hline
\end{tabular}

En la tabla 37 se presenta los centros de los cuatro conglomerados finales expresados en puntuaciones centiles en función de las medias que obtienen en las cuatro dimensiones.

Tabla 37. Centros de los conglomerados expresados en centiles

\begin{tabular}{lcccc} 
& \multicolumn{5}{c}{ Conglomerado } \\
\cline { 2 - 5 } & 1 & 2 & 3 & 4 \\
\hline FORTALEZAS & 50 & 70 & 10 & 10 \\
DEMANDAS & 50 & 50 & 20 & 20 \\
RETOS & 60 & 40 & 10 & 40 \\
RELACIONES & 20 & 75 & 30 & 10 \\
\hline
\end{tabular}

Las diferencias entre los clusters en los cuatro componentes son estadísticamente significativas ( $p=.000$ ), como puede verse en la tabla 38 ANOVA 
Tabla 38. ANOVA

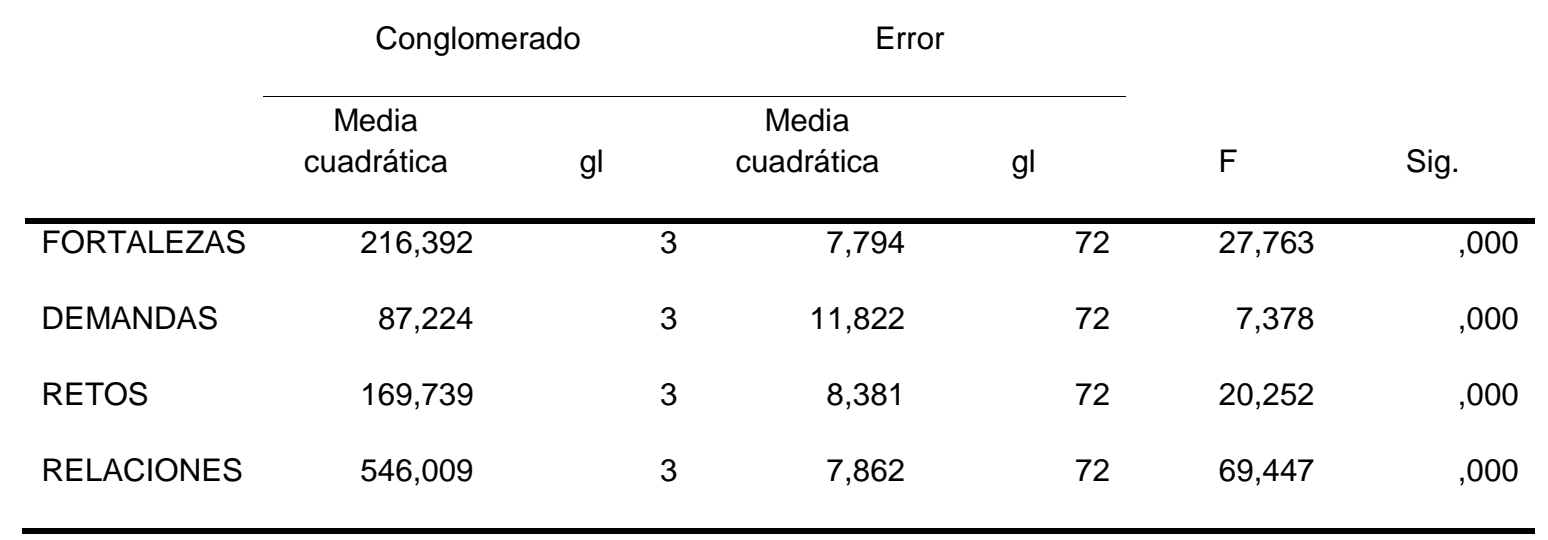

Las pruebas $\mathrm{F}$ sólo se deben utilizar con una finalidad descriptiva puesto que los conglomerados han sido elegidos para maximizar las diferencias entre los casos en diferentes conglomerados. Los niveles críticos no son corregidos, por lo que no pueden interpretarse como pruebas de la hipótesis de que los centros de los conglomerados son iguales.

En la tabla 39 se presentan el número de sujetos incluidos en cada grupo.

Tabla 39. Número de casos en cada conglomerado

$\begin{array}{ccc}\text { Conglomerado } & 1 & 27,000 \\ & 2 & 34,000 \\ & 3 & 13,000 \\ & 4 & 2,000 \\ \text { Válidos } & & 76,000 \\ \text { Perdidos } & & , 000\end{array}$




\section{DISCUSION}


En este apartado vamos a proceder a la formulación de los resultados obtenidos y a discusión de los mismos siguiendo la directriz que se ha marcado del objetivo propuesta en este trabajo que a modo de recordatorio es el establecimiento de tipologías modales multivariados en edades comprendidas entre los 60 a 90 años de edad en población chilena.

Lo primero objeto de discusión es lo limitado de la muestra debida a causas dificultades serias que se han tenido para su obtención. No obstante ya se ha indicado que la distribución obtenida en función de las variables de género, edad, nivel formativo y situación ocupacional presenta una distribución ajustada a la realidad demográfica a la que se ha hecho alusión cuando se ha desarrollado el estado demográfico chileno en esta etapa de la vida. Eso no quita la cautela que ha de tenerse a la hora de proceder a una generalización de estos resultados.

Respecto a la verificación de las características psicométricas del instrumento empleados en lo referente a fiabilidad, validez y normalización del mismo en la población/muestra objeto de nuestro estudio cabe indicar que los resultados obtenidos corroboran unos índices de fiabilidad general y de factores aceptables y admisibles en el argot de la psicometría y una normalización en todos sus factores igualmente equilibrada.

Respecto al Análisis de las diferencias existentes en la población/muestra empleadas en función de las distintas variables que se 
recogen tales como género, edad, nivel formativo y situación ocupacional en la que se encuentran no se han obtenido diferencias estadísticamente significas en ninguna de los cuatro factores. Cabe señalar que el cuestionario original centrado en población adulta comprendida entre los 30 a 59 años de edad, si se presentaban baremos diferenciados por factores en función de algunas variables: el factor Relaciones en relación al nivel de estudio y el los factores Fortalezas y Retos a nivel de edad. Una explicación posible a este dato viene dado por el nivel de experiencia supuestamente alcanzado en estas edades en donde las Relaciones del yo se ve menos afectado por el nivel formativo alcanzado y las Fortalezas y los Retos del yo menos variable en función de la edad ya alcanzada consideraba como más estable en relación a la autopercepción de sí mismo y en relación a la forma de afrontar los problemas y tomar decisiones.

Respecto al análisis de las diferencias existentes con carácter general de la muestra estudiada con edades precedentes comprendidas entre los 30 a 59 años de edad se han encontrado diferencias estadísticamente significativas en relación al factor Fortaleza y el factor Relaciones.

La media en el factor fortalezas del Yo es, en términos estadísticos, significativamente superior en la los mayores de 60 años en relación a la población comprendida entre los 30 a 50 años. Este dato es esperado en la medida que corrobora un proceso creciente de valoración y aceptación de la 
propia identidad personal, en condiciones normales, a medida que se avanza en experiencia de vida, lo que hace que el grupo de mayor edad tenga respuestas más altas en lo referente a las fortalezas del yo.

En cambio la media en el factor Relaciones del Yo es, en términos estadísticos, significativamente superior en la población comprendido entre los 30 a 59 años que en la de mayores de 60 años. Igualmente es un dato explicable en la medida en que conforme se avanza en edad las respuestas más egocéntricas o centradas en el propio suelen predominar frente a las respuestas alocentricas centradas en el otro.

Realizados estos análisis previos nuestro trabajo se ha centrado fundamentalmente en el establecimiento de perfiles tipológicos de personalidad eficaz en estad edad y una comparativa de las tipologías modales obtenidas con las tipologías obtenidas en edades previas comprendidas entre los 30 a 59 años de edad.

Respecto al establecimiento de los perfiles tipológicos de personalidad eficaz en la muestra estudiada se ha realizado el agrupamiento en cuatro grupos.

Este agrupamiento no ha sido aleatorio. Está basado en empíricamente en estudios previos realizados sobre tipologías de personalidad eficaz en edades anteriores: muestra infantil: Fueyo (2010) y 
Pizarro (2012); muestra adolescente: Di Giusto (2013), Muñoz Rojo (2013) y Arraño (2014); muestra juvenil: Gómez (2011) y Bernal (2014), y muestra adulta: López Pérez (2011) y Ramírez (2013), donde se han obtenido cuatro tipos modales multivariados integrados.

Con anterioridad se han presentado las tipologías obtenidas en población adulta Española (López Pérez, 2011) y Chilena (Ramírez, 2013).

Los resultados obtenidos con cuatro grupos presentan los siguientes tipos.

\section{El tipo I El tipo I: Eficaz Introvertido}

Estaría caracterizado por puntuaciones normales en Fortalezas, demandas y Retos y bajo en Relaciones.

Su denominación seria Eficaz introvertido

Representa a una persona que en lo que respecta a las fortalezas del yo se acepta físicamente, se siente satisfecho y se acepta como es con sus cualidades y defectos, sintiéndose orgulloso de algunas de ellas. Intenta que las cosas que emprende le resulten bien pues confía en su talento para ello y se considera una persona valiosa para los demás.

En lo que respecta a las demandas del yo piensa que sus éxitos porfesionales se deben a su esfuerzo, dedicación y capacidad de trabajo y en general tiene expectativas de éxito en lo que emprende. 
En lo que respecta a Retos tiende a planificar bien los pasos que debe hacer antes de tomar una decisión reuniendo la máxima información posible, controla sus emociones e intenta aprender de los fracasos.

No obstante sus mayores dificultades la experimentan en la Relaciones del yo con los demás. Se considera en general con falta de habilidades para iniciar amistades y relaciones, siendo consciente de su dificultad para hacer amigos y del posible rechazo que origine en los demás por su forma de ser.

Lo hemos clasificado dentro del grupo de tipos eficaces pues las dimensiones constitutivas de una eficacia como son las Fortalezas del yo, las demandas del yo y los retos del yo son aceptables y ello le beneficia a la hora de ser eficaz aunque sin duda alguna tiene una limitación a la hora de desarrollar su eficacia en campos de actividad social, que por otra parte son los más frecuentes.

\section{El tipo II: Personalidad eficaz}

Estaría caracterizado por puntuaciones altas en Fortalezas y Relaciones y puntuaciones normales e Demandas y Retos. Integran este grupo 34 personas. Su denominación sería Eficaz.

Este perfil se caracteriza por una persona con un buen autoconcepto, pero sobretodo, que se valoran y quieren como es. Son adultos que valoran positivamente sus actitudes y capacidades en los principales contextos en los que se desenvuelven en estas edades (trabajo, familia y grupo de 
iguales). Se consideran atractivos, estables emocionalmente, capaces e importantes.

Con respecto a la esfera Relaciones del yo, este grupo de sujetos se percibe con habilidades sociales y capacidad asertiva. Se desenvuelven bien en situaciones sociales, sin timidez. Refieren un amplio círculo de amistades y expectativas de éxito en sus relaciones con el grupo de iguales.

No obstante, las dimensiones relacionadas con las demandas del yo y los retos del yo tales como motivación, expectativas y atribuciones (demandas del yo) como las de afrontamiento de problemas y toma de decisiones no se sitúan en niveles altos pero si en torno a la media lo que indica que se trata de personas adaptadas, que suelen evaluar correctamente "qué" quieren conseguir y "cómo", que gestionan adecuadamente sus recursos y que mantienen una visión relativamente positiva sobre su futuro. A ello se añade que generalmente presentan motivación interna hacia el trabajo, un funcionamiento atribucional eficaz y orientado a la obtención de rendimiento profesional (atribuye sus éxitos tanto a su esfuerzo como a su capacidad) y expectativas optimistas sobre su rendimiento inmediato y a más largo plazo.

Igualmente presenta una adecuada gestión de sus recursos y de afrontar problemas y tomar decisiones (esfera Retos del yo). No adoptarán actitudes pasivas de afrontamiento, ni esperarán a que otros les resuelvan sus problemas. Se juzgarán capaces de resolverlos y antes de tomar una 
decisión reflexionarán sobre sus consecuencias, manteniendo una postura confiada y optimista sobre su resolución.

La eficacia tiene sus fundamentos en sus fortalezas que le hace proyectar seguridad cara al resto de las dimensiones de su personalidad. Si este primera dimensión los motivos, las expectativas, las atribuciones de causalidad, los afrontamientos de problemas, las tomas de decisiones y las relaciones sociales

\section{El tipo III: El tipo III Ineficaz}

Estarían caracterizado estas personas por puntuaciones bajas en todas las dimensiones: Fortalezas, Demandas, Retos y relaciones. Su denominación sería Ineficacia acusada.

Los sujetos que quedan enmarcados dentro de este clúster se ven a ellos mismo como problemáticos, poco importantes y en desacuerdo con su forma de ser y actuar. No se gustan ni física, ni emocionalmente. Presentan una baja autoestima como trabajadores y como amigos, repercutiendo en sus labores y en sus relaciones con los iguales.

Es decir la dimensión Fortalezas del yo constitutivas o eje de la eficacia está por debajo de los niveles mínimos de aceptabilidad.

Las demandas del yo igualmente está por debajo de esos niveles mínimos. De forma más concreta presentan escasa motivación laboral o en su caso ocupacional repercutiendo en su rendimiento. Sus atribuciones no presentan locus de control interno, y se perciben con falta de aptitudes para 
obtener buen rendimiento. Esto repercute en una visión pesimista sobre acontecimientos futuros.

La dimensión Retos del yo son igualmente bajas. Muestran dificultades en el afrontamiento de problemas y la toma de decisiones, presentando dificultades para decidir por sí mismos y optando por una actitud en ocasiones pasiva, y en ocasiones impulsiva, a la hora de abordar conflictos.

Y finalmente la dimensión retos del yo son también bajas.

Se perciben con pocas amistades y dificultad para relacionarse con sus iguales. Manifiestan expectativas de fracaso en relaciones sociales hipotéticas futuras. Sus escasas capacidades empática y asertiva y sus problemas a la hora de desenvolverse en situaciones social están presentes y le condicionan bastante en su vida normal.

Esta ineficacia tiene igualmente su base en las deficiencias en la dimensión Fortalezas del yo. Un desfigurado autoconcepto acompañado de la consiguiente baja autoestima va incidir en toda su actividad personal y relacionar. Sin duda influye en sus motivaciones en sus atribuciones y en sus expectativas. No cree en si mismo y en consecuencia no tiene grandes expectativas y en ocasiones se las plantea a corto plazo y sin grandes pretensiones.

La secuencia lógica de este proceso le lleva a afrontar los problemas de una forma más pasiva que activa dejando en muchas ocasiones a la 
suerte y al azar o a los demás la resolución de los problemas y la toma de decisiones. Esto genera un alto grado de ineficacia.

\section{EI tipo IV: El tipo IV Ineficaz resolutivo}

Estaría caracterizado por puntuaciones bajas en Fortalezas, Demandas y Relaciones y normales en Retos.

Los sujetos que quedan enmarcados dentro de este clúster presentan una valoración negativa de sí mismos y cierta dificultad en sus relaciones sociales junto con una baja motivación intrínseca hacia las tareas, la falta de locus de control en lo que le ocurre y la presencia de expectativas pesimistas.

Sin embargo, sí que consideran sin grandes dificultades una en la resolución de problemas y la toma de decisiones.

Estamos hablando de adultos caracterizados por con carencias en Fortalezas del yo, y Demandas del Yo (presentan escasa motivación laboral repercutiendo en su rendimiento, sus atribuciones no presentan locus de control interno, y se perciben con falta de aptitudes para obtener buen rendimiento.) y en Relaciones del yo (dificultades para establecer buenas relaciones con los iguales y para desenvolverse en situaciones sociales de manera adaptativa,) pero con competencias en lo relacionado con los Retos del yo ( afrontamiento de problemas y la toma de decisiones).

Este tipo se diferencia del tipo III español y Tipo 2 Chileno únicamente en la dimensión Relaciones. Las valoraciones relativamente 
normales hacia altas en retos es su diferencia. No obstante le incluimos en el grupo de ineficacia en razón a que las raíces de la eficacia como don las Fortalezas y las Demandas son bajas.

Respecto a la comparativa con los perfiles obtenidos en población adulta española y chilena se señala los siguientes aspectos

Los perfiles obtenidos presentan una relativa similitud con los cuatro perfiles de personalidad eficaz obtenidos en población adulta (30 a 59 años de edad) con las siguientes matizaciones.

El tipo I que hemos denominado Eficaz Introvertido es semejante al mismo tipo de Ineficaz introvertido hallado en población adulta española y chilena.

El tipo II que hemos denominado Eficaz es semejante al mismo tipo de Eficaz hallado en población adulta española y Chilena.

El tipo III que hemos denominado Ineficaz es semejante al mismo tipo de Ineficaz hallado en población adulta española y chilena.

La dificultad la encontramos en el tipo IV que hemos denominado Ineficaz resolutivo que no se encuentra un paralelismo con los tipos obtenidos en población adulta española y chilena. En estas poblaciones aparecía un tipo Ineficaz social pero no resolutivo. 
Presentamos un cuadro comparativo de los cuatro tipos en que se han agrupados las muestras obtenidas en poblacional adulta española y chilena comprendida entre los 30 a 59 años de edad y población adulta chilena objeto de nuestro trabajo mayor de 60 a 90 años.

\begin{tabular}{|c|c|c|}
\hline $\begin{array}{l}\text { Tipología Española } \\
30 \text { a } 59 \text { años }\end{array}$ & $\begin{array}{l}\text { Tipologia Chilena } \\
30 \text { a } 59 \text { años }\end{array}$ & $\begin{array}{l}\text { Tipologia Chilena } \\
\text { Adulta } 60 \text { a } 90 \text { años }\end{array}$ \\
\hline $\begin{array}{l}\text { Tipo IV: Eficaz Esta } \\
\text { tipología de sujetos } \\
\text { demuestra } \\
\text { puntuaciones } \\
\text { superiores a la media } \\
\text { en los cuatro factores } \\
\text { del cuestionario. Los } \\
\text { adultos que pertenecen } \\
\text { a este cluster presentan } \\
\text { puntuaciones cercanas } \\
\text { al centil } 70 \text { en todos los } \\
\text { factores a excepción de } \\
\text { Retos del yo con un } \\
\text { centil 60, pero en los } \\
\text { factores Fortalezas y } \\
\text { Relaciones se } \\
\text { encuentran por encima } \\
\text { del percentil 75. } \\
\text { Representarían el } \\
\text { prototipo de Persona } \\
\text { Eficaz. } \\
\text { Hablamos de adultos } \\
\text { con un buen } \\
\text { autoconcepto, pero } \\
\text { sobretodo, que se } \\
\text { valoran y quieren como } \\
\text { son. Son personas que } \\
\text { valoran positivamente } \\
\text { sus actitudes y } \\
\text { capacidades en los }\end{array}$ & $\begin{array}{l}\text { Tipo I: Eficaz . Esta } \\
\text { tipología de sujetos } \\
\text { demuestra } \\
\text { puntuaciones } \\
\text { superiores a la media } \\
\text { en los cuatro factores } \\
\text { del cuestionario. Los } \\
\text { adultos que pertenecen } \\
\text { a este cluster presentan } \\
\text { puntuaciones cercanas } \\
\text { por encima del centil } \\
75 \text { en todos los } \\
\text { factores. } \\
\text { Representarían el } \\
\text { prototipo de Persona } \\
\text { Eficaz. } \\
\text { Hablamos de adultos } \\
\text { con un buen } \\
\text { autoconcepto, pero } \\
\text { sobretodo, que se } \\
\text { valoran y quieren como } \\
\text { son. Son adultos que } \\
\text { valoran positivamente } \\
\text { sus actitudes y } \\
\text { capacidades en los } \\
\text { principales contextos } \\
\text { en los que se } \\
\text { desenvuelven en estas } \\
\text { edades (trabajo, familia } \\
\text { v grupo de iguales). Se }\end{array}$ & $\begin{array}{l}\text { El tipo II: } \\
\text { Personalidad eficaz } \\
\text { Estaría caracterizado } \\
\text { por puntuaciones altas } \\
\text { en Fortalezas y } \\
\text { Relaciones y } \\
\text { puntuaciones normales } \\
\text { e Demandas y Retos. } \\
\text { Integran este grupo } 34 \\
\text { personas. Su } \\
\text { denominación sería } \\
\text { Eficaz } \\
\text { Este perfil se } \\
\text { caracteriza por una } \\
\text { persona con un buen } \\
\text { autoconcepto, pero } \\
\text { sobretodo, que se } \\
\text { valoran y quieren como } \\
\text { es. Son adultos que } \\
\text { valoran positivamente } \\
\text { sus actitudes y } \\
\text { capacidades en los } \\
\text { principales contextos } \\
\text { en los que se } \\
\text { desenvuelven en estas } \\
\text { edades (trabajo, familia } \\
\text { y grupo de iguales). Se } \\
\text { consideran atractivos, } \\
\text { estables } \\
\text { emocionalmente. }\end{array}$ \\
\hline
\end{tabular}




\begin{tabular}{|c|c|c|}
\hline 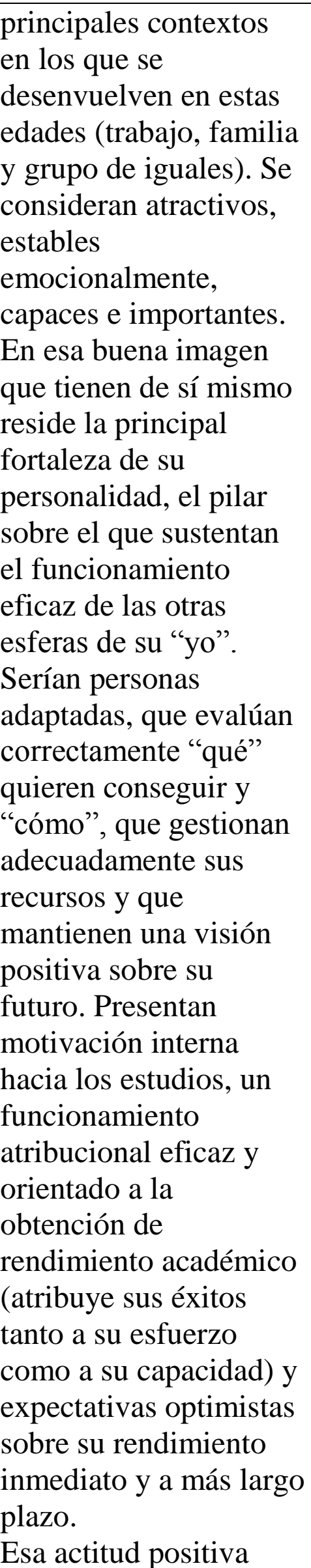 & $\begin{array}{l}\text { consideran atractivos, } \\
\text { estables } \\
\text { emocionalmente, } \\
\text { capaces e importantes. } \\
\text { En esa buena imagen } \\
\text { que tienen de sí mismo } \\
\text { reside la principal } \\
\text { fortaleza de su } \\
\text { personalidad, el pilar } \\
\text { sobre el que sustentan } \\
\text { el funcionamiento } \\
\text { eficaz de las otras } \\
\text { esferas de su "yo". } \\
\text { Serían personas } \\
\text { adaptadas, que evalúan } \\
\text { correctamente "qué” } \\
\text { quieren conseguir y } \\
\text { "cómo", que gestionan } \\
\text { adecuadamente sus } \\
\text { recursos y que } \\
\text { mantienen una visión } \\
\text { positiva sobre su } \\
\text { futuro. Presentan } \\
\text { motivación interna } \\
\text { hacia el trabajo, un } \\
\text { funcionamiento } \\
\text { atribucional eficaz y } \\
\text { orientado a la } \\
\text { obtención de } \\
\text { rendimiento profesional } \\
\text { (atribuye sus éxitos } \\
\text { tanto a su esfuerzo } \\
\text { como a su capacidad) y } \\
\text { expectativas optimistas } \\
\text { sobre su rendimiento } \\
\text { inmediato y a más largo } \\
\text { plazo. } \\
\text { fusa actitud positiva } \\
\text { aute a } \\
\text { estables }\end{array}$ & 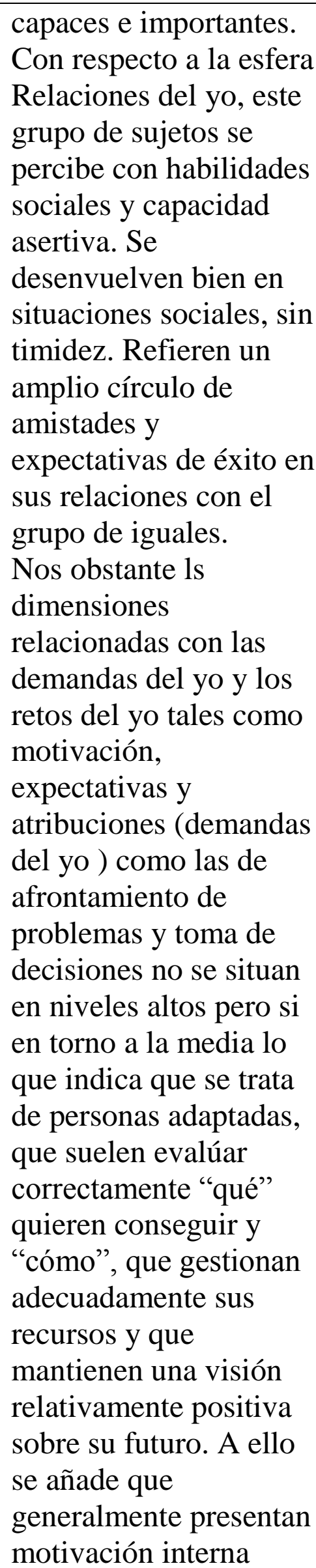 \\
\hline
\end{tabular}




\begin{tabular}{|c|c|c|}
\hline $\begin{array}{l}\text { frente a } \\
\text { acontecimientos } \\
\text { futuros, su } \\
\text { autopercepción como } \\
\text { estables } \\
\text { emocionalmente, la } \\
\text { adecuada gestión de sus } \\
\text { recursos y la capacidad } \\
\text { para establecer } \\
\text { atribuciones de forma } \\
\text { correcta sobre lo que } \\
\text { les ocurre, explican en } \\
\text { gran medida su buen } \\
\text { funcionamiento a la } \\
\text { hora de afrontar } \\
\text { problemas y tomar } \\
\text { decisiones (esfera } \\
\text { Retos del yo). No } \\
\text { adoptarán actitudes } \\
\text { pasivas de } \\
\text { afrontamiento, ni } \\
\text { esperarán a que otros } \\
\text { les resuelvan sus } \\
\text { problemas. Se juzgarán } \\
\text { capaces de resolverlos } \\
\text { y antes de tomar una } \\
\text { decisión reflexionarán } \\
\text { sobre sus } \\
\text { consecuencias, } \\
\text { manteniendo una } \\
\text { postura confiada y } \\
\text { optimista sobre su } \\
\text { resolución. } \\
\text { Con respecto a la esfera } \\
\text { Relaciones del yo, este } \\
\text { grupo de sujetos se } \\
\text { percibe con habilidades } \\
\text { sociales y capacidad } \\
\text { asertiva. Se } \\
\text { desenvuelven bien en } \\
\text { situaciones sociales, sin } \\
\text { timidez. Refieren un } \\
\text { amplio círculo de } \\
\text { andiola }\end{array}$ & $\begin{array}{l}\text { emocionalmente, la } \\
\text { adecuada gestión de sus } \\
\text { recursos y la capacidad } \\
\text { para establecer } \\
\text { atribuciones de forma } \\
\text { correcta sobre lo que } \\
\text { les ocurre, explican en } \\
\text { gran medida su buen } \\
\text { funcionamiento a la } \\
\text { hora de afrontar } \\
\text { problemas y tomar } \\
\text { decisiones (esfera } \\
\text { Retos del yo). No } \\
\text { adoptarán actitudes } \\
\text { pasivas de } \\
\text { afrontamiento, ni } \\
\text { esperarán a que otros } \\
\text { les resuelvan sus } \\
\text { problemas. Se juzgarán } \\
\text { capaces de resolverlos } \\
\text { y antes de tomar una } \\
\text { decisión reflexionarán } \\
\text { sobre sus } \\
\text { consecuencias, } \\
\text { manteniendo una } \\
\text { postura confiada y } \\
\text { optimista sobre su } \\
\text { resolución. } \\
\text { Con respecto a la esfera } \\
\text { Relaciones del yo, este } \\
\text { grupo de sujetos se } \\
\text { percibe con habilidades } \\
\text { sociales y capacidad } \\
\text { asertiva. Se } \\
\text { desenvuelven bien en } \\
\text { situaciones sociales, sin } \\
\text { timidez. Refieren un } \\
\text { amplio círculo de } \\
\text { amistades y } \\
\text { expectativas de éxito en } \\
\text { sus relaciones con el } \\
\text { grupo de iguales. } \\
\text { Así, las personas }\end{array}$ & $\begin{array}{l}\text { hacia el trabajo, un } \\
\text { funcionamiento } \\
\text { atribucional eficaz y } \\
\text { orientado a la } \\
\text { obtención de } \\
\text { rendimiento profesional } \\
\text { (atribuye sus éxitos } \\
\text { tanto a su esfuerzo } \\
\text { como a su capacidad) y } \\
\text { expectativas optimistas } \\
\text { sobre su rendimiento } \\
\text { inmediato y a más } \\
\text { largo plazo. } \\
\text { Igualmente presenta } \\
\text { una adecuada gestión } \\
\text { de sus recursos y de } \\
\text { afrontar problemas y } \\
\text { tomar decisiones } \\
\text { (esfera Retos del yo). } \\
\text { No adoptarán actitudes } \\
\text { pasivas de } \\
\text { afrontamiento, ni } \\
\text { esperarán a que otros } \\
\text { les resuelvan sus } \\
\text { problemas. Se juzgarán } \\
\text { capaces de resolverlos } \\
\text { y antes de tomar una } \\
\text { decisión reflexionarán } \\
\text { sobre sus } \\
\text { consecuencias, } \\
\text { manteniendo una } \\
\text { postura confiada y } \\
\text { optimista sobre su } \\
\text { resolución. } \\
\text { La eficacia tiene sus } \\
\text { fundamentos en sus } \\
\text { fortalezas que le hace } \\
\text { proyectar seguridad } \\
\text { cara al resto de las } \\
\text { dimensiones de su } \\
\text { personalidad. Si este } \\
\text { primera dimensión los } \\
\text { motivos, las }\end{array}$ \\
\hline
\end{tabular}




\begin{tabular}{|c|c|c|}
\hline $\begin{array}{l}\text { amistades y } \\
\text { expectativas de éxito en } \\
\text { sus relaciones con el } \\
\text { grupo de iguales. } \\
\text { Así, las personas } \\
\text { encuadradas dentro del } \\
\text { Tipo IV son adultos } \\
\text { con buen autoconcepto } \\
\text { y alta autoestima, con } \\
\text { motivación orientada a } \\
\text { la tarea, un estilo } \\
\text { atribucional adaptativo, } \\
\text { expectativas optimistas } \\
\text { sobre su futuro, estilo } \\
\text { resolutivo en el } \\
\text { afrontamiento de sus } \\
\text { problemas y buena } \\
\text { capacidad asertiva y } \\
\text { comunicativa. } \\
\text { La muestra de esta } \\
\text { tipología es la que } \\
\text { como la más numerosa } \\
\text {.. }\end{array}$ & $\begin{array}{l}\text { encuadradas dentro del } \\
\text { Tipo I son adultos con } \\
\text { buen autoconcepto y } \\
\text { alta autoestima, con } \\
\text { motivación orientada a } \\
\text { la tarea, un estilo } \\
\text { atribucional adaptativo, } \\
\text { expectativas optimistas } \\
\text { sobre su futuro, estilo } \\
\text { resolutivo en el } \\
\text { afrontamiento de sus } \\
\text { problemas y buena } \\
\text { capacidad asertiva y } \\
\text { comunicativa. } \\
\text { La muestra de esta } \\
\text { tipología es mayor que } \\
\text { el resto con 203, } \\
\text { aspecto que } \\
\text { consideramos positivo } \\
\text { ya que es la tipología } \\
\text { donde se representa un } \\
\text { buen funcionamiento } \\
\text { de la personalidad } \\
\text { eficaz en todas sus } \\
\text { dimensiones }\end{array}$ & $\begin{array}{l}\text { expectativas, las } \\
\text { atribuciones de } \\
\text { causalidad, los } \\
\text { afrontamientos de } \\
\text { problemas, las tomas } \\
\text { de decisiones y las } \\
\text { relaciones sociales }\end{array}$ \\
\hline $\begin{array}{l}\text { Tipo III: Ineficaz } \\
\text { Social Los sujetos que } \\
\text { quedan enmarcados } \\
\text { dentro de este clúster } \\
\text { presentan puntuaciones } \\
\text { muy bajas en tres } \\
\text { factores del } \\
\text { cuestionario CPE- } \\
\text { Adultos: Fortalezas, } \\
\text { Demandas y Retos del } \\
\text { YO. Por el contrario, } \\
\text { la única dimensión que } \\
\text { presenta un } \\
\text { funcionamiento por } \\
\text { encima de la media es } \\
\text { las Relaciones del yo } \\
\text { cuyo percentil se sitúa } \\
\text { por encima de } 50 .\end{array}$ & $\begin{array}{l}\text { Tipo II: Ineficaz } \\
\text { social. Los sujetos que } \\
\text { quedan enmarcados } \\
\text { dentro de este clúster } \\
\text { presentan puntuaciones } \\
\text { bajas en tres factores } \\
\text { del cuestionario CPE- } \\
\text { Adultos. Demanmadas } \\
\text { y Retos están en torno } \\
\text { al centil } 30 \text { y el centil } \\
40 \text { en Fortalezas . Por } \\
\text { el contrario, el único } \\
\text { factor que presenta un } \\
\text { funcionamiento eficaz } \\
\text { es Relaciones del yo } \\
\text { cuyo percentil se sitúa } \\
\text { por encima de } 60 \text {. } \\
\text { Muestran, por tanto, }\end{array}$ & $\begin{array}{l}\text { El tipo IV Ineficaz } \\
\text { resolutivo } \\
\quad \text { Estaría caracterizado } \\
\text { por puntuaciones bajas } \\
\text { en Fortalezas, } \\
\text { Demandas y } \\
\text { Relaciones y normales } \\
\text { en Retos. } \\
\text { Los sujetos que quedan } \\
\text { enmarcados dentro de } \\
\text { este clúster presentan } \\
\text { una valoración negativa } \\
\text { de sí mismos y cierta } \\
\text { dificultad en sus } \\
\text { relaciones sociales } \\
\text { junto con una baja } \\
\text { motivación intrínseca } \\
\text { hacia las tareas, la falta }\end{array}$ \\
\hline
\end{tabular}




\begin{tabular}{|c|c|c|}
\hline $\begin{array}{l}\text { Demuestran, por tanto, } \\
\text { una valoración negativa } \\
\text { de sí mismos y en } \\
\text { resolución de } \\
\text { problemas, destacando } \\
\text { la falta de una } \\
\text { motivación interna, } \\
\text { atribución a esfuerzo o } \\
\text { capacidad y } \\
\text { expectativas de éxito. } \\
\text { Estamos hablando de } \\
\text { adultos caracterizados } \\
\text { por buenas relaciones } \\
\text { con los iguales y para } \\
\text { desenvolverse en } \\
\text { situaciones sociales de } \\
\text { manera adaptativa, pero } \\
\text { con carencias en } \\
\text { competencias de } \\
\text { afrontamiento de } \\
\text { problemas y la toma de } \\
\text { decisiones, con baja } \\
\text { autoestima, y presentan } \\
\text { escasa motivación } \\
\text { laboral repercutiendo } \\
\text { en su rendimiento. Sus } \\
\text { atribuciones no } \\
\text { presentan locus de } \\
\text { control interno, y se } \\
\text { perciben con falta de } \\
\text { aptitudes para obtener } \\
\text { buen rendimiento. }\end{array}$ & 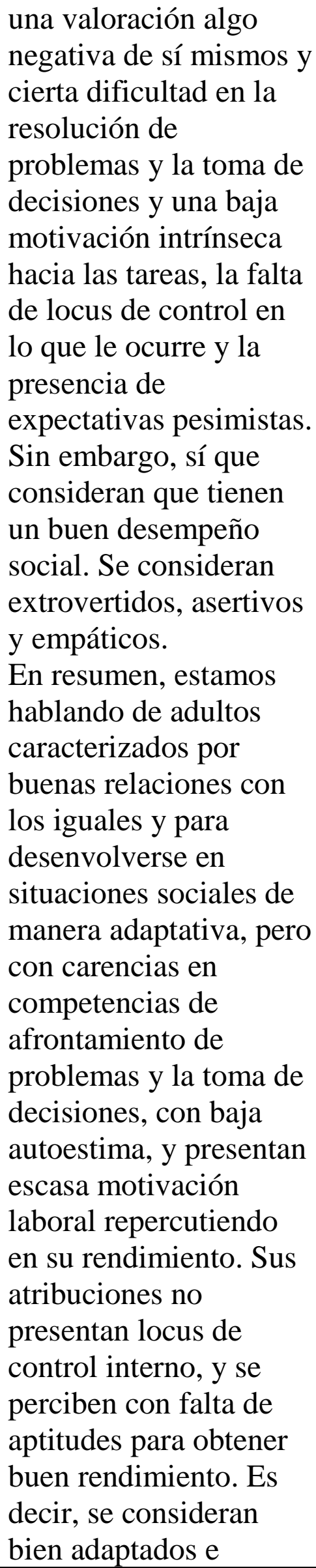 & 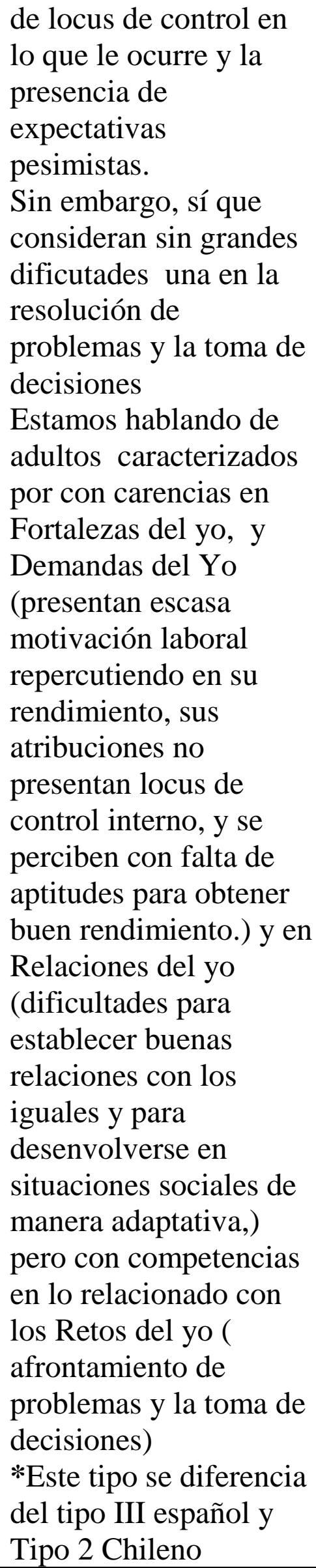 \\
\hline
\end{tabular}




\begin{tabular}{|c|c|c|}
\hline & $\begin{array}{l}\text { integrados socialmente } \\
\text { a pesar de la mala } \\
\text { imagen que tienen de sí } \\
\text { mismos en los otros } \\
\text { tres factores del } \\
\text { cuestionario. }\end{array}$ & $\begin{array}{l}\text { únicamente en la } \\
\text { dimensión Relaciones. } \\
\text { Las valoraciones } \\
\text { relativamente normales } \\
\text { hacia altas en retos es u } \\
\text { diferencia. No obstante } \\
\text { le incluimos en el } \\
\text { grupo de ineficacia en } \\
\text { razón a que las raíces } \\
\text { de la eficacia como don } \\
\text { las Fortalezas y las } \\
\text { Demandas son bajas. }\end{array}$ \\
\hline $\begin{array}{l}\text { Tipo II: Ineficaz. Los } \\
\text { sujetos que quedan } \\
\text { enmarcados dentro de } \\
\text { este clúster presentan } \\
\text { puntuaciones muy bajas } \\
\text { en los cuatro factores } \\
\text { del cuestionario de } \\
\text { Personalidad Eficaz: } \\
\text { Fortalezas del yo, } \\
\text { Demandas del yo, } \\
\text { Retos del yo y } \\
\text { Relaciones del yo. } \\
\text { Se ven a ellos mismo } \\
\text { como problemáticos, } \\
\text { poco importantes y en } \\
\text { desacuerdo con su } \\
\text { forma de ser y actuar. } \\
\text { No se gustan ni físicas, } \\
\text { ni emocionalmente. } \\
\text { Presentan una baja } \\
\text { autoestima como } \\
\text { trabajadores y como } \\
\text { amigos, repercutiendo } \\
\text { en sus labores y en sus } \\
\text { relaciones con los } \\
\text { iguales. La imagen } \\
\text { negativa que tienen de } \\
\text { sí mismos afecta a las } \\
\text { otras esferas de su yo } \\
\text { desembocando en un } \\
\text { funcionamiento poco }\end{array}$ & $\begin{array}{l}\text { Tipo IV: Ineficaz. Los } \\
\text { sujetos que quedan } \\
\text { enmarcados dentro de } \\
\text { este clúster presentan } \\
\text { puntuaciones muy bajas } \\
\text { en los cuatro factores } \\
\text { del cuestionario de } \\
\text { Personalidad Eficaz } \\
\text { CPE-A. En Demandas } \\
\text { y Fortalezas puntúan } \\
\text { por debajo del percentil } \\
\text { 10. Y en Retos y } \\
\text { Relaciones, por debajo } \\
\text { del percentil 20. } \\
\text { Se ven a ellos mismo } \\
\text { como problemáticos, } \\
\text { poco importantes y en } \\
\text { desacuerdo con su } \\
\text { forma de ser y actuar. } \\
\text { No se gustan ni física, } \\
\text { ni emocionalmente. } \\
\text { Presentan una baja } \\
\text { autoestima como } \\
\text { trabajadores y como } \\
\text { amigos, repercutiendo } \\
\text { en sus labores y en sus } \\
\text { relaciones con los } \\
\text { iguales. La imagen } \\
\text { negativa que tienen de } \\
\text { sí mismos afecta a las } \\
\text { otras esferas de su yo }\end{array}$ & $\begin{array}{l}\text { El tipo III Ineficaz } \\
\text { Estarían caracterizado } \\
\text { estas personas por } \\
\text { puntuaciones bajas en } \\
\text { todas las dimensiones: } \\
\text { Fortalezas, Demandas, } \\
\text { Retos y relaciones. Su } \\
\text { denominación sería } \\
\text { Ineficacia acusada. } \\
\text { Los sujetos que quedan } \\
\text { enmarcados dentro de } \\
\text { este clúster se ven a } \\
\text { ellos mismo como } \\
\text { problemáticos, poco } \\
\text { importantes y en } \\
\text { desacuerdo con su } \\
\text { forma de ser y actuar. } \\
\text { No se gustan ni física, } \\
\text { ni emocionalmente. } \\
\text { Presentan una baja } \\
\text { autoestima como } \\
\text { trabajadores y como } \\
\text { amigos, repercutiendo } \\
\text { en sus labores y en sus } \\
\text { relaciones con los } \\
\text { iguales. } \\
\text { Es decir la dimensión } \\
\text { Fortalezas del yo } \\
\text { constitutivas o eje de la } \\
\text { eficacia está por debajo } \\
\text { de los niveles mínimos }\end{array}$ \\
\hline
\end{tabular}




\begin{tabular}{|c|c|c|}
\hline $\begin{array}{l}\text { adaptativo o lo que } \\
\text { podríamos llamar, } \\
\text { siguiendo con la } \\
\text { terminología del } \\
\text { constructo, } \\
\text { "Personalidad } \\
\text { Ineficaz". } \\
\text { Representarían la } \\
\text { antítesis del sujeto } \\
\text { prototipo de } \\
\text { "Personalidad Eficaz" } \\
\text { (Tipo IV), que cuenta } \\
\text { con un amplio abanico } \\
\text { de competencias } \\
\text { personales y sociales } \\
\text { para desenvolverse en } \\
\text { su vida cotidiana. } \\
\text { Presenta escasa } \\
\text { motivación laboral } \\
\text { repercutiendo en su } \\
\text { rendimiento. Sus } \\
\text { atribuciones no } \\
\text { presentan locus de } \\
\text { control interno, y se } \\
\text { perciben con falta de } \\
\text { aptitudes para obtener } \\
\text { buen rendimiento. Esto } \\
\text { repercute en una visión } \\
\text { pesimista sobre } \\
\text { acontecimientos } \\
\text { futuros. En el contexto } \\
\text { laboral se concreta en } \\
\text { la creencia de que en la } \\
\text { actualidad su } \\
\text { rendimiento será bajo o } \\
\text { que en el futuro no les } \\
\text { va a ir bien, pudiendo } \\
\text { desembocar en } \\
\text { "profecías } \\
\text { autocumplidas" por las } \\
\text { escasas herramientas } \\
\text { que estos sujetos } \\
\text { despliegan para hacer }\end{array}$ & $\begin{array}{l}\text { desembocando en un } \\
\text { funcionamiento poco } \\
\text { adaptativo o lo que } \\
\text { podríamos llamar, } \\
\text { siguiendo con la } \\
\text { terminología del } \\
\text { constructo, } \\
\text { "Personalidad } \\
\text { Ineficaz". } \\
\text { Representarían la } \\
\text { antítesis del sujeto } \\
\text { prototipo de } \\
\text { "Personalidad Eficaz" } \\
\text { (Tipo I), que cuenta } \\
\text { con un amplio abanico } \\
\text { de competencias } \\
\text { personales y sociales } \\
\text { para desenvolverse en } \\
\text { su vida cotidiana. } \\
\text { Presenta escasa } \\
\text { motivación laboral } \\
\text { repercutiendo en su } \\
\text { rendimiento. Sus } \\
\text { atribuciones no } \\
\text { presentan locus de } \\
\text { control interno, y se } \\
\text { perciben con falta de } \\
\text { aptitudes para obtener } \\
\text { buen rendimiento. Esto } \\
\text { repercute en una visión } \\
\text { pesimista sobre } \\
\text { acontecimientos } \\
\text { futuros. En el contexto } \\
\text { laboral se concreta en } \\
\text { la creencia de que en la } \\
\text { actualidad su } \\
\text { rendimiento será bajo o } \\
\text { que en el futuro no les } \\
\text { va a ir bien, pudiendo } \\
\text { desembocar en } \\
\text { "profecías } \\
\text { autocumplidas" por las } \\
\text { escasas herramientas }\end{array}$ & $\begin{array}{l}\text { de aceptabilidad. } \\
\text { Las demandas del yo } \\
\text { igualmente está por } \\
\text { debajo de esos niveles } \\
\text { mínimos . De forma } \\
\text { más concreta presentan } \\
\text { escasa motivación } \\
\text { laboral o en su caso } \\
\text { ocupacional } \\
\text { repercutiendo en su } \\
\text { rendimiento. Sus } \\
\text { atribuciones no } \\
\text { presentan locus de } \\
\text { control interno, y se } \\
\text { perciben con falta de } \\
\text { aptitudes para obtener } \\
\text { buen rendimiento. Esto } \\
\text { repercute en una visión } \\
\text { pesimista sobre } \\
\text { acontecimientos } \\
\text { futuros. } \\
\text { La dimensión Retos } \\
\text { del yo son igualmente } \\
\text { bajas. Muestran } \\
\text { dificultades en el } \\
\text { afrontamiento de } \\
\text { problemas y la toma de } \\
\text { decisiones, presentando } \\
\text { dificultades para } \\
\text { decidir por sí mismos y } \\
\text { optando por una actitud } \\
\text { en ocasiones pasiva, y } \\
\text { en ocasiones impulsiva, } \\
\text { a la hora de abordar } \\
\text { conflictos. } \\
\text { Y finalmente la } \\
\text { dimensión retos del yo } \\
\text { son también bajas } \\
\text { Se perciben con pocas } \\
\text { amistades y dificultad } \\
\text { para relacionarse con } \\
\text { sus iguales. } \\
\text { Manifiestan }\end{array}$ \\
\hline
\end{tabular}




\begin{tabular}{|c|c|c|}
\hline $\begin{array}{l}\text { frente a las creencias } \\
\text { negativas que tienen de } \\
\text { sí mismos, y que queda } \\
\text { reflejado en sus bajas } \\
\text { puntuaciones en el } \\
\text { factor Retos del yo. } \\
\text { Muestran dificultades } \\
\text { en el afrontamiento de } \\
\text { problemas y la toma de } \\
\text { decisiones, presentando } \\
\text { dificultades para } \\
\text { decidir por sí mismos y } \\
\text { optando por una actitud } \\
\text { en ocasiones pasiva, y } \\
\text { en ocasiones impulsiva, } \\
\text { a la hora de abordar } \\
\text { conflictos. Poniendo en } \\
\text { relación estas actitudes } \\
\text { y la pobre imagen que } \\
\text { tienen de sí mismos se } \\
\text { hace difícil que, por } \\
\text { ellos mismos, den el } \\
\text { paso de "tomar las } \\
\text { riendas" ante las } \\
\text { dificultades o pongan } \\
\text { en marcha recursos que } \\
\text { les permitan mejorar su } \\
\text { autoestima. } \\
\text { Se perciben con pocas } \\
\text { amistades y dificultad } \\
\text { para relacionarse con } \\
\text { sus iguales. } \\
\text { Manifiestan } \\
\text { expectativas de fracaso } \\
\text { en relaciones sociales } \\
\text { hipotéticas futuras. Sus } \\
\text { escasas capacidades } \\
\text { empática y asertiva y } \\
\text { sus problemas a la hora } \\
\text { de desenvolverse en } \\
\text { situaciones social } \\
\text { explican las bajas } \\
\text { puntuaciones en el }\end{array}$ & $\begin{array}{l}\text { que estos sujetos } \\
\text { despliegan para hacer } \\
\text { frente a las creencias } \\
\text { negativas que tienen de } \\
\text { sí mismos, y que queda } \\
\text { reflejado en sus bajas } \\
\text { puntuaciones en el } \\
\text { factor Retos del yo. } \\
\text { Muestran dificultades } \\
\text { en el afrontamiento de } \\
\text { problemas y la toma de } \\
\text { decisiones, presentando } \\
\text { dificultades para } \\
\text { decidir por sí mismos y } \\
\text { optando por una actitud } \\
\text { en ocasiones pasiva, y } \\
\text { en ocasiones impulsiva, } \\
\text { a la hora de abordar } \\
\text { conflictos. Poniendo en } \\
\text { relación estas actitudes } \\
\text { y la pobre imagen que } \\
\text { tienen de sí mismos se } \\
\text { hace difícil que, por } \\
\text { ellos mismos, den el } \\
\text { paso de "tomar las } \\
\text { riendas" ante las } \\
\text { dificultades o pongan } \\
\text { en marcha recursos que } \\
\text { les permitan mejorar su } \\
\text { autoestima. } \\
\text { Se perciben con pocas } \\
\text { amistades y dificultad } \\
\text { para relacionarse con } \\
\text { sus iguales. } \\
\text { Manifiestan } \\
\text { expectativas de fracaso } \\
\text { en relaciones sociales } \\
\text { hipotéticas futuras. Sus } \\
\text { escasas capacidades } \\
\text { empática y asertiva y } \\
\text { sus problemas a la hora } \\
\text { de desenvolverse en } \\
\text { situaciones social }\end{array}$ & $\begin{array}{l}\text { expectativas de fracaso } \\
\text { en relaciones sociales } \\
\text { hipotéticas futuras. Sus } \\
\text { escasas capacidades } \\
\text { empática y asertiva y } \\
\text { sus problemas a la hora } \\
\text { de desenvolverse en } \\
\text { situaciones social están } \\
\text { presentes y le } \\
\text { condicionan bastante } \\
\text { en su vida normal. } \\
\text { Esta ineficacia tiene } \\
\text { igualmente su base en } \\
\text { las deficiencias en la } \\
\text { dimensión Fortalezas } \\
\text { del yo. Un desfigurado } \\
\text { autoconcepto } \\
\text { acompañado de la } \\
\text { consiguiente baja } \\
\text { autoestima va incidir en } \\
\text { toda su actividad } \\
\text { personal y relacionar. } \\
\text { Sin duda influye en sus } \\
\text { motivaciones en sus } \\
\text { atribuciones y en sus } \\
\text { expectativas. No cree } \\
\text { en si mismo y en } \\
\text { consecuencia no tiene } \\
\text { grandes expectativas y } \\
\text { en ocasiones se las } \\
\text { plantea a corto plazo y } \\
\text { sin grandes } \\
\text { pretensiones } \\
\text { La secuencia lógica de } \\
\text { este proceso le lleva a } \\
\text { afrontar los problemas } \\
\text { de una forma más } \\
\text { pasiva que activa } \\
\text { dejando en muchas } \\
\text { ocasiones a la suerte y } \\
\text { al azar o a los demás la } \\
\text { resolución de los } \\
\text { problemas y la toma de }\end{array}$ \\
\hline
\end{tabular}




\begin{tabular}{|c|c|c|}
\hline $\begin{array}{l}\text { segundo factor del } \\
\text { cuestionario, aunque } \\
\text { estas se sitúan dentro } \\
\text { de la normalidad. } \\
\text { Son por tanto adultos } \\
\text { que presentan } \\
\text { cogniciones y } \\
\text { comportamientos } \\
\text { desadaptativos: baja } \\
\text { autoestima, escasa } \\
\text { motivación laboral (ni } \\
\text { de logro, ni orientada a } \\
\text { la tarea), expectativas } \\
\text { pesimistas, déficit en } \\
\text { habilidades sociales y } \\
\text { dificultades para } \\
\text { afrontar dificultades de } \\
\text { su día a día. } \\
\text { Hablaríamos, como ya } \\
\text { se ha señalado, de } \\
\text { Personalidad Ineficaz. } \\
\text { Por otro lado, la } \\
\text { muestra integrante en } \\
\text { esta tipología, } \\
\text { representa el menor } \\
\text { número de todas las } \\
\text { cuatro tipologías } \\
\text { encontradas. }\end{array}$ & $\begin{array}{l}\text { explican las bajas } \\
\text { puntuaciones en el } \\
\text { segundo factor del } \\
\text { cuestionario, aunque } \\
\text { estas se sitúan dentro } \\
\text { de la normalidad. } \\
\text { Son por tanto adultos } \\
\text { que presentan } \\
\text { cogniciones y } \\
\text { comportamientos } \\
\text { desadaptativos: baja } \\
\text { autoestima, escasa } \\
\text { motivación laboral (ni } \\
\text { de logro, ni orientada a } \\
\text { la tarea), expectativas } \\
\text { pesimistas, déficit en } \\
\text { habilidades sociales y } \\
\text { dificultades para } \\
\text { afrontar dificultades de } \\
\text { su día a día. } \\
\text { Hablaríamos, como ya } \\
\text { se ha señalado, de } \\
\text { Personalidad Ineficaz. } \\
\text { La muestra integrante } \\
\text { en esta tipología, } \\
\text { representa el menor } \\
\text { número de sujetos de } \\
\text { todas las tipologías }\end{array}$ & $\begin{array}{l}\text { decisiones. Esto genera } \\
\text { un alto grado de } \\
\text { ineficacia- }\end{array}$ \\
\hline $\begin{array}{l}\text { Tipo I: Eficaz } \\
\text { Introvertido. Estos } \\
\text { sujetos presentan un } \\
\text { buen funcionamiento } \\
\text { en dos de las cuatro } \\
\text { esferas del yo que } \\
\text { conforman el } \\
\text { cuestionario de } \\
\text { Personalidad Eficaz. } \\
\text { Puntúan por encima de } \\
\text { la media, en los } \\
\text { factores Demandas de } \\
\text { yo y Retos del yo. Son } \\
\text { sujetos con valores }\end{array}$ & $\begin{array}{l}\text { Tipo III: Eficaz } \\
\text { Introvertido. Estos } \\
\text { sujetos presentan un } \\
\text { buen funcionamiento } \\
\text { en tres de los cuatro } \\
\text { factores que conforman } \\
\text { el cuestionario de } \\
\text { Personalidad Eficaz. } \\
\text { Relaciones del yo } \\
\text { Autorrealización Social } \\
\text { el que funciona de } \\
\text { manera diferente al } \\
\text { resto. Sería la tipología } \\
\text { opuesta a la II. }\end{array}$ & $\begin{array}{l}\text { EI tipo I : Eficaz } \\
\text { Introvertido } \\
\text { Estaría caracterizado } \\
\text { por puntuaciones } \\
\text { normales en Fortalezas, } \\
\text { demandas y Retos y } \\
\text { bajo en Relaciones. } \\
\text { Su denominación seria } \\
\text { Eficaz introvertido } \\
\text { Representa a una } \\
\text { persona que en lo que } \\
\text { respecta a las fortalezas } \\
\text { del yo se acepta } \\
\text { físicamente, se siente }\end{array}$ \\
\hline
\end{tabular}




\begin{tabular}{|c|c|c|}
\hline $\begin{array}{l}\text { ligeramente superiores } \\
\text { a la media en } \\
\text { motivación orientada a } \\
\text { la tarea. Establecen } \\
\text { atribuciones de éxito } \\
\text { (debidas al esfuerzo o } \\
\text { la capacidad) en la } \\
\text { mayoría de las } \\
\text { situaciones, y por lo } \\
\text { general, suelen } \\
\text { mantener expectativas } \\
\text { de éxito futuro. } \\
\text { Frecuentemente } \\
\text { adoptan una } \\
\text { perspectiva resolutiva a } \\
\text { la hora de abordar } \\
\text { situaciones } \\
\text { problemáticas, } \\
\text { reflexionando antes de } \\
\text { tomar una decisión o } \\
\text { actuar. } \\
\text { Esta tipología pone de } \\
\text { manifiesto la relación } \\
\text { existente entre las } \\
\text { variables motivación, } \\
\text { atribución y } \\
\text { expectativas y las } \\
\text { variables afrontamiento } \\
\text { de problemas y toma de } \\
\text { decisiones. Una visión } \\
\text { optimista de los } \\
\text { problemas y la } \\
\text { confianza en que se } \\
\text { superarán; un estilo } \\
\text { atribucional con locus } \\
\text { de control interno que } \\
\text { les permite partir de la } \\
\text { idea de que con más } \\
\text { esfuerzo se superan las } \\
\text { dificultades, así como } \\
\text { las atribuciones de } \\
\text { éxitos pasados a sus } \\
\text { capacidades; y el }\end{array}$ & \begin{tabular}{l}
\multicolumn{1}{c}{ Son sujetos con } \\
valores ligeramente \\
superiores a la media \\
en motivación \\
orientada a la tarea, \\
autoestima y \\
autoconcepto y en \\
afrontamiento y \\
resolución de \\
problemas. Establecen \\
atribuciones de éxito \\
(debidas al esfuerzo o \\
la capacidad) en la \\
mayoría de las \\
situaciones, y por lo \\
general, suelen \\
mantener expectativas \\
de éxito futuro. \\
Frecuentemente \\
adoptan una \\
perspectiva resolutiva a \\
la hora de abordar \\
situaciones \\
problemáticas, \\
reflexionando antes de \\
tomar una decisión o \\
actuar. \\
Presentan una visión \\
optimista de los \\
problemas y la \\
confianza en que se \\
superarán; un estilo \\
atribucional con locus \\
de control interno que \\
les permite partir de la \\
idea de que con más \\
esfuerzo se superan las \\
dificultades, así como \\
las atribuciones de \\
éxitos pasados a sus \\
capacidades; y el \\
disfrute (o motivación) \\
que nace del propio \\
\end{tabular} & $\begin{array}{l}\text { satisfecho y se acepta } \\
\text { como es con sus } \\
\text { cualidades y defectos, } \\
\text { sintiéndose orgulloso } \\
\text { de algunas de ellas. } \\
\text { Intenta que las cosas } \\
\text { que emprende le } \\
\text { resulten bien pues } \\
\text { confía en su talento } \\
\text { para ello y se considera } \\
\text { una persona valiosa } \\
\text { para los demás. } \\
\text { En lo que respecta a las } \\
\text { demandas del yo piensa } \\
\text { que sus éxitos } \\
\text { porfesionaless se deben } \\
\text { a su esfuerzo, } \\
\text { dedicación y capacidad } \\
\text { de trabajo y en general } \\
\text { tiene expectativas de } \\
\text { éxito en lo que } \\
\text { emprende. } \\
\text { En lo que respecta a } \\
\text { Retos tiende a } \\
\text { planificar bien los } \\
\text { pasos que debe hacer } \\
\text { antes de tomar una } \\
\text { decisión reuniendo la } \\
\text { máxima información } \\
\text { posible, controla sus } \\
\text { emociones e intenta } \\
\text { aprender de los } \\
\text { fracasos. } \\
\text { No obstante sus } \\
\text { mayores dificultades la } \\
\text { experimentan en la } \\
\text { Relaciones del yo con } \\
\text { los demás. Se considera } \\
\text { en general con falta de } \\
\text { habilidades para iniciar } \\
\text { amistades y relaciones, } \\
\text { siendo consciente de su } \\
\text { dificultad para hacer }\end{array}$ \\
\hline
\end{tabular}




\begin{tabular}{|c|c|c|}
\hline $\begin{array}{l}\text { esferas restantes, } \\
\text { especialmente en } \\
\text { Relaciones del yo. En } \\
\text { este factor puntúan por } \\
\text { en el percentil 20, casi } \\
\text { una desviación típica } \\
\text { por debajo de la media. } \\
\text { Y en el factor } \\
\text { Fortalezas del yo } \\
\text { puntúan en el percentil } \\
\text { 40. Demuestran, por } \\
\text { tanto, una valoración } \\
\text { negativa de sí mismos, } \\
\text { pero sobretodo, déficit } \\
\text { en habilidades sociales: } \\
\text { comunicación } \\
\text { asertividad y empatía. } \\
\text { En resumen, estamos } \\
\text { hablando de adultos } \\
\text { caracterizados por un } \\
\text { estilo motivacional y } \\
\text { atribucional adaptativo, } \\
\text { expectativas optimistas } \\
\text { y competentes en el } \\
\text { afrontamiento de }\end{array}$ & $\begin{array}{l}\text { ejercicio de } \\
\text { desempeñar una tarea } \\
\text { parece tener relación } \\
\text { directa con una postura } \\
\text { resolutiva (frente a } \\
\text { evitativa o pasiva) a la } \\
\text { hora de afrontar } \\
\text { problemas y reflexiva, } \\
\text { o poco impulsiva: } \\
\text { buscando información } \\
\text { y tomando en } \\
\text { consideración distintas } \\
\text { alternativas antes de } \\
\text { actuar. } \\
\text { Sin embargo, presentan } \\
\text { deficiencias en el factor } \\
\text { Relaciones del yo. . } \\
\text { Puntúan por debajo del } \\
\text { percentil 20, } \\
\text { demostrando, por tanto, } \\
\text { déficit en habilidades } \\
\text { sociales: comunicación, } \\
\text { asertividad y empatía. } \\
\text { Se sienten poco } \\
\text { integrados y con } \\
\text { dificultades para } \\
\text { desenvolverse en } \\
\text { situaciones sociales. } \\
\text { En definitiva, estamos } \\
\text { hablando de adultos } \\
\text { caracterizados por un } \\
\text { estilo motivacional y } \\
\text { atribucional adaptativo, } \\
\text { expectativas optimistas, } \\
\text { competentes en el } \\
\text { afrontamiento de } \\
\text { problemas y la toma de } \\
\text { decisiones y con alta } \\
\text { autoestima, pero con } \\
\text { dificultades en las } \\
\text { relaciones con los } \\
\text { iguales y afrontar } \\
\text { interacciones sociales. }\end{array}$ & $\begin{array}{l}\text { amigos y del posible } \\
\text { rechazo que origine en } \\
\text { los demás por su forma } \\
\text { de ser. } \\
\text { Lo hemos clasificado } \\
\text { dentro del grupo de } \\
\text { tipos eficaces pues las } \\
\text { dimensiones } \\
\text { constitutivas de una } \\
\text { eficacia como son las } \\
\text { Fortalezas del yo, las } \\
\text { demandas del yo y los } \\
\text { retos del yo son } \\
\text { aceptables y ello le } \\
\text { beneficia a la hora de } \\
\text { ser eficaz aunque sin } \\
\text { duda alguna tiene una } \\
\text { limitación a la hora de } \\
\text { desarrollar su eficacia } \\
\text { en campos de actividad } \\
\text { social, que por otra } \\
\text { parte son los más } \\
\text { frecuentes. }\end{array}$ \\
\hline
\end{tabular}




\begin{tabular}{|l|l|}
\hline problemas y la toma de & $\begin{array}{l}\text { Tendrían dificultades } \\
\text { decisiones; pero con } \\
\text { paja autoestima, }\end{array}$ \\
dificultades en las & $\begin{array}{l}\text { derechos frente a otros, } \\
\text { para hablar en público } \\
\text { relaciones con los }\end{array}$ \\
o para interaccionar \\
iguales y para & con el otro sexo. \\
desenvolverse en & \\
situaciones sociales. & \\
En cuanto al número de & \\
sujetos de la muestra & \\
integrante en esta & \\
tipología, podemos & \\
observar que es el & \\
segundo grupo con & \\
mayor muestra &
\end{tabular}

A la luz de estos resultados se confirman las hipótesis que se formularon al principio de este trabajo en los siguientes términos:

Respecto a la Hipótesis 1: "En el periodo de edad comprendido entre los 60 y 90 años de edad se da una tipología modal multivariada en torno a la personalidad eficaz alta en todas las dimensiones que la integran". Se confirma en términos generales la hipótesis pero con algunas matizaciones que da lugar a esta nueva formulación:

Reformulación de Hipótesis 1. "En el periodo de edad comprendido entre los 60 y 90 años de edad se da una tipología modal multivariada en torno a la personalidad eficaz alta en Fortalezas Y Relaciones del yo y normales con tendencia en su caso a alta en Retos y Demandas”. 
Respecto a la Hipótesis 2: "En el periodo de edad comprendido entre los 60 y 90 años de edad se da una tipología modal multivariada en torno a la personalidad eficaz baja en todas las dimensiones que la integran" Se confirma la hipótesis en su totalidad.

Respecto a la Hipótesis 3: "En el periodo de edad comprendido entre los 60 y 90 años de edad se da una tipología modal multivariada en torno a la personalidad eficaz oscilante en todas las dimensiones que la integran", por los datos obtenidos la confirmación de esta hipótesis debería concretarse en los siguientes términos.

Hipótesis 3.1 "En el periodo de edad comprendido entre los 60 y 90 años de edad se da una tipología modal multivariada en torno a la personalidad eficaz eficaz pero con dificultades en las relaciones del Yo".

Hipótesis 3.2. En el periodo de edad comprendido entre los 60 y 90 años de edad se da una tipología modal multivariada en torno a la personalidad eficaz ineficaz pero con capacidad en lo que respecta Ralaciones del yo". 


\section{IV.CONCLUSIONES}


En este apartado una vez presentado los antecedentes relacionados con el objetivo de nuestro trabajo, formulado este, establecidas las hipótesis de partida, y empleada una metodología de carácter empírico se presentan las conclusiones finales que de forma escueta se enuncia siguiendo las normativas al uso para este tipo de trabajos.

1.Se han verificación las características psicométricas del instrumento sobre Personalidad eficaz en población adulta chilena (CPE-A) empleados en población adulta mayor de 60 años obteniendo unas características psicométricas aceptables de fiabilidad, validez y normalización del mismo lo que permite su emplea en este tipo de población.

2. No existen diferencias en la población/muestra empleadas en función de las distintas variables que se recogen tales como género, edad, nivel formativo y situación ocupacional en la que se encuentran

3. Existen diferencias significativas respecto a muestras comprendidas entre los 30 a 59 años de edad en las dimensiones de Fortalezas del yo y Relaciones del Yo.

4. Se han obtenido cuatro tipos relacionados con el constructo de Personalidad eficaz: Eficaz, Ineficaz, Eficaz introvertido e Ineficaz social 5. La hipótesis de partida relacionado con la presencia de un tipo de personalidad eficaz en el periodo de edad comprendido entre los 60 y 90 años de edad se confirma en el sentido de la presencia de una tipología modal multivariada en torno a la personalidad eficaz alta en Fortalezas y 
Relaciones del yo y normales con tendencia en su caso a alta en Retos y Demandas".

6. La hipótesis de partida que postula que en el periodo de edad comprendido entre los 60 y 90 años de edad se da una tipología modal multivariada baja en todas las dimensiones que la integran se confirma en todos sus términos.

8. Se confirma parte de la hipótesis de partida que postula que en el periodo de edad comprendido entre los 60 y 90 años de edad se da una tipología modal multivariada en torno a la personalidad eficaz con dificultades en algunas dimensiones se confirma al aparecer un tipo eficaz con dificultades en las relaciones del Yo".

9. Se confirma parte de la hipótesis de partida que postula que en el periodo de edad comprendido entre los 60 y 90 años de edad se da una tipología modal multivariada en torno a la personalidad eficaz con dificultades en algunas dimensiones se confirma al aparecer un tipo ineficaz que no presenta con dificultades en las dimensión Retos del yo. 


\section{LIMITACIONES Y}

\section{PERSPECTIVAS}


En este trabajo se ha optado por la opción de establecer Tipologias. En su lugar ya hemos indicado el alcance y las limitaciones que tiene este tipo de agrupamiento.

Por un lado las funciones y trascendencia metodológicas de la clasificación tipológica tienen un doble aspecto: la codificación y la predicción. Una tipología simplifica la ordenación de los elementos de una población y los rasgos relevantes de dicha población en agrupamientos distintos. Pero al codificar los fenómenos permite al investigador predecir las relaciones entre fenómenos que no parecían estar en conexión a simple vista. Cuanto más explícitamente enunciada esté la tipología mejor funcionará como método predictivo.

No obstante la construcción de una tipología no obedece a consideraciones lógicas sino que entraña un acto inicial de creación por parte del investigador. Al asignar un elemento de una población a un tipo dado es una condición necesaria, pero no suficiente para explicar los atributos particulares y el comportamiento de los individuos.

La explicación tipológica puede ser de utilidad para aclarar el comportamiento biológico no humano, pero las grandes diferencias de los seres humanos que resultan del aprendizaje y la elección consciente, así como la historicidad hacen que los tipos fijos sean de dudoso valor para explicar el comportamiento individual humano.

Las tipologías sirven como una primera etapa hacia un conocimiento en profundidad y originalidad individual y como tal deben considerarse.

El ser humano es el centro de un triple dinamismo. Primero está el dinamismo interno del carácter, formado por la interferencia de los rasgos que lo componen y de su intensidad. Después el dinamismo de la relación entre el carácter y los otros elementos de la personalidad, o sea, entre lo 
innato y lo adquirido. Y por último el dinamismo entre el complejo psíquico personal y el medio actual y futuro.

Es aquí donde intervienen el libre albedrío del yo, como ser con capacidad de elección, de cambio y de creación personal.

En consecuencia consideramos que la tipología es un referencial útil para hacer una primera valoración psicodiagnostica de un caso que sin dudad tiene su utilidad en el campo clínica, educativa, profesional y relacional. Pero las clasificaciones obtenidas en nuestro estudio tienen la limitación de la muestra. Es cierto que los perfiles tipológicas aquí obtenidos son coincidentes a los encontrados en investigaciones previas realizadas en otras poblaciones de edad y que posiblemente con una muestra mayor los resultados que se encuentre sean parecidos pero es bueno señalar esta limitación.

Finalmente cabe hacer una referencia a la posible modificación de los tipos hallados y en todo caso la modificación mediante el correspondiente entrenamiento en aquellos tipos con altas o moderadas deficiencias en las distintas dimensiones que componen el constructo.

El constructo sobre Personalidad eficaz ha elaborado junto con cuestionarios de medición programas de intervención para el desarrollo de los factores que integran las fortalezas del, las Demandas del yo, los Retos del yo y las relaciones del Yo. Se han hecho programas de intervención por módulos en contextos de educación primearía, secundaria, universitaria, profesional, empresarial y para la edad adulta. La pregunta que surge aquí es si es posible desarrollar un programa de intervención en estas edades de adultez mayor. Y si es positiva esta respuesta preguntarse sobre el cómo y la forma de hacerlo. Construir programas de entrenamiento para estas edades es un reto a desarrollar en un futuro. 
Compartimos la idea de que las cuatro dimensiones del constructo son entrenarles y que ese entrenamiento es constante y no admite "tregua" a lo largo de todo el Ciclo vital. En este sentido la intervención en algunos de los perfiles será puramente de mantenimiento y en otros de mayor o menor intervención, pero necesario y permanente. 


\section{REFERENCIAS BIBLIOGRÁFICAS}


Arraño, M. (2014). Evaluación del Constructo de la Personalidad Eficaz enriquecido con el Modelo Integrativo Supraparadigmático, en población adolescente entre 14 y 18 años. Tesis doctoral. Universidad de Oviedo.

Bandura, A. (1975). The ethics and social purposes of behavior modification. En C. M. Franks y G. T. Wilson (Eds.), Annual review of behavior therapy theory and practice (Vol. 3). New York: Brunner/Mazel.

Bandura, A. (1977). Social learning theory. Eglewood Cliffs. N.J: Prentice Hall.

Bandura, A. (1985). Model of causality in social learning theory. En M. J. Mahoney y A. Freeman (Eds.), Cognition and psychotherapy (pp. 81-99). New York: Plenum Publishing Corporation.

Bandura, A. (1997). Self Efficacy: the exercise of control. Englewood Cliffs, N.J: Prentice Hall.

Bar-On, R. (2006). The Bar-On model of emotional-social intelligence (ESI). Psicothema, 18(1), 13-25.

Bernal, F. (2014). Tipologías modales multivariadas de Personalidad Eficaz en contextos universitarios chilenos. Análisis de diferencias con muestras universitarias españolas. Tesis doctoral. Universidad de Oviedo. 
Bolz, C.H. (1972). Personality Types en Multivariate Personality. N.Y.: Ralph Maxion Dreger.

Bradberry, T. y Greaves, J. (2005). The Emotional Intelligence Quick Book. New York: Simon and Schuster.

Buss, A. R. y Poley, W. (1979). Diferencias individuales. Rasgos y factores. Ciudad de México: El Manual Moderno S.A.

Cattell, R.B. (1979). Rasgos. Enciclopedia Universal de las Ciencias Sociales. Madrid: Aguilar.

Cattell, R.B., Couter, M.A. y Tsujioja, B. (1966). The taxonometric recognition of types and functional emergemts. En R. Catell (Ed). Handbook of multivariate experimental psychology. Chicago: Rand McNally.

Chambers, A.L. y Wilson, M.N. (2007). Assessing male batterers with the Personality Assessment Inventor. Journal of Personality Assessment, $88,57-65$.

Coie, J.D., Dodge, K.A. y Coppotelli, H.A. (1982). Dimensions and types of social status: A cross-age perspective. Developmental Psychology, $18,557-569$.

Cronbach, L. J. (1951). Coefficient alpha and the internal structure of the tests. Psychometryka, 12, 1-16. 
Dapelo, B. y Martín del Buey, F. (2006). Estudiante Eficaz en el contexto de formación de profesores. Adaptación del cuestionario de Personalidad Eficaz al ámbito universitario. Revista de Orientación Educacional, 20(38), 63-77.

Dapelo, B. y Martín del Buey, F. (2007). Personalidad eficaz (PECE) en el contexto de la educación técnico -profesional. Revista de Orientación Educacional, 39,13-29.

Dapelo, B., Marcone, R., Martín Palacio, E., Martín del Buey, F. y Fernández, A. (2006). Adaptación Chilena del cuestionario de Personalidad Eficaz para adolescentes. Psicothema, 18 (1), 130-134.

Di Giusto, C. (2013). Evaluación de la personalidad eficaz en contextos de enseñanza secundaria: estudio comparativo entre muestra española y chilena. Tesis Doctoral. Universidad de Oviedo.

Fernández Zapico, A. (2009). Estilos de Comportamiento emocional adolescente. Tesis Doctoral. Universidad de Oviedo.

Folstein, M.F., Folstein, S.E. y McHugh, P.R. (1975). Mini-Mental State: A practical method for grading the cognitive state of pacients for the clinicial. Journal Psychiatr Res. 12: 189. 
Forttes, P. y Massad, C. (2009). Las personas mayores en Chile: Situación, avances y desafíos del envejecimiento y la vejez. Santiago de Chile: Servicio Nacional del Adulto Mayor.

Fueyo, E. (2010). Evaluación de la Personalidad Eficaz en segundo y tercer ciclo de Educación Primaria. Tesis doctoral. Universidad de Oviedo.

Gardner, H. (1999). Inteligence Reframed: Multiple Intelligences for the 21 st Century. Nueva York: Basisc Books.

Garmezy, N. y Masten, A. (1991). The protective role of competence indicators in children at risk. En E. M. Cummings, A.L. Greene y K.K. Karraker (Eds), Life-span developmental psychology: perspectives on stress and coping (pp.151-176). Hillsdale, NJ: Erlbaum.

Goleman, D. (1998). La inteligencia emocional en la empresa. Vergara: Argentina.

Gómez, R. (2012). Evaluación de la personalidad eficaz en población universitaria. Tesis Doctoral. Universidad de Huelva.

Heath, D.H. (1965). Explorations of maturitu. N.Y., Apleton: Century Crofts

Holtzworth-Munroe, A., Meehan, J.C., Herron, K., Rehman, U., y Stuart, G.L. (2003). Do subtypes of martially violent men continue to differ 
over time? Journal of Consulting and Clinical Psychology, 71, 728740.

Holtzworth-Munroe, A., y Stuart, G. L. (1994). Typologies of male batterers: Three subtypes and the differences among them. Psychological Bulletin, 116, 476-497

Huss, M.T. y Ralston, A. (2008). Do batterer subtypes actually matter? Treatment completion, treatment response and recidivism across a batterer typology. Criminal Justice and Behavior, 35, 710-724.

Loinaz, I., Echeburúa, E. y Torrubia, R. (2010). Tipología de Agresores contra la Pareja en Prisión. Psicothema, 22(1), 106-111.

López Pérez, J.M. (2011). Tipologías modales multivariadas de Personalidad Eficaz en población adulta de 30 a 60 años. Tesis doctoral. Universidad de Oviedo.

Maassen, G.H., Akkermans, W., y van der Linden, J.L. (1996). Two dimensional sociometric status determination with rating scales. Small Group Research, 27, 56-78.

Maassen, G.H. y Landsheer, H.A. (1998). SSRAT: The processing or rating scales for the determination of two-dimensional sociometric status. Behavior Researh Methods, Instruments and Computers, 30, 674679. 
Maassen, G.H., Steenbeek, H., y van Geert, P. (2004). Stability of three methods for two-dimensional sociometric status determination based on the procedure of Asher, Singleton, Tinsley and Hymel. Social Behavior and Personality, 32, 535-550.

Marcote, F. (2001). Tipologías motivacionales y su incidencia sobre el rendimiento académico. Tesis doctoral. Universidad de Oviedo.

Martín del Buey, F. (1985). Tipologías Modales Multivariadas y Rendimiento Académico. Tesis Doctoral Servicio de Publicaciones. Universidad Complutense de Madrid.

Martín del Buey, F. (2003). Cuestionario de Personalidad Eficaz en Secundaria. Documento Inédito. Facultad de Psicología. Universidad de Oviedo

Martín del Buey, F., Fernández, A., Martín Palacio, E., Dapelo, B., Marcone, R. y Granados, P. (2008). Cuestionario de Personalidad Eficaz para la formación profesional. Psicothema, 20 (2), 224-228.

Martín del Buey, F. y Martín Palacio, M.E. (2012). Competencias personales y sociales: personalidad eficaz. Material inédito. Editado en formato digital sin finalidad venal.

Mayer, J.D. y Salovey, P. (1997). The intelligence of emotional intelligence. Intelligence, 17(4), 433-442. 
Ministerio de Planificación de Chile. (1992). Encuesta de Caracterización Socioeconómica, CASEN. Santiago de Chile: Ministerio de Planificación.

Ministerio de Planificación de Chile. (2006). Encuesta de Caracterización Socioeconómica, CASEN. Santiago de Chile: Ministerio de Planificación.

Morales, M.E. (2000). CHILE ENVEJECE: Prospectiva de los impactos políticos y sociales de este fenómeno hacia el bicentenario. Disponible en: http://www.gerontologia.uchile.cl/docs/chien.htm. Consultado en Mayo de 2014.

Mulet, B., Sanchez-Casas, R., Arrufat, T., Figuera, L., Labad, A. y Rosich, M. (2005). Deterioro cognitivo ligero anterior a la enfermedad de Alzheimer: tipologías y evolución. Psicothema, 17(2), 250-256

Muñoz Rojo, M.I. (2013). Estilos de comportamiento emocional adolescente en el marco de la Personalidad Eficaz en contextos educativos chilenos. Tesis doctoral. Universidad de Oviedo.

Muñoz, J., Navas, E., Graña, J.L. y Martínez, R. (2006). Subtipos de drogodependientes en tratamiento: apoyo empírico para una distinción entre tipo A y tipo B. Psicothema, 18(1), 43-51. 
Muñoz, V., Moreno, M. C. y Jiménez, I. (2008). Las Tipologías de estatus sociométrico durante la adolescencia: Contraste de distintas técnicas y fórmulas para su cálculo. Psicothema, 20(4), 665-671.

Newcomb, A.F. y Bukowski, W.M. (1983). Social impact and social preference as determinants of Children's Peer Group Status. Developmental Psychology, 9, 856-867.

Ortiz-Tallo, M., Cardenal, V., Blanca, M.J., Sánchez, L.M., y Morales, I. (2007). Multiaxial evaluation of violent criminals. Psychological Reports, 100, 1065-1075.

Petersen, R.C., Doody, R., Kurz, A., Mohs, R.C., Morris, J.C. y Rabins, P.V. (2001). A typology of men who batter: Three types derived from cluster analysis. American Journal of Orthopsychiatry, 62, 246275.

Petrides, K. V. y Furnham, A. (2000). On the dimensional structure of emotional intelligence. Personality and Individual Differences, 29, 313-320.

Petrides, K.V., Furnham, A. y Martin, G.N. (2004). Estimates of emotional and psychometric intelligence: evidence for gender-based stereotypes. Journal of Social Psychology, 144, 149-162. 
Petrides, K.V., Pérez González. J.C. y Furnham, A. (2007). On the criterion and incremental validity of trait emotional intelligence. Cognition and Emotion, 21, 26-55.

Pinillos J. L. (1978). Principios de Psicología. Madrid: Alianza.

Pizarro, J.P. (2012). Evaluación de competencias personales y sociales en contextos de educación primaria. Tesis Doctoral. Universidad de Oviedo.

Ramírez, E. (2013). Tipologías modales multivariadas de Personalidad Eficaz en población adulta chilena de 30 a 60 años. Tesis Doctoral. Universidad de Oviedo.

Romero, M. (2001). Motivación, atribución, expectativas y rendimiento académico en la Enseñanza Secundaria Obligatoria. Tesis doctoral. Universidad de Oviedo.

Saunders, D.G. (1992). A typology of men who batter: Three types derived from cluster analysis. American Journal of Orthopsychiatry, 62, 246275.

Stein, M. (1963). Explorations in Typology. En Robert. W. White (Eds.), The estudy of lives: essays on Personality in Honor of Henry A. Murray. New York : Atherton.

Sternberg, R.J. (1985). Beyond IQ: a triarchic theory of human inteligence. Cambridge: University Press. 
Tyler, L. E. (1972). Psicología de las diferencias humanas. Madrid: Napova.

Waltz, J., Babcock, J.C., Jacobson, N.S. y Gottman, J.M. (2000). Testing a typology of batterers. Journal of Consulting and Clinical Psychology, 68, 658-669.

Waters, E. y Sroufe, L.A. (1983). A developmental perspective on competence. Developmental Review, 3, 79-97.

White, R.W. (1959). Motivation reconsidered: The concept of competence. Psichological Review, 66, 297-333.

Yesavage, J.A. y Sheikh, J.I. (1986). Geriatric Depression Scale (GDS). Recent evidence and development of a shoter violence. Journal Clinical Gerontologist 5(1-2), 165-173. 


\section{ANEXOS}




\section{ANEXO I}

\section{El protocolo de}

\section{CPE-A}

Este cuestionario pretende obtener información acerca de cómo es usted en general y cómo se desenvuelve en algunos aspectos de su vida diaria. Todos los datos que usted aporte serán tratados de forma absolutamente confidencial, teniendo la posibilidad de recibir, si usted lo desea, un informe con los resultados obtenidos, por eso se le ruega ser sincero en sus respuestas.

Primero se le solicitarán algunos datos personales, seguidos del cuestionario. Si usted desea que la información extraída de su cuestionario se le envíe, ponga por favor en la casilla "identificación" su nombre completo, o algún nombre distintivo que recuerde y le identifique al recibir su informe. El cuestionario consta de 30 ítems a los que deberá responder escribiendo, en la casilla en blanco, el número que usted considere en cada respuesta

(1 nunca, - 5 siempre). Si algún ítem le genera duda, señale la opción (2 algo, 3 normal, 4 bastante) que suceda el mayor número de veces.

1. NUNCA

2. POCAS VECES

3. ALGUNA VEZ

4. MUCHAS VECES

5. SIEMPRE

Muchas gracias por su colaboración.

Rellene por favor:

\begin{tabular}{|l|}
\hline Identificación \\
\hline Sexo \\
\hline Edad \\
\hline Estudios \\
\hline Profesión \\
\hline
\end{tabular}




\begin{tabular}{|c|c|c|c|}
\hline & \begin{tabular}{l|l}
$\mathrm{D}$ & $\mathrm{RR}$ \\
\end{tabular} & F. & $\mathrm{R}$ \\
\hline 1. Mis éxitos en mi profesión se deben a mi esfuerzo y dedicación & & & \\
\hline 2. Tengo pocos amigos porque me cuesta tratar con los demás & & & \\
\hline 3. Me siento muy bien con mi aspecto físico & & & \\
\hline $\begin{array}{l}\text { 4. Cuando tengo que tomar una decisión, planifico cuidadosamente lo que } \\
\text { voy a hacer }\end{array}$ & & & \\
\hline $\begin{array}{l}\text { 5. Mi éxito en una tarea se debe a que me esmero por realizar un buen } \\
\text { trabajo }\end{array}$ & & & \\
\hline 6. Hago amigos con facilidad & & & \\
\hline 7. Hay muchas cosas acerca de mí mismo que me gustaría cambiar si pudiera & & & \\
\hline 8. Cuando tengo un problema trato de ver el lado positivo que posee & & & \\
\hline 9. Tengo buena capacidad para trabajar & & & \\
\hline $\begin{array}{l}\text { 10. Mis fracasos en las relaciones con los demás se deben a mi falta de } \\
\text { habilidad para hacer amigos }\end{array}$ & & & \\
\hline 11. En general me siento satisfecho conmigo mismo & & & \\
\hline 12. Para tomar una decisión reúno toda la información que puedo encontrar & & & \\
\hline 13. Me considero un buen trabajador & & & \\
\hline $\begin{array}{l}\text { 14. Creo que, conociéndome como soy, tendré problemas en mis relaciones } \\
\text { con los demás }\end{array}$ & & & \\
\hline 15. Me acepto tal y como soy, con mis cualidades, limitaciones y defectos & & & \\
\hline 16. Controlo bien mis emociones & & & \\
\hline 17. Trabajo porque me gusta superar los retos que me presentan las tareas & & & \\
\hline $\begin{array}{l}\text { 18. Creo, con toda seguridad, que tendré éxito en mis relaciones con los } \\
\text { demás }\end{array}$ & & & \\
\hline 19. Tengo muchas cualidades para estar orgulloso y satisfecho de mi mismo & & & \\
\hline 20. Cuando experimento un fracaso intento aprender de esa experiencia & & & \\
\hline 21. Mi éxito en el trabajo se debe a mi capacidad personal & & & \\
\hline $\begin{array}{l}\text { 22. Mis éxitos en las relaciones con los demás se deben a mi habilidad para } \\
\text { hacer amigos }\end{array}$ & & & \\
\hline
\end{tabular}


23. Logro que casi todas las cosas me resulten bien

24. Cuando tengo un problema dedico tiempo y esfuerzo para resolverlo

25. Mis éxitos en las relaciones con los demás se deben a que son ellos los que toman la iniciativa

26. Creo que soy una persona valiosa para los otros

27. Estoy convencido de que tendré éxito cuando trabaje

28. Pienso que mi fracaso en las relaciones con los demás se deben a que no le agrado a la mayoría de las personas

29. Creo que tengo el talento para hacer que las cosas funcionen

30. Me siento a gusto compartiendo con otras personas

TOTAL

Compruebe que ha respondido todos los ítems. 